\title{
All106 Q64b?0
}

\section{REFEENQE}

PUBLICATIONS

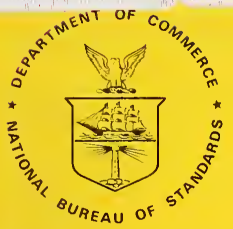

Standard Reference Materials:

\section{Holmium Oxide Solution Wavelength Standard From 240 to $640 \mathrm{~nm}-$ SRM 2034}

QC

100

.457

\#260-102

1986
V. R. Weidner, R. Mavrodineanu, K. D. Mielenz, R. A. Velapoldi, K. L. Eckerle, and B. Adams 
he National Bureau of Standards ${ }^{1}$ was established by an act of Congress on March 3, 1901. The

Bureau's overall goal is to strengthen and advance the nation's science and technology and facilitate their effective application for public benefit. To this end, the Bureau conducts research and provides: (1) a basis for the nation's physical measurement system, (2) scientific and technological services for industry and government, (3) a technical basis for equity in trade, and (4) technical services to promote public safety. The Bureau's technical work is performed by the National Measurement Laboratory, the National Engineering Laboratory, the Institute for Computer Sciences and Technology, and the Institute for Materials Science and Engineering.

\section{The National Measurement Laboratory}

Provides the national system of physical and chemical measurement; coordinates the system with measurement systems of other nations and furnishes essential services leading to accurate and uniform physical and chemical measurement throughout the Nation's scientific community, industry, and commerce; provides advisory and research services to other Government agencies; conducts physical and chemical research; develops, produces, and distributes Standard Reference Materials; and provides calibration services. The Laboratory consists of the following centers:
- Basic Standards ${ }^{2}$

- Radiation Research

- Chemical Physics

- Analytical Chemistry

\section{The National Engineering Laboratory}

Provides technology and technical services to the public and private sectors to address national needs and to solve national problems; conducts research in engineering and applied science in support of these efforts; builds and maintains competence in the necessary disciplines required to carry out this research and technical service; develops engineering data and measurement capabilities; provides engineering measurement traceability services; develops test methods and proposes engineering standards and code changes; develops and proposes new engineering practices; and develops and improves mechanisms to transfer results of its research to the ultimate user. The Laboratory consists of the following centers:

\section{The Institute for Computer Sciences and Technology}

Conducts research and provides scientific and technical services to aid Federal agencies in the selection, acquisition, application, and use of computer technology to improve effectiveness and economy in Government operations in accordance with Public Law 89-306 (40 U.S.C. 759), relevant Executive Orders, and other directives; carries out this mission by managing the Federal Information Processing Standards Program, developing Federal ADP standards guidelines, and managing Federal participation in ADP voluntary standardization activities; provides scientific and technological advisory services and assistance to Federal agencies; and provides the technical foundation for computer-related policies of the Federal Government. The Institute consists of the following centers:
- Applied Mathematics

- Electronics and Electrical Engineering $^{2}$

- Manufacturing Engineering

- Building Technology

- Fire Research

- Chemical Engineering ${ }^{2}$

\section{The Institute for Materials Science and Engineering}

Conducts research and provides measurements, data, standards, reference materials, quantitative understanding and other technical information fundamental to the processing, structure, properties and performance of materials; addresses the scientific basis for new advanced materials technologies; plans research around cross-country scientific themes such as nondestructive evaluation and phase diagram development; oversees Bureau-wide technical programs in nuclear reactor radiation research and nondestructive evaluation; and broadly disseminates generic technical information resulting from its programs. The Institute consists of the following Divisions:
- Programming Science and Technology

- Computer Systems Engineering
- Ceramics

- Fracture and Deformation ${ }^{3}$

- Polymers

- Metallurgy

- Reactor Radiation 
Standard Reference Materials:

\section{Holmium Oxide Solution Wavelength Standard From 240 to $640 \mathrm{~nm}$ - SRM 2034}

V. R. Weidner*, R. Mavrodineanu* ${ }^{*}$, K. D. Mielenz*,

R. A. Velapoldi ${ }^{*}$, K. L. Eckerle*, and B. Adams*

*Radiometric Physics Division

* *Center for Analytical Chemistry

National Measurement Laboratory

National Bureau of Standards

Gaithersburg, MD 20899

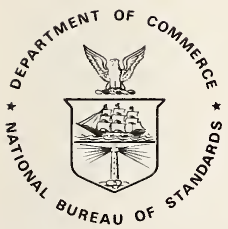

U.S. DEPARTMENT OF COMMERCE, Malcolm Baldrige, Secretary

NATIONAL BUREAU OF STANDARDS, Ernest Ambler, Director

Issued July 1986 
Library of Congress Catalog Card Number: 86-600560

National Bureau of Standards Special Publication 260-102

Natl. Bur. Stand. (U.S.), Spec. Publ. 260-102, 67 pages (July 1986) CODEN: XNBSAV 
Standard Reference Materials (SRM's) as defined by the National Bureau of Standards (NBS) are well-characterized materials, produced in quantity and certified for one or more physical or chemical properties. They are used to assure the accuracy and compatibility of measurements throughout the Nation. SRM's are widely used as primary standards in many diverse fields in science, industry, and technology, both within the United States and throughout the world. They are also used extensively in the fields of environmental and clinical analysis. In many applications, traceability of quality control and measurement processes to the national measurement system is carried out through the mechanism and use of SRM's. For many of the Nation's scientists and technologists it is therefore of more than passing interest to know the details of the measurements made at NBS in arriving at the certified values of the SRM's produced. An NBS series of papers, of which this publication is a member, called the NBS Special Publication - 260 Series, is reserved for this purpose.

The 260 Series is dedicated to the dissemination of information on different phases of the preparation, measurement, certification and use of NBS SRM's. In general, much more detail will be found in these papers than is generally allowed, or desirable, in scientific journal articles. This enables the user to assess the validity and accuracy of the measurement processes employed, to judge the statistical analysis, and to learn details of techniques and methods utilized for work entailing the greatest care and accuracy. These papers also should provide sufficient additional information not found on the certificate so that new applications in diverse fields not foreseen at the time the SRM was originally issued will be sought and found.

Inquiries concerning the technical content of this paper should be directed to the author(s). other questions concerned with the availability, delivery, price, and so forth, will receive prompt attention from:

Office of Standard Reference Materials

National Bureau of Standards

Gaithersburg, MD 20899

(301) 921-2045

Stanley D. Rasberry, Chief

office of Standard Reference Materials 


\section{OTHER NBS PUBLICATIONS IN THIS SERIES}

Catalog of NBS Standard Reference Materials (1984-85 edition), Catherine H. Hudson, ed., NBS Spec. Publ. 260 (February 1984). \$5.50* SN003003-02558-5.

Michaelis, R. E., and Wyman, L. L. Standard Reference Materials: Preparation of White Cast 1ron Spectrochemical Standards. NBS Misc. Publ. 260-1 (June 1964). COM74-11061**

Michaelis, R. E., Wyman, L. L., and Flitsch, R., Standard Reference Materials: Preparation of NBS Copper-Base Spectrochemical Standards. NBS Misc. Publ. 260-2 (October 1964). COM74$11063^{* *}$

Michaelis, R. E., Yakowitz, H., and Moore, G. A., Standard Reference Materials: Metallographic Characterization of an NBS Spectrometric LowAlloy Steel Standard. NBS Misc. Publ. 260-3 (October 1964). COM74-11060**

Hague, J. L. Mears, T. W., and Michaelis, R. E, Standard Reference Materials: Sources of Information, NBS Misc. Publ. 260-4 (February 1965). COM74-11059

Alvarez, R., and Flitsch R., Standard Reference Materials: Accuracy of Solution X-Ray Spectrometric Analysis of Copper-Base Alloys. NBS Misc. Publ. 260-5 (March 1965). PB168068**

Shultz, J. I., Standard Reference Materials: Methods for the Chemical Analysis of White Cast 1ron Standards, NBS Misc. Publ. 260-6 (July 1965). COM74-11068**

Bell, R. K., Standard Reference Materials: Methods for the Chemical Analysis of NBS Copper-Base Spectrochemical Standards. NBS Misc. Publ. 260-7 (October 1965). COM74$11067^{* *}$

Richmond, M.S., Standard Reference Materials: Analysis of Uranium Concentrates at the National Bureau of Standards. NBS Misc. Publ. 260-8 (December 1965). COM74-11066**

Anspach, S. C., Cavallo, L. M. Garfinkel, S. B. Hutchinson, J. M. R., and Smith, C. N., Standard Reference Materials: Half Lives of Materials Used in the Preparation of Standard Reference Materials of Nineteen Radioactive Nuclides lssued by the National Bureau of Standards NBS Misc. Publ. 260-9 (November 1965). COM74-11065**

Yakowitz, H., Vieth, D. L., Heinrich, K. F. J., and Michaelis, R. E., Standard Reference Materials: Homogeneity Characterization of NBS Spectrometric Standards I1: Cartridge Brass and LowAlloy Steel, NBS Misc. Publ. 260-10 (December (1965). COM74-11064**

Napolitano, A., and Hawkins, E. G., Standard Reference Materials: Viscosity of Standard Lead-Silica Glass, NBS Misc. Publ. 260-11 (November 1966). NBS Misc. Publ. 260-11**

Yakowitz, H., Vieth, D. L., and Michaelis, R. E., Standard Reference Materials: Homogeneity Characterization of NBS Spectrometric Standards III: White Cast Iron and Stainless Steel Powder Compact, NBS Misc. Publ. 260-12 (September 1966). NBS Misc. Publ. 260-12**
Spijkerman, J. L., Snediker, D. K., Ruegg, F. C. and DeVoe, J. R., Standard Reference Materials: Mossbauer Spectroscopy Standard for the Chemical Shift of Iron Compounds, NBS Misc. Publ. 260-13 (July 1967). NBS Misc. Publ. 260-13**

Menis, O., and Sterling, J. T., Standard Reference Materials: Determination of Oxygen in Ferrous Materials - SRM 1090, 1091, and 1092, NBS Misc. Publ. 260-14 (September 1966). NBS Misc. Publ. 260-14**

Passaglia, E., and Shouse, P. J., Standard Reference Materials: Recommended Method of Use of Standard Light-Sensitive Paper for Calibrating Carbon Arcs Used in Testing Textiles for Colorfastness to Light, NBS Misc. Publ. 260-15 (June 1967). (Replaced by NBS Spec. Publ. 260-41.)

Yakowitz, H., Michaelis, R. E., and Vieth, D. L., Standard Reference Materials: Homogeneity Characterization of NBS Spectrometric Standards 1V: Preparation and Microprobe Characterization of W-20\% MO Alloy Fabricated by Powder Metallurgical Methods, NBS Spec. Publ. 260-16 (January 1969). COM74-11062**

Catanzaro, E. J., Champion, C. E., Garner, E. L., Marinenko, G., Sappenfield, K. M., and Shields, W. R., Standard Reference Materials: Boric Acid; Isotopic and Assay Standard Reference Materials, NBS Spec. Publ. 260-17 (February 1970). Out of Print.

Geller, S. B., Mantek, P. A., and Cleveland, N. G., Standard Reference Materials: Calibration of NBS Secondary Standard Magnetic Tape (Computer Amplitude Reference) Using the Reference Tape Amplitude Measurement "Process A," NBS Spec. Publ. 260-18 (November 1969). (See NBS Spec. Publ. 260-29.)

Paule, R. C., and Mandel, J., Standard Reference Materials: Analysis of Interlaboratory Measurements on the Vapor Pressure of Gold (Certification of Standard Reference Material 745). NBS Spec. Publ. 260-19 (January 1970). PB190071**

Paule, R. C., and Mandel, J., Standard Reference Materials: Analysis of Interlaboratory Measurements on the Vapor Pressures of Cadmium and Silver, NBS Spec. Publ. 260-21 (January 1971). COM74-11359**

Yakowitz, H., Fiori, C. E., and Michaelis, R. E., Standard Reference Materials: Homogeneity Characterization of Fe-3 Si Alloy, NBS Spec. Publ. 260-22 (February 1971). COM74-11357**

Napolitano, A., and Hawkins, E. G., Standard Reference Materials: Viscosity of a Standard Borosilicate Glass, NBS Spec. Publ. 260-23 (December 1970). COM71-00157**

Sappenfield, K. M., Marineko, G., and Hague, J. L., Standard Reference Materials: Comparison of Redox Standards, NBS Spec. Publ. 260-24 (January 1972). COM72-50058** 
Hicho, G. E., Yakowitz, H., Rasberry, S. D., and Michaelis, R. E., Standard Reference Materials: A Standard Reference Material Containing Nominally Four Percent Austenite, NBS Spec. Publ. 260-25 (February 1971). COM74-11356**

Martin, J. F., Standard Reference Materials: National Bureau of Standards-US Steel Corporation Joint Program for Determining Oxygen and Nitrogen in Steel, NBS Spec. Publ. 260-26 (February 1971). 85 cents* PB 81176620

Garner, E. L., Machlan, L. A., and Shields, W. R., Standard Reference Materials: Uranium Isotopic Standard Reference Materials, NBS Spec. Publ. 260-27 (April 1971). COM74$11358^{* *}$

Heinrich, K. F. J., Myklebust, R. L., Rasberry, S. D., and Michaelis, R. E., Standard Reference Materials: Preparation and Evaluation of SRM's 481 and 482 Gold-Silver and GoldCopper Alloys for Microanalysis, NBS Spec. Publ. 260-28 (August 1971). COM71-50365**

Geller, S. B., Standard Reference Materials: Calibration of NBS Secondary Standard Magnetic Tape (Computer Amplitude Reference) Using the Reference Tape Amplitude Measurement "Process A-Model 2," NBS Spec. Publ. 260-29 (June 1971). COM71-50282

Gorozhanina, R. S., Freedman, A. Y., and Shaievitch, A. B. (translated by M. C. Selby), Standard Reference Materials: Standard Samples Issued in the USSR (A Translation from the Russian). NBS Spec. Publ. 260-30 (June 1971). COM71-50283**

Hust, J. G., and Sparks, L. L., Standard Reference Materials: Thermal Conductivity of Electrolytic Iron SRM 734 from 4 to $300 \mathrm{~K}$, NBS Spec. Publ. 260-31 (November 1971). COM71-50563**

Mavrodineanu, R., and Lazar, J. W., Standard Reference Materials: Standard Quartz Cuvettes, for High Accuracy Spectrophotometry, NBS Spec. Publ. 260-32 (December 1973). 55 cents* SN003-003-01213-1

Wagner, H. L., Standard Reference Materials: Comparison of Original and Supplemental SRM 705, Narrow Molecular Weight Distribution Polystyrene, NBS Spec. Publ. 260-33 (May 1972). COM72-50526**

Sparks, L. L., and Hust, J. G., Standard Reference Materials: Thermoelectric Voltage, NBS Spec. Publ. 260-34, (April 1972). COM72-50371**

Sparks, L. L., and Hust, J. G., Standard Reference Materials: Thermal Conductivity of Austenitic Stainless Steel, SRM 735 from 5 to $280 \mathrm{~K}$, NBS Spec. Publ. 260-35 (April 1972.) 35 cents* COM72-50368**

Cali, J. P., Mandel, J., Moore, L. J., and Young, D. S., Standard Reference Materials: A Referee Method for the Determination of Calcium in Serum, NBS SRM 915, NBS Spec. Publ. 260-36 (May 1972). COM72-50527**

Shultz, J. I. Bell., R. K. Rains, T. C., and Menis, O., Standard Reference Materials: Methods of Analysis of NBS Clay Standards, NBS Spec. Publ. 260-37 (June 1972). COM72-50692**
Richmond, J. C., and Hsia, J. J., Standard Reference Materials: Preparation and Calibration of Standards of Spectral Specular Reflectance, NBS Spec. Publ. 260-38 (May 1972). COM72$50528^{* *}$

Clark, A. F., Denson, V.A., Hust, J. G., and Powell, R. L., Standard Reference Materials: The Eddy Current Decay Method for Resistivity Characterization of High-Purity Metals, NBS Spec. Publ. 260-39 (May 1972). COM72-50529**

McAdie, H. G., Garn, P.D., and Menis, O., Standard Reference Materials: Selection of Thermal Analysis Temperature Standards Through a Cooperative Study (SRM 758, 759, 760), NBS Spec. Publ. 260-40 (August 1972.) COM7250776**

Wood, L. A., and Shouse, P. J., Standard Reference Materials: Use of Standard LightSensitive Paper for Calibrating Carbon Arcs Used in Testing Textiles for Colorfastness to Light, NBS Spec. Publ. 260-41 (August 1972) COM72-50775**

Wagner, H. L. and Verdier, P. H., eds., Standard Reference Materials: The Characterization of Linear Polyethylene, SRM 1475, NBS Spec. Publ. 260-42 (September 1972). COM72. 50944**

Yakowitz, H., Ruff, A. W., and Michaelis, R. E., Standard Reference Materials: Preparation and Homogeneity Characterization of an Austenitic Iron-Chromium-Nickel Alloy, NBS Spec. Publ. 260-43 (November 1972). COM73-50760**

Schooley, J. F., Soulen, R. J., Jr., and Evans, G. A., Jr., Standard Reference Materials: Preparation and Use of Superconductive Fixed Point Devices, SRM 767, NBS Spec. Publ. 260-44 (December 1972). COM73-50037**

Greifer, B., Maienthal, E. J., Rains, T. C., and Rasberry, S. D., Standard Reference Materials: Powdered Lead-Based Paint, SRM 1579, NBS Spec. Publ. 260-45 (March 1973). COM7350226**

Hust, J. G., and Giarratano, P. J., Standard Reference Materials: Thermal Conductivity and Electrical Resistivity Standard Reference Materials: Austenitic Stainless Steel, SRM's 735 and 798 , from 4 to $1200 \mathrm{~K}$, NBS Spec. Publ. 260-46 (March 1975). SN003-003-01278-5*

Hust, J. G., Standard Reference Materials: Electrical Resistivity of Electrolytic Iron, SRM 797, and Austenitic Stainless Steel, SRM 798, from 5 to $280 \mathrm{~K}$, NBS Spec. Publ. 260-47 (February 1974). COM74-50176**

Mangum, B. W., and Wise, J. A., Standard Reference Materials: Description and Use of Precision Thermometers for the Clinical Laboratory, SRM 933 and SRM 934, NBS Spec. Publ. 260-48 (May 1974), 60 cents* SN003-003-01278-5

Carpenter, B. S., and Reimer, G. M., Standard Reference Materials: Calibrated Glass Standards for Fission Track Use, NBS Spec. Publ. 260-49 (November 1974). COM74-51185 
Hust, J. G., and Giarratano, P. J., Standard Reference Materials: Thermal Conductivity and Electrical Resistivity Standard Reference Materials: Electrolytic Iron, SRM's 734 and 797 from 4 to $1000 \mathrm{~K}$, NBS Spec. Publ. 260-50 (June 1975). $\$ 1.00 *$ SN003-003-01425-7

Mavrodineanu, R., and Baldwin, J. R., Standard Reference Materials: Glass Filters As a Standard Reference Material for Spectrophotometry; Selection; Preparation; Certification; Use-SRM 930, NBS Spec. Publ. 260-51 (November 1975). $\$ 1.90 *$ SN003-003-01481-8

Hust, J. G., and Giarratano, P. J., Standard Reference Materials: Thermal Conductivity and Electrical Resistivity Standard Reference Materials 730 and 799 , from 4 to $3000 \mathrm{~K}$, NBS Spec. Publ. 260-52 (September 1975). \$1.05* SN003-00301464-8

Durst, R. A., Standard Reference Materials: Standardization of $\mathrm{pH}$ Measurements, NBS Spec. Publ. 260-53 (December 1975, Revised). \$1.05 SN003-003-01551-2

Burke, R. W., and Mavrodineanu, R., Standard Reference Materials: Certification and Use of Acidic Potassium Dichromate Solutions as an Ultraviolet Absorbance Standard, NBS Spec. Publ. 260-54 (August 1977). \$3.00* SN003-00301828-7

Ditmars, D. A., Cezairliyan, A., Ishihara, S., and Douglas, T. B., Standard Reference Materials: Enthalpy and Heat Capacity; Molybdenum SRM 781, from 273 to $2800 \mathrm{~K}$, NBS Spec. Publ. 260-55 (September 1977). \$2.20* SN003-00301836-8

Powell, R. L., Sparks, L. L., and Hust, J. G., Standard Reference Materials: Standard Thermocouple Materials, Pt.67: SRM 1967, NBS Spec. Publ. 260-56 (February 1978). \$2.20* SN003-003-018864

Cali, J. P. and Plebanski, T., Guide to United States Reference Materials, NBS Spec. Publ. 260-57 (February 1978). \$2.20* PB 277173

Barnes, J. D., and Martin, G. M., Standard Reference Materials: Polyester Film for Oxygen Gas Transmission Measurements SRM 1470, NBS Spec. Publ. 260-58 (June 1979) \$2.00* SN003003-02077

Chang, T., and Kahn, A. H. Standard Reference Materials: Electron Paramagnetic Resonance Intensity Standard; SRM 2601, NBS Spec. Publ. 260-59 (August 1978) \$2.30* SN003003-01975-5

Velapoldi, R. A., Paule, R. C., Schaffer, R., Mandel, J., and Moody, J. R., Standard Reference Materials: A Reference Method for the Determination of Sodium in Serum, NBS Spec. Publ. 260-60 (August 1978). \$3.00* SN003-003 01978-0

Verdier, P. H., and Wagner. H. L., Standard Reference Materials: The Characterization of Linear Polyethylene (SRM 1482, 1483, 1484), NBS Spec. Publ. 260-61 (December 1978). \$1.70* SN003-003-02006-1
Soulen, R. J., and Dove, R. B., Standard Reference Materials: Temperature Reference Standard for Use Below 0.5 K (SRM 768). NBS Spec. Publ. 260-62 (April 1979). \$2.30* SN003-00302047-8

Velapoldi, R. A., Paule, R. C., Schaffer, R. Mandel, J., Machlan, L. A., and Gramlich, J. W. Standard Reference Materials: A Reference Method for the Determination of Potassium in Serum. NBS Spec. Publ. 260-63 (May 1979). \$3.75* SN003-003-02068

Velapoldi, R. A., and Mielenz, K. D., Standard Reference Materials: A Fluorescence Standard Reference Material Quinine Sulfate Dihydrate (SRM 936), NBS Spec. Publ. 260-64 (January 1980). $\$ 4.25 *$ SN003-003-02148-2

Marinenko, R. B., Heinrich, K. F. J., and Ruegg, F. C., Standard Reference Materials: MicroHomogeneity Studies of NBS Standard Reference Materials, NBS Research Materials, and Other Related Samples. NBS Spec. Publ. 260-65 (September 1979). \$3.50* SN003-003-02114-1

Venable, W. H., Jr., and Eckerle, K. L., Standard Reference Materials: Didymium Glass Filters for Calibrating the Wavelength Scale of Spectrophotometers (SRM 2009, 2010, 2013). NBS Spec. Publ. 260-66 (October 1979). \$3.50* SN003-00302127-0

Vela poldi, R. A., Paule, R. C., Schaffer, R., Mandel, J., Murphy, T. J., and Gramlich, J. W., Standard Reference Materials: A Reference Method for the Determination of Chloride in Serum, NBS Spec. Publ. 260-67 (November 1979). \$3.75* SN003003-02136-9

Mavrodineanu, R. and Baldwin, J. R., Standard Reference Materials: Metal-On-Quartz Filters as a Standard Reference Material for Spectrophotometry-SRM 2031, NBS Spec. Publ. 260-68 (April 1980). \$4.25* SN003-003-02167-9

Velapoldi, R. A., Paule, R. C., Schaffer, R., Mandel, J., Machlan, L. A., Garner, E. L., and Rains, T. C., Standard Reference Materials: A Reference Method for the Determination of Lithium in Serum, NBS Spec. Publ. 260-69 (July) 1980). \$4.25* SN003-003-02214-4

Marinenko, R. B., Biancaniello, F., Boyer, P. A., Ruff, A. W., De Robertis, L., Standa rd Reference Materials: Preparation and Characterization of an Iron-Chromium-Nickel Alloy for Microanalysis, NBS Spec. Publ. 260-70 (May 1981). \$2.50* SN003-003-02328-1

Seward, R. W., and Mavrodineanu, R., Standard Reference Materials: Summary of the Clinical Laboratory Standards Issued by the National Bureau of Standards, NBS Spec. Publ. 260-71 (November 1981). \$6.50* SN003-003-02381-7

Reeder, D.J., Coxon, B., Enagonio, D., Christensen, R. G., Schaffer, R., Howell, B. F., Paule, R. C., Mandel, J., Standard Reference Materials: SRM 900, Antiepilepsy Drug Level Assay Standard, NBS Spec. Publ. 260-72 (June 1981). \$4.25* S N003-003-02329-9 
Interrante, C. G., and Hicho, G. E., Standard Reference Materials: A Standard Reference Material Containing Nominally Fifteen Percent Austenite (SRM 486), NBS Spec. Publ. 260-73 (January 1982). $\$ 2.75^{*}$ SN003-003-02386-8

Marinenko, R. B., Standard Reference Materials: Preparation and Characterization of $\mathrm{K}-411$ and K-414 Mineral Glasses for Microanalysis: SRM 470. NBS Spec. Publ. 260-74 (April 1982). $\$ 3.50$ SN003-003-023-95-7

Weidner, V. R., and Hsia, J. J., Standard Reference Materials: Preparation and Calibration of First Surface Aluminum Mirror Specular Reflectance Standards (SRM 2003a), NBS Spec. Publ. 260-75 (May 1982). \$3.75 SN003-003-023-99-0

Hicho, G. E. and Eaton, E. E., Standard Reference Materials: A Standard Reference Material Containing Nominally Five Percent Austenite (SRM 485a), NBS Spec. Publ. 260-76 (August 1982). \$3.50 SN003-003-024-33-3

Furukawa, G. T., Riddle, J. L., Bigge, W. G., and Pfieffer, E. R., Standard Reference Materials: Application of Some Metal SRM's as Thermometric Fixed Points, NBS Spec. Publ. 260-77 (August 1982). \$6.00 SN003-003-024-34-1

Hicho, G. E. and Eaton, E. E., Standard Reference Materials: Standard Reference Material Containing Nominally Thirty Percent Austenite (SRM 487), NBS Spec. Publ. 260-78 (September 1982). \$3.75* SN003-003-02435-0

Richmond, J. C., Hsia, J. J. Weidner, V. R., and Wilmering, D. B., Standard Reference Materials: Second Surface Mirror Standards of Specular Spectral Reflectance (SRM's 2023, 2024, 2025), NBS Spec. Publ. 260-79 (October 1982). $\$ 4.50^{*}$ SN003-003-02447-3

Schaffer, R., Mandel, J., Sun, T., Cohen, A., and Hertz, H. S., Standard Reference Materials: Evaluation by an ID/MS Method of the AACC Reference Method for Serum Glucose, NBS Spec. Publ. 260-80 (October 1982). \$4.75* SN003003-02443-1

Burke, R. W., and Mavrodineanu, R. (NBS retired), Standard Reference Materials: Accuracy in Analytical Spectrophotometry, NBS Spec. Publ. 260-81 (April 1983). \$6.00* SN003-003-024-8

Weidner, V. R., Standard Reference Materials: White Opal Glass Diffuse Spectral Reflectance Standards for the Visible Spectrum (SRM's 2015 and 2016). NBS Spec. Publ. 260-82 (April 1983). \$3.75* SN003-003-02489-9**

Bowers, G. N., Jr., Alvarez, R., Cali, J. P. (NBS retired), Eberhardt, K. R., Reeder, D. J., Schaffer, R., Uriano, G. A., Standard Reference Materials: The Measurement of the Catalytic (Activity) Concentration of Seven Enzymes in NBS Human Serum SRM 909, NBS Spec. Publ. 260-83 (June 1983). \$4.50* SN003-003-024 99-6
Gills, T. E., Seward, R. W., Collins, R. J., and Webster, W. C., Standard Reference Materials: Sampling, Materials Handling, Processing, and Packaging of NBS Sulfur in Coal Standard Reference Materials, 2682, 2683, 2684, and 2685, NBS Spec. Publ. 260-84 (August 1983). \$4.50* SN003-003-02520-8

Swyt, D. A., Standard Reference Materials: A Look at Techniques for the Dimensional Calibration of Standard Microscopic Particles, NBS Spec. Publ. 260-85 (September 1983). \$5.50* SN003-00302521-6

Hicho, G. E. and Eaton, E. E., Standard Reference Materials: A Standard Reference Material Containing Two and One-Half Percent Austenite, SRM 488, NBS Spec. Publ. 260-86 (December 1983). \$1.75* SN003-003-02541-1

Mangum, B. W., Standard Reference Materials: SRM 1969: Rubidium Triple-Point - A Temperature Reference Standard Near $39.30{ }^{\circ} \mathrm{C}$, NBS Spec. Publ. 260-87 (December 1983). \$2.25* SN003-003-02544-5

Gladney, E. S., Burns, C. E., Perrin, D. R., Roelandts, I., and Gills, T. E., Standard Reference Materials: 1982 Compilation of Elemental Concentration Data for NBS Biological, Geological, and Environmental Standard Reference Materials, Spec. Publ. 260-88 (March 1984). \$7.00* SN003-003-02565-8

Hust, J. G., Standard Reference Materials: A FineGrained, Isotropic Graphite for Use as NBS Thermophysical Property R M's from 5 to $2500 \mathrm{~K}$, NBS Spec. Publ. 260-89 (September 1984). \$4.50* SN003-003-02608-5

Hust, J. G., and Langford, A. B., Standard Reference Materials: Update of Thermal Conductivity and Electrical Resistivity of Electrolytic Iron, Tungsten, and Stainless Steel, NBS Spec. Publ. 260-90 (September 1984). \$3.00* SN003-003-02609-3

Goodrich, L. F., Vecchia, D. F., Pittman, E. S., Ekin, J. W., and Clark, A. F., Standard Reference Materials: Critical Current Measurements on an NbTi Superconducting Wire Standard Reference Material, NBS Spec. Publ. 260-91 (September 1984). \$2.75* SN003-003-02614-0

Carpenter, B. S., Standard Reference Materials: Calibrated Glass Standards for Fission Track Use (Supplement to NBS Spec. Publ. 260-49). NBS Spec. Publ. 260-92 (September 1984). \$1.50* SN003-003-02610-7

Ehrstein, J., Preparation and Certification of Standard Reference Materials for Calibration of Spreading Resistance Probes, NBS Spec. Publ. 260-93 (January 1985). \$2.25* SN003-003-02633-6

Gills, T. E., Koch, W. F., Stolz, J. W., Kelly, W. R., Paulsen, P. J., Colbert, J. C., Kirklin, D. R., Pei, P.T.S., Weeks, S., Lindstrom, R. M., Fleming, R. F., Greenberg, R. R., and Paule, R. C., Methods and Procedures Used at the National Bureau of Standards to Certify Sulfur in Coal SRM's for Sulfur Content, Calorific Value, Ash Content, NBS Spec. Publ. 260-94 (December 1984). \$2.25* SN003-003-02629-8 
Mulholland, G. W., Hartman, A. W., Hembree, G. G., Marx, E., and Lettieri, T. R., Standard Reference Materials: Development of a $1 \mathrm{~m}$ Diameter Particle Size Standard, SRM 1690, NBS Spec. Publ. 260-95 (May 1985). SN003-00302665-4

Carpenter, B. S., Gramlich, J. W., Greenberg, R. R., and Machlan, L. A., Standard Reference Materials: Uranium-235 Isotopic Abundance Standard Reference Materials for Gamma Spectrometry Measurements, NBS Spec. Publ. 260-96 (In Preparation).

Mavrodineanu, R. and Gills, T. E., Standard Reference Materials: Summary of the Coal, Ore, Mineral, Rock, and Refractory Standards Issued by the National Bureau of Standards, NBS Spec. Publ. 260-97 (September 1985).

Hust, J. G., Standard Reference Materials: Glass Fiberboard SRM for Thermal Resistance, NBS Spec. Publ. 260-98 (August 1985). SN003-00302674-3

Callanan, J. E., Sullivan, S. A., and Vecchia, D. F., Standard Reference Materials: Feasibility Study for the Development of Standards Using Differential Scanning Calorimetry, NBS Spec. Publ. 260-99 (August 1985). SN003-003-02675-1

Taylor, J. K., Standard Reference Materials: Handbook for SRM Users, NBS Spec. Publ. 260-100 (September 1985).

Mangum, B. W., Standard Reference Materials: SRM 1970, Succinonitrile Triple-Point Standard: A Temperature Reference Standard Near 58.08 ${ }^{\circ} \mathrm{C}$, NBS Spec. Publ. 260-101 (March 1986).
Weidner, V. R., Mavrodineanu, R., Mielenz, K. D. Velapoldi, R. A., Eckerle, K. L., and Adams, B., Standard Reference Materials: Holmium Oxide Solution Wavelength Standard from 240-650 nm, SRM 2034, NBS Spec. Publ. 260-102 (In Press).

Hust, J. G., Standard Reference Materials: Glass Fiberblanket SRM for Thermal Resistance, NBS Spec. Publ. 260-103 (September 1985). SN003003-02687-5

Mavrodineanu, R. and Alvarez, R., Standard Reference Materials: Summary of the Biological and Botanical Standards Issued by the National Bureau of Standards, NBS Spec. Publ. 260-104 (November 1985).

Mavrodineanu, R. and Rasberry, S.D., Standard Reference Materials: Summary of the Environmental Research, Analysis, and Control Standards Issued by the National Bureau of Standards, NBS Spec. Publ. 260-105 (March 1986).

* Send order with remittance to Superintendent of Documents, US Government Printing Office Washington, DC 20402. Remittance from foreign countries should include an additional one-fourth of the purchase price for postage.

** May be ordered from: National Technical Information Services (NTIS). Springfield Virginia 22161. 
Preface . . . . . . . . . . . . . . . . . . . . . . . . . . iii

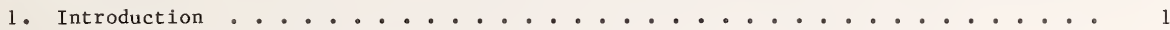

2. Experimental

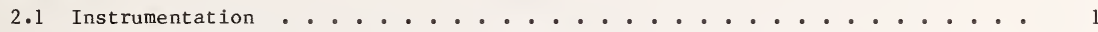

2.2 Materials

2.2.1 Holmium Oxide ....................... . . . . . 2

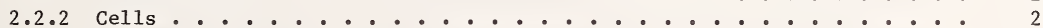

2.3 Measurement Techniques

2.3.1 Calibration of the Spectrophotometer Wavelength Scale . . . . . . 2

2.3.2 Confirmation of Spectral Bandwidths ................ 3

2.3.3 Determination of the Wavelengths of Minimum Transmittance . . . . . 3

2.3.4 Accuracy of the Wavelengths of Minimum Transmittance . . . . . . . 5

3. Measurements

3.1 Influence of the Blank Cuvette, Solvent and Water . . . . . . . . . 5

3.2 Influence of Temperature . . . . . . . . . . . . . . . . 6

3.3 Influence of Purity . . . . . . . . . . . . . . . . . . . 6

3.4 Influence of Concentration . . . . . . . . . . . . . . . . . . 6

3.5 Influence of Spectral Bandwidth . . . . . . . . . . . . . . . . 7

4. Results

4.1 Transmittance of Holmium Oxide Solution . . . . . . . . . . . . . . 7

4.2 Selection of Useful Wavelengths of Minimum Transmittance . . . . . . . . . 7

4.3 Numerical Data . . . . . . . . . . . . . . . . . . . . 7

4.4 Uncertainty of Measured Wavelengths . . . . . . . . . . . . . . . . . 7

4.5 Comparison of Results with Measurements Made on NBS Reference

Spectrofluorimeter ... . . . . . . . . . . . . . . . . 7

4.6 Other Measurements Outside NBS . . . . . . . . . . . . . . . 10

5. Conclusions . . . . . . . . . . . . . . . . . . . . . 11

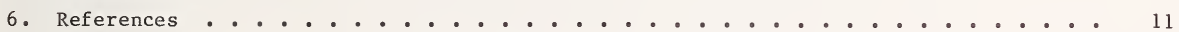


A-1 Standard Reference Materials for Spectrophotometry Provided

by the National Bureau of Standards . . . . . . . . . . . . . . . . .

A-2 Certificates of Standard Reference Materials for Spectrophotometry

A-2.1 SRM 930D, Glass Filters for Spectrophotometry . . . . . . . . . 18

A-2.2 SRM 931c, Liquid Absorbance Standards for U1traviolet and

Visible Spectrophotometry . . . . . . . . . . . . . . 21

A-2.3 SRM 932, Quartz Cuvette for Spectrophotometry . . . . . . . . . 24

A-2.4 SRM 935, Crystalline Potassium Dichromate for Use as an

Ultraviolet Absorbance Standard . . . . . . . . . . . . 26

A-2.5 SRM 936, Quinine Sulfate Dihydrate . . . . . . . . . . . . 30

A-2.6 SRM 2010a, Didymium Glass Filter for Checking the Wavelength

Scale of Spectrophotometers . . . . . . . . . . . . . . 34

A-2.7 SRM 2031, Metal-on-Quartz Filters for Spectrophotometry . . . . . . . 42

A-2.8 SRM 2032, Crystalline Potassium Iodide: Heterochromatic Stray Radiant Energy Standard for Ultraviolet Absorption

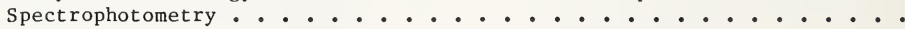

A-2.9 SRM 2033, Crystalline Potassium Iodide with Attenuator:

Heterochromatic and Isochromatic Stray Radiant Energy Standard

for Ultraviolet Absorption Spectrophotometry ..............

A-2.10 SRM 2034, Holmium Oxide Solution Wavelength Standard From

240 to $640 \mathrm{~nm} \ldots \ldots \ldots$ 
1. Ten cycles repetitive measurements of three holmium oxide transmittance minima .. . . . . . . . . . . . . . . . . . . . . . . . 5

2. Influence of holmium oxide concentration on the wavelengths of minimum

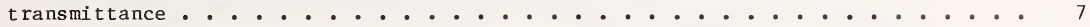

3. Results of holmium oxide solution analysis for transmittance minima 1 through 7 for spectral bandwidths of $0.1,0.25,0.5,1,2$, and $3 \mathrm{~nm}$....... 9

4. Results of holmium oxide solution analysis for transmittance minima 8 through 14 for spectral bandwidths of $0.1,0.25,0.5,1,2$, and $3 \mathrm{~nm} . \ldots$

5. Comparison of values for holmium oxide transmittance minima with values obtained with the NBS Reference Spectrofluorimeter . . . . . . . . . . . . 10

6. Comparison of values for holmium oxide transmittance minima with values obtained by other workers . . . . . . . . . . . . . . . . . . . .

A-1. Standard Reference Materials for Spectrophotometry Provided by the National Bureau of Standards . . . . . . . . . . . . . . . . . . . . .

\section{List of Figures}

Figure No.

1. Wavelength scale calibration of the spectrophotometer . . . . . . . . . . 2

2. Spectral transmittance of a $4 \%$ solution of holmium oxide in $10 \%$ perchloric

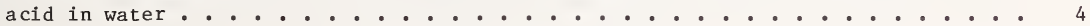

3. Graphical technique used to determine the transmittance minima from digital spectral transmittance data . . . . . . . . . . . . . . . . . . 5

4. Spectral transmittances of an empty fused silica cuvette, a cuvette filled with water, and a cuvette filled with a solution of $10 \%$ perchloric acid . . . . . 6

5. Spectral differences of solutions prepared from holmium oxide specimens of $99.99 \%$ purity and $99.999 \%$ purity . . . . . . . . . . . . . . . . .

6-19. Fourteen holmium oxide transmittance minima as a function of spectral bandwidth . . . . . . . . . . . . . . . . . . . . . . . . . . 



\title{
Holmium Oxide Solution Wavelength Standard From 240 to $640 \mathrm{~nm}$ - SRM 2034
}

\author{
Victor R. Weidner, Radu Mavrodineanu, Klaus D. Mielenz, Rance A. Velapoldi, \\ Kenneth L. Eckerle, and Bradley Adams \\ National Bureau of Standards, Gaithersburg, MD 20899
}

\begin{abstract}
Accepted: November 28, 1984
The work describes the methods and procedures used to determine the wavelengths of minimum transmittance of holmium oxide in perchloric acid solution. Measurements of spectral transmittance of the solutions were made by means of a high precision spectrophotometer over the wavelength range $200 \mathrm{~nm}$ to $680 \mathrm{~nm}$. The wavelength scale accuracy of this instrument was verified by extensive measurements of mercury and deuterium emission lines. The measurements of spectral transmittance of the holmium oxide solutions were made as a function of temperature, purity, concentration, and spectral bandwidth. Analysis of the uncertainties associated with these parameters and the uncertainties associated with the calibration of the instrument wavelength scale and the data analysis have resulted in an estimated uncertainty of $\pm 0.1 \mathrm{~nm}$ for the determination ef the wavelengths of minimum transmittance of the holmium oxide solution.
\end{abstract}

Key words: holmium oxide; spectral bandwidth; spectrophotometer calibration; spectral transmittance; wavelength calibration; wavelength standard.

\section{Introduction}

This work describes the methods and procedures used to determine the wavelengths of minimum spectral transmittance of holmium oxide $\left(\mathrm{Ho}_{2} \mathrm{O}_{3}\right)$ in perchloric acid $\left(\mathrm{HClO}_{4}\right)$ solution in the spectral region 200 to 680 $\mathrm{nm}$. The object of this activity was to develop a standard for verifying the wavelength scale of uv/visible spectrophotometers, and to provide assistance toward improving the accuracy of measurements in the fields of

\footnotetext{
About the Authors: Victor R. Weidner is with NBS' Radiometric Physics Division, headed by Klaus D. Mielenz and served also by Kenneth L. Eckerle; Radu Mavrodineanu is associated with the Bureau's Inorganic Analytical Research Division as a reemployed annuitant; Rance A. Velapoldi is deputy director of the NBS Center for Analytical Chemistry; and Bradley Adams served the Bureau as a student worker.
}

molecular absorption spectrometry or spectrophotometry $[1]^{1}$.

Holmium oxide in a glass matrix has been issued by the National Bureau of Standards (NBS) as a wavelength standard for the ultraviolet and visible spectrum since 1961 [2]. Didymium glass wavelength standards have been issued since 1945 . The didymium glass wavelength standards are available from NBS as Standard Reference Material 2009; 2010; 2013; and 2014 [3].

\section{Experimental \\ 2.1 Instrumentation}

Measurements of spectral transmittance of the holmium oxide solutions were made by means of a Varian Cary Model 2390 recording spectrophotometer ${ }^{2}$.

\footnotetext{
${ }^{1}$ Numbers in brackets indicate literature references.

${ }^{2}$ Certain commercial equipment or products are mentioned in this paper in order to adequately document the work. In no case does this imply that the equipment or product is being endorsed by NBS or that it is necessarily the best equipment or product for the application.
} 
The optical system of this double beam instrument consists of a filter predisperser and a double-pass double-sided grating monochromator. A deuterium lamp is used over the wavelength range 185 to $340 \mathrm{~nm}$ and a tungsten-halogen lamp is used over the wavelength range 340 to $3150 \mathrm{~nm}$ as a source. The spectral bandwidths are selectable from $0.07 \mathrm{~nm}$ to $3.6 \mathrm{~nm}$. Data can be recorded by a digital readout system with thermal printer and an analog chart display.

\subsection{Materials}

\subsubsection{Holmium Oxide}

The holmium oxide solutions were prepared by dissolving the powder in a $10 \%$ perchloric acid in distilled water. The purity of the holmium oxide specimens used in the preparation of these solutions was indicated by the manufacturer [4] to be $99.99 \%$ (Lot No. Ho-0-4-007) and $99.999 \%$ (Lot No. Ho-0-5-007). Solutions were prepared with $2 \%, 4 \%$, and $6 \%$ holmium oxide. These solutions were placed in $10 \mathrm{~mm}$ pathlength nonfluorescent fused silica cuvettes.

The actual form in which $\mathrm{Ho}$ is formed when $\mathrm{Ho}_{2} \mathrm{O}_{3}$ is dissolved in $\mathrm{HClO}_{4}$ is that of an aquo ion of the general formula $\mathrm{Ho}\left(\mathrm{H}_{2} \mathrm{O}\right)_{n}^{3}+$. The term "holmium oxide" and the spectral transmittances reported in the manuscript refer to this chemical species. Aqueous solutions of perchloric acid are used in this study to dissolve $\mathrm{Ho}_{2} \mathrm{O}_{3}$ since the resulting aquo ion is least likely to form complexes when subjected to changes in temperature and concentration [5].

The holmium oxide powder is stated by the manufacturer to have an average particle size of about $2 \mathrm{mi}$ crometers. The perchloric acid was a nominal $70-72 \%$ reagent grade (considered here as $100 \%$ ). The distilled water was produced by thermal distillation. The aqueous solutions of holmium oxide in $10 \%$ perchloric acid were prepared by weighing 2,4 , or $6 \mathrm{~g}$ of the oxide and adding $10 \mathrm{~mL}$ of distilled water and $10 \mathrm{~mL}$ of perchloric acid. The holmium oxide was dissolved by heating at about $80^{\circ} \mathrm{C}$ for one hour. The clear solution was transferred quantitatively to a $100 \mathrm{~mL}$ volumetric flask and was brought to volume with distilled water at room temperature.

\subsubsection{Cells}

The cells used for the transmission measurements of the holmium oxide solutions were conventional nonfluorescent, fused silica, cuvettes with a nominal pathlength of $10 \mathrm{~mm}$. These cuvettes were provided with graded quartz-to-pyrex tubes with rubber caps.

\subsection{Measurement Techniques}

\subsubsection{Calibration of the Spectrophotometer Wavelength Scale}

The spectophotometer wavelength scale error was evaluated by measuring the emission spectrum of the instrument's deuterium lamp and the emission spectrum of a mercury pen lamp $[6,7,8]$.

The wavelength calibration was performed at the beginning of the holmium oxide solution measurements and again at the completion of the measurements. A number of emission lines of mercury and two emission lines of deuterium were used over the wavelength range $230 \mathrm{~nm}$ to $690 \mathrm{~nm}$ (see fig. 1). The wavelength scale errors were determined for spectral bandwidths of 0.1 $\mathrm{nm}, 1 \mathrm{~nm}, 2 \mathrm{~nm}$, and $3 \mathrm{~nm}$.

Each emission line was scanned at a rate of $0.01 \mathrm{~nm}$ per second and recorded on a scale of $0.2 \mathrm{~nm}$ per centi-

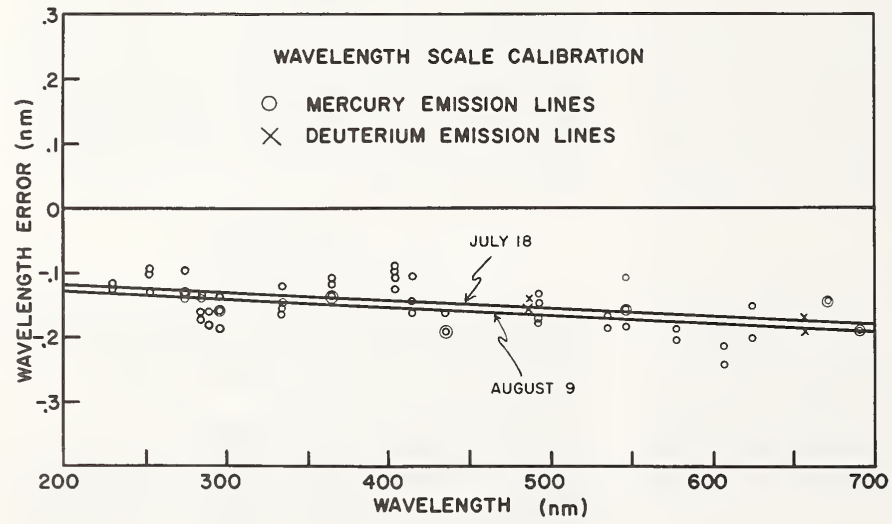

Figure 1-Wavelength scale calibration of the spectrophotometer. 
meter. The recorded emission peaks were bisected, using a proportional divider, to determine the wavelengths at the center of the recorded triangular lines. Using this technique, the wavelength scale was read to the nearest $0.01 \mathrm{~nm}$ with a precision of $\pm 0.005 \mathrm{~nm}$. The differences between the measured wavelengths of mercury emission lines and the true wavelengths are plotted in figure 1. A linear least squares fit of these wavelength differences for the two dates July 18 and August 9 (also shown in fig. 1) was used to correct the measured values of the holmium oxide transmission minima for errors in the wavelength scale of the instrument.

The wavelength error of the instrument was essentially the same for spectral bandwidths less than $1 \mathrm{~nm}$. However, at spectral bandwidths of $2 \mathrm{~nm}$ and $3 \mathrm{~nm}$, the wavelength error was slightly different and a different correction was required.

The deuterium lamp emission lines were measured at two wavelengths each day during the holmium oxide solution characterization to verify the accuracy of the wavelength scale. These measurements showed that the calibration of the wavelength scale is constant to \pm 0.02 $\mathrm{nm}$ after a nominal warm-up of one hour. These results, as well as the repeatability of the calibration with the mercury line source, indicate that the overall stability of the instrument wavelength scale was better than \pm 0.05 $\mathrm{nm}$ during the period of time required to complete the wavelength characterization of the holmium oxide solution.

The mercury pen lamp is mounted in the lamp positioning device that ordinarily holds the deuterium lamp of the spectrophotometer. The arc tube of the mercury pen was aligned parallel to the entrance slit of the monochromator. The lamp holder is equipped with screw adjustments for vertical and horizontal alignment of the source. The entrance slit cannot be directly observed. Therefore, the source was adjusted with instrument operating in the single-beam mode until a maximum signal is observed. To test the effect of the positioning of the mercury line source on the observed emission line maxima, the pen lamp was moved horizontally across the field of view of the entrance slit to the monochromator in approximately $0.22 \mathrm{~mm}$ steps for a total of 12 steps or a $2.64 \mathrm{~mm}$ distance. The results of this experiment showed that the recorded emission maxima varied by less than $\pm 0.01 \mathrm{~nm}$ for lamp positions within $\pm 1 \mathrm{~mm}$ of the center position. The center position corresponded to the position of maximum signal.

\subsubsection{Confirmation of Spectral Bandwidths}

The mercury line source was used to confirm the spectral bandwidth settings of the spectrophotometer. The mercury emission line at $435.8 \mathrm{~nm}$ was scanned for spectral bandwidths of $0.1 \mathrm{~nm}, 0.25 \mathrm{~nm}, 0.5 \mathrm{~nm}, 1 \mathrm{~nm}, 2$ $\mathrm{nm}$ and $3 \mathrm{~nm}$. The emission peak was normalized to $100 \%$ on the chart recorder by adjusting the instrument gain. The bandwidth at half peak height is approximately equal to the spectral bandwidth. The natural bandwidth of the emission line is much less than the instrument bandwidth. The recorded curve has a triangular symmetry for all settings of the monochromator slitwidths. For the above-mentioned nominal spectral bandwidth settings of the spectrophotometer, the measured spectral bandwidths were $0.092 \mathrm{~nm}, 0.228 \mathrm{~nm}$, $0.468 \mathrm{~nm}, 1.04 \mathrm{~nm}, 2.18 \mathrm{~nm}$, and $3.20 \mathrm{~nm}$, respectively. This technique for determining spectral bandwidths has some uncertainties due to assumptions made. However, it serves to confirm that the desired spectral bandwidths are closely approximated when the instrument is programmed to provide those settings; hence the effect on the transmittance minima is negligible.

\subsubsection{Determination of the Wavelengths of Minimum Transmittance}

The spectral transmittance of holmium oxide in an aqueous solution of perchloric acid exhibits many absorption bands in the ultraviolet and visible spectrum. The spectrum is shown in figure 2 for a $0.1 \mathrm{~nm}$ spectral bandwidth scan. The total number of observed absorption bands varies as a function of the spectral bandwidth used during the recording of the spectrum. There are approximately 14 major absorption features or bands between 200 and $650 \mathrm{~nm}$ that can be observed clearly for a wide range of spectral bandwidth settings. Most of the major absorption bands have lesser bands between them or in close association. These smaller bands are better resolved at bandwidths less than $1 \mathrm{~nm}$. Only the major absorption bands that could be of use as possible wavelength standards were selected for detailed study. The various parameters affecting the measured wavelengths of minimum transmittance of the holmium oxide solution are discussed in section 3. These include such parameters as temperature, purity, concentration, and spectral bandwidth.

The spectral transmittance of the holmium oxide solution was digitally recorded on a thermal printer at 0.1 $\mathrm{nm}$ intervals with the monochromator scanning at a rate of $0.05 \mathrm{~nm} / \mathrm{s}$. The transmittance was simultaneously recorded on a chart with a wavelength display of 0.5 $\mathrm{nm} / \mathrm{cm}$.

The holmium oxide solution was contained in a 10 $\mathrm{mm}$ pathlength fused silica cuvette. The transmittance of the solution in this cuvette was measured relative to an air-only path in the reference beam.

The determination of the wavelengths of the transmittance minimum of the holmium oxide solution was derived from an analysis of the recorded digital output. The $0.1 \mathrm{~nm}$ interval transmittance data were plotted on 

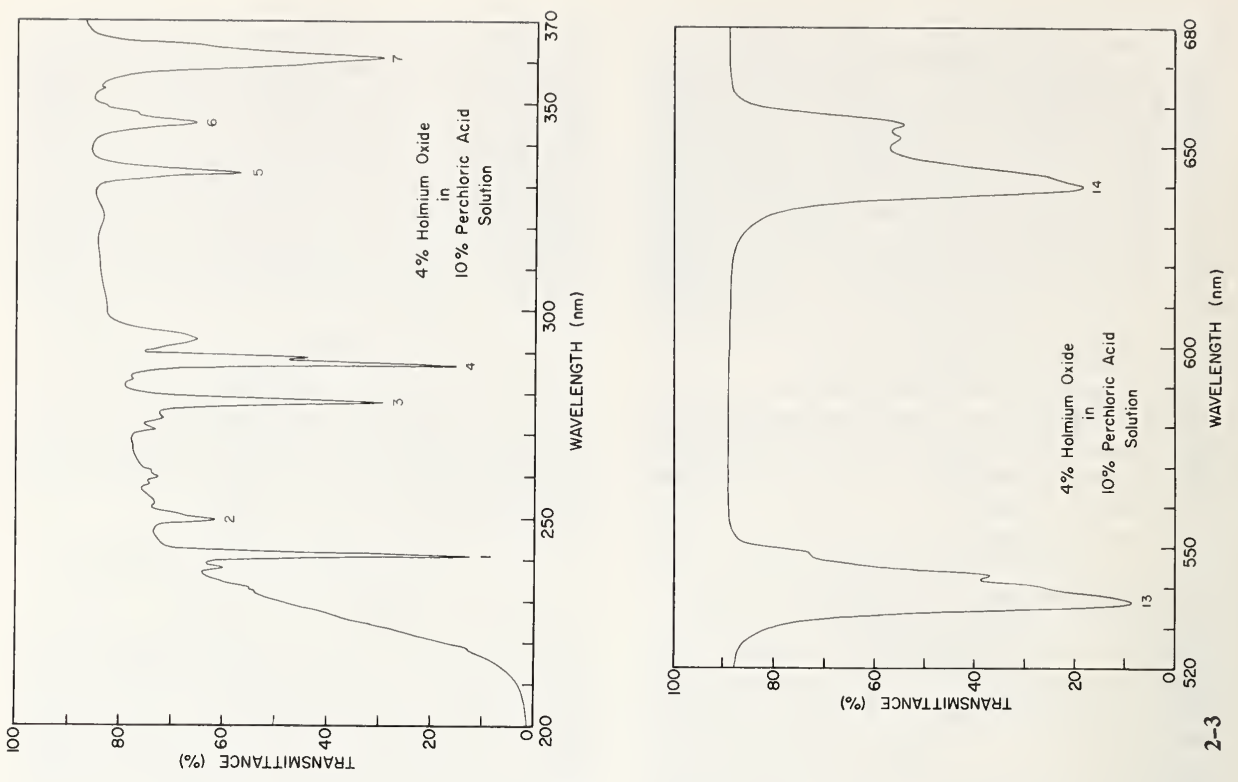

i
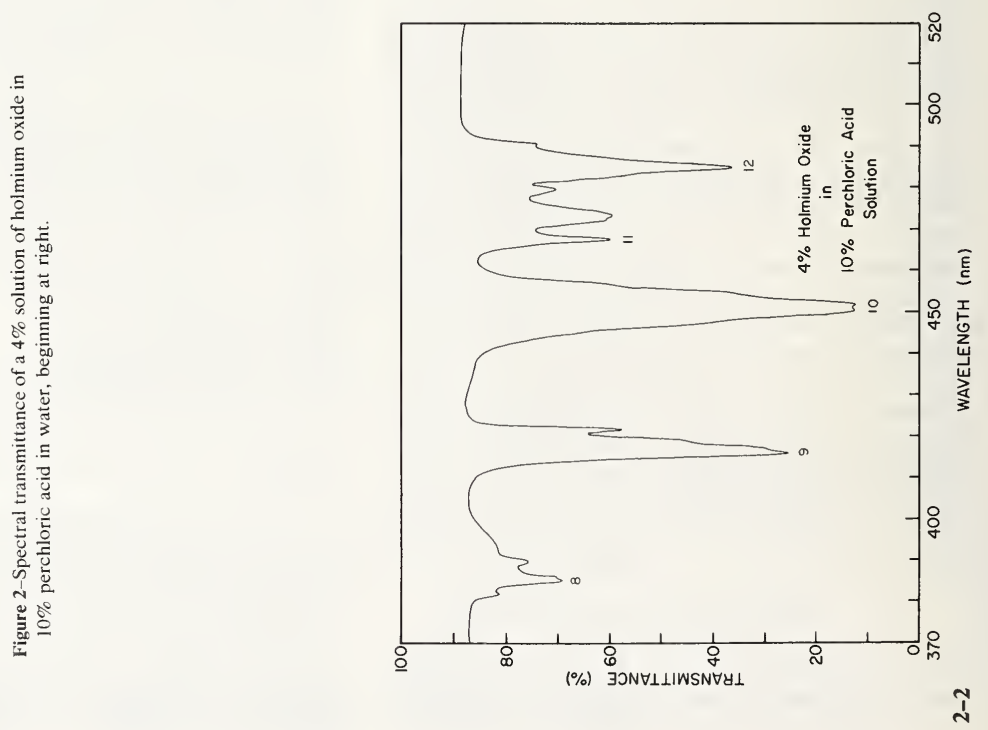
graph paper on a scale of $0.1 \mathrm{~nm}$ per $\mathrm{cm}$ with subdivisions of $0.01 \mathrm{~nm}$ per $\mathrm{mm}$ so that the wavelength interval of this plotted digital data could be read to the nearest $0.01 \mathrm{~nm}$ between the measured data points. The location of the wavelength of minimum transmittance for a given holmium oxide band was determined graphically (fig. 3) by drawing a curve through the data points and bisecting the horizontal grid lines between the two slopes of the curve representing the absorption feature. Several of these bisection points locate the line between the two slopes that intersects the minimum transmittance point, (usually at the lowest point of the curve). The wavelength at this point of intersection was taken as the measured wavelength of minimum transmittance for the absorption feature. The true wavelength of the minimum was determined by applying a wavelength correction to the instrumental wavelength scale, as determined in section 2.3.1.

\subsubsection{Accuracy of the Wavelengths of Minimum Transmittance}

The overall uncertainty in the location of the wavelengths of minimum transmittance is believed to be no greater than $\pm 0.1 \mathrm{~nm}$ at the $95 \%$ confidence limit. This conclusion is based on the reproducibility of the following calibration procedures:

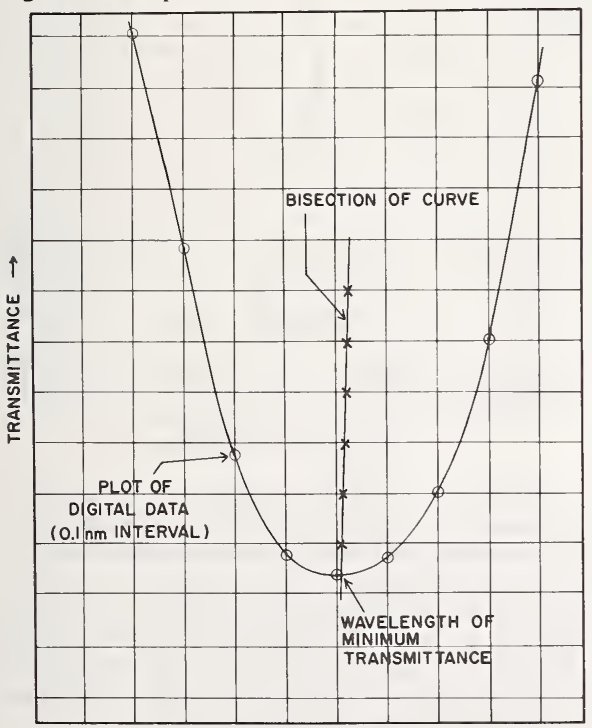

WAVELENGTH $(\mathrm{nm})$

Figure 3-Graphical technique used to determine the transmittance minima from digital spectral transmittance data.
- The uncertainty of the calibration of the instrument wavelength scale using the mercury and deuterium lamps, and the long-term and day-to-day instabilities of the instrument wavelength scale ( less than $\pm 0.05 \mathrm{~nm}$ ).

- The imprecision of the graphical technique for deriving the measured wavelengths of minimum transmittance. $( \pm 0.02 \mathrm{~nm})$.

- The dependence of the measured wavelengths of minimum transmittance on variations in temperature or concentration of the solution. $( \pm 0.02 \mathrm{~nm})$.

These uncertainties have been discussed in section 2.3.1. The imprecision of the graphical technique is illustrated in table 1 , where data are shown for three absorption features. Ten sets of digital results were produced by the instrument for each of these features. The digital data were plotted and the wavelengths of minimum transmittance for each absorption feature were determined for the 10 sets of data by the graphical technique. The standard deviation and standard error for the 10 determinations is also given in table 1 .

\section{Measurements}

\subsection{Influence of the Blank Cuvette, Solvent, and Water}

The spectral transmittances of an empty fused silica cuvette, a cuvette filled with distilled water, and a

Table 1. Ten cycle repetitive measurements of three holmium oxide transmittance minima. Listed minima are obtained by graphical techniques, using the digitally recorded $0.1 \mathrm{~nm}$ interval transmittance measurement.

\begin{tabular}{|c|c|c|c|}
\hline \multirow[b]{3}{*}{ Cycle } & \multicolumn{3}{|c|}{ (spectral bandwidth $=0.1 \mathrm{~nm}$ ) } \\
\hline & Minima & Minima & Minima \\
\hline & No. 1 & No. 12 & No. 14 \\
\hline 1 & $240.88 \mathrm{~nm}$ & $485.08 \mathrm{~nm}$ & $640.28 \mathrm{~nm}$ \\
\hline 2 & 240.87 & 485.10 & 640.30 \\
\hline 3 & 240.86 & 485.11 & 640.30 \\
\hline 4 & 240.84 & 485.11 & 640.30 \\
\hline 5 & 240.85 & 485.10 & 640.29 \\
\hline 6 & 240.84 & 485.11 & 640.30 \\
\hline 7 & 240.85 & 485.11 & 640.29 \\
\hline 8 & 240.85 & 485.11 & 640.30 \\
\hline 9 & 240.84 & 485.10 & 640.30 \\
\hline 10 & 240.85 & 485.11 & 640.29 \\
\hline Average: & 240.853 & 485.104 & 640.295 \\
\hline \multicolumn{4}{|l|}{ Standard } \\
\hline Deviation: & 0.0134 & 0.0097 & 0.0071 \\
\hline \multicolumn{4}{|l|}{ Standard } \\
\hline Error: & .0042 & .0031 & .0022 \\
\hline
\end{tabular}

Note: The data shown in this table have not been corrected for the wave length scale error of the spectrophotometer 
cuvette filled with the diluted perchloric acid (without holmium oxide) are illustrated in figure 4 . These measurements are relative to an air path in the reference beam.

Measurements of the wavelength of minimum transmittance for the band at $241 \mathrm{~nm}$ were made with the holmium oxide in perchloric acid solution versus a cuvette containing only the perchloric acid in the reference beam. The wavelength of minimum transmittance of this band was found to be the same when the holmium oxide solution was measured relative to air in the reference beam and when it was measured relative to a cuvette containing the perchloric acid solution. Since the $241 \mathrm{~nm}$ band is within the spectral range showing a slope in the transmittance of the cuvette-perchloric acid spectra, (see fig. 4) it was considered to be the band most likely to be influenced by this slope. However, no measurable influence was detected in the location of the wavelength of minimum transmittance of this band due to these spectral features associated with the solvent or cuvette.

\subsection{Influence of Temperature}

The wavelengths of minimum transmittance of the holmium oxide solution were determined at $20^{\circ} \mathrm{C}$, $25^{\circ} \mathrm{C}$, and $30{ }^{\circ} \mathrm{C}$ for spectral bandwidths of $0.1 \mathrm{~nm}$ and $1 \mathrm{~nm}$. If there is a temperature-related influence on the location of the wavelengths of minimum transmittance, it was not detected within these temperature ranges. The measured differences were attributed to random uncertainties.

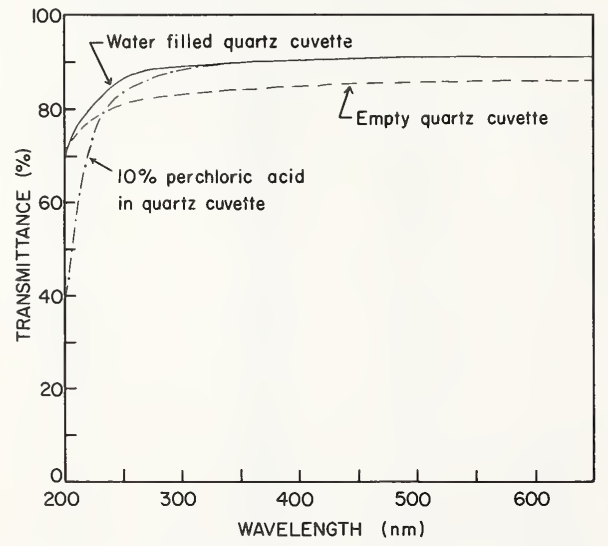

Figure 4-Spectral transmittances of an empty fused silica cuvette, a cuvette filled with water, and a cuvette filled with a solution of $10 \%$ perchloric acid in water.

\subsection{Influence of Purity}

Complete spectral scans of solutions made with the $99.99 \%$ and $99.999 \%$ purity holmium oxides showed no spectral differences except in the extreme ultraviolet cut-off at wavelengths less than $230 \mathrm{~nm}$. The differences are illustrated in figure 5 for the wavelength range 200 to $300 \mathrm{~nm}$. The wavelengths of the minimum transmittances for the 14 selected absorption bands were found to be the same for solutions prepared from these two lots of holmium oxide.

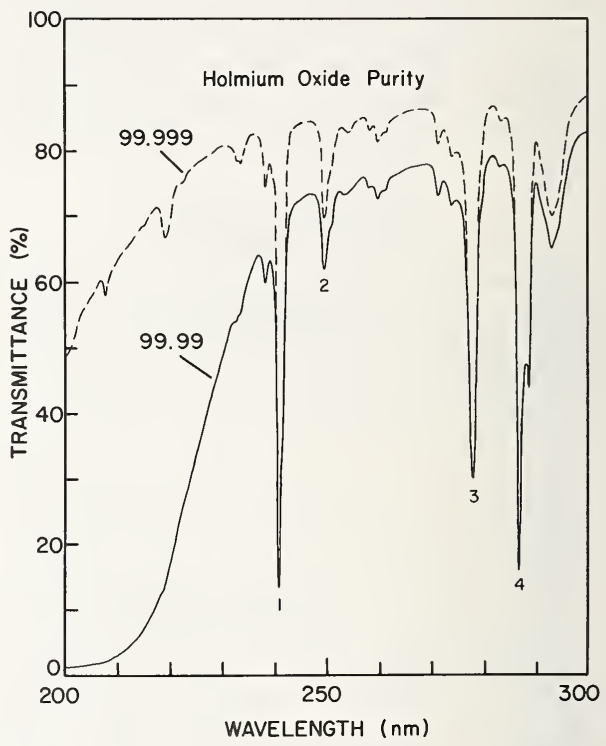

Figure 5-Spectral differences of solutions prepared from holmium oxide specimens of $99.99 \%$ purity and $99.999 \%$ purity.

\subsection{Influence of Concentration}

The location of the wavelengths of minimum transmittance of the holmium oxide solution as a function of concentration was tested with concentrations of $2 \%$, $4 \%$, and $6 \%$ in the perchloric acid solution. The general spectral scan indicated that the changes in concentration affected the measured transmittance as would be expected but did not influence the location of the transmittance minima. To verify this further, three of the bands were evaluated by the graphical technique described in section 2.3.1. The results of these concentration measurements for these bands are shown in table 2 . 
Table 2. Influence of holmium oxide concentration on the wavelengths of minimum transmittance.

\begin{tabular}{clll}
\hline & \multicolumn{3}{c}{ (spectral bandwidth=0.1 $\mathrm{nm}$ ) } \\
Holmium oxide & Minima & Minima & Minima \\
concentration & No. 1 & No. 12 & No. 14 \\
\hline $2 \%$ & $240.84 \mathrm{~nm}$ & $485.11 \mathrm{~nm}$ & $640.30 \mathrm{~nm}$ \\
$4 \%$ & 240.86 & 485.11 & 640.32 \\
$6 \%$ & 240.84 & 485.12 & 640.31 \\
\hline
\end{tabular}

Note: The data shown in this table have not been corrected for the wavelength scale error of the spectrophotometer

\subsection{Influence of Spectral Bandwidth}

The wavelengths of minimum transmittance of the holmium oxide solution were determined for spectral bandwidths of $0.1 \mathrm{~nm}, 0.25 \mathrm{~nm}, 0.5 \mathrm{~nm}, 1 \mathrm{~nm}, 2 \mathrm{~nm}$, and $3 \mathrm{~nm}$. Measurement of the instrumental spectral bandwidths is discussed in section 2.3.2. The influence of spectral bandwidth was by far the most important parameter affecting the location of the measured wavelengths of minimum transmittance. The results of this study are showil in figures 6 through 19 for the 14 minima identified in figures $2-1,2-2$, and 2-3. The data for bandwidth effects are also listed in tables 3 and 4 . The measurements indicate that for most of the holmium oxide bands, the location of the wavelengths of minimum transmittance does not change significantly for spectral bandwidths of less than $1 \mathrm{~nm}$. From these data it can be seen that a $0.1 \mathrm{~nm}$ spectral bandwidth is adequate to define the wavelengths of minimum transmittance within the stated uncertainties. For some bands the location of the minimum transmittance shifts only slightly for spectral bandwidths greater than $1 \mathrm{~nm}$. However, many do show large shifts for larger bandwidth settings. These results indicate that for instruments with spectral bandwidth settings of less than $1 \mathrm{~nm}$, the holmium oxide solution can serve as an excellent wavelength standard. For instruments having bandwidth settings between $1 \mathrm{~nm}$ and $3 \mathrm{~nm}$ the standard can still be of use if the instrument bandwidth is known.

\section{Results}

\subsection{Transmittance of Holmium Oxide Solution}

The general spectral signature of the holmium oxide solution is illustrated in figures $2-1,2-2$, and $2-3$ for a spectral bandwidth of $0.1 \mathrm{~nm}$. Some of the finer spectral features shown in these figures will be absent when the spectrum is recorded at bandwidths greater than $1 \mathrm{~nm}$. The major transmittance minima selected for this study are indicated by numbers 1 through 14 as shown in these figures. These band numbers are used throughout the manuscript as a key to associate the data in the tables with the spectral features illustrated in the figures.

\subsection{Selection of Useful Wavelengths of Minimum Transmittance}

The selection of holmium oxide bands that are considered useful for calibration purposes was based on the influence of spectral bandwidth on the location of these minima. The transmittance minima of small side bands associated with major absorption features usually shift in wavelength with bandwidth setting or are not resolved over the normal instrumental bandwidth range. The 14 major absorption bands are listed in tables 3 and 4. The absorption bands not listed in the tables are not considered useful for wavelength calibration purposes.

\subsection{Numerical Data}

The wavelengths of minimum transmittance of the $4 \%$ holmium oxide solution are listed in tables 3 and 4 for six spectral bandwidths. The results of the measurements as a function of temperature are also listed for $0.1 \mathrm{~nm}$ and $1 \mathrm{~nm}$ spectral bandwidths at temperature settings of $20^{\circ} \mathrm{C}, 25^{\circ} \mathrm{C}$, and $30^{\circ} \mathrm{C}$.

The shift in wavelengths of minimum transmittance as a function of spectral bandwidth is shown in figures 6 through 19 for the 14 selected minima. The recommended values of minimum transmittance are listed in table 3 and 4 for the measurements made at $25^{\circ} \mathrm{C}$.

\subsection{Uncertainty of Measured Wavelengths}

The uncertainties associated with the data listed in tables 3 and 4 have been discussed in section 2.3.4. The uncertainty in the determination of the wavelengths of minimum transmittance for the holmium oxide solution is believed to be no greater than $\pm 0.1 \mathrm{~nm}$ at the $95 \%$ confidence limit using the instrumentation and techniques described in this paper.

\subsection{Comparison of Results with Measurements Made on the NBS Reference Spectrofluorimeter}

The wavelengths of minimum transmittance of several absorption bands of holmium oxide solution were determined by analysis of spectral data obtained with the NBS Reference Spectrofluorimeter [9]. This reference instrument is primarily designed to be used as a research tool for high accuracy spectral analysis of fluorescent materials and in the development of standards for use in this area of research. The versatile design of the instrument allows for its use as a high accu- 
Figures 6-19-Fourteen holmium oxide transmittance minima as a function of spectral bandwidth.
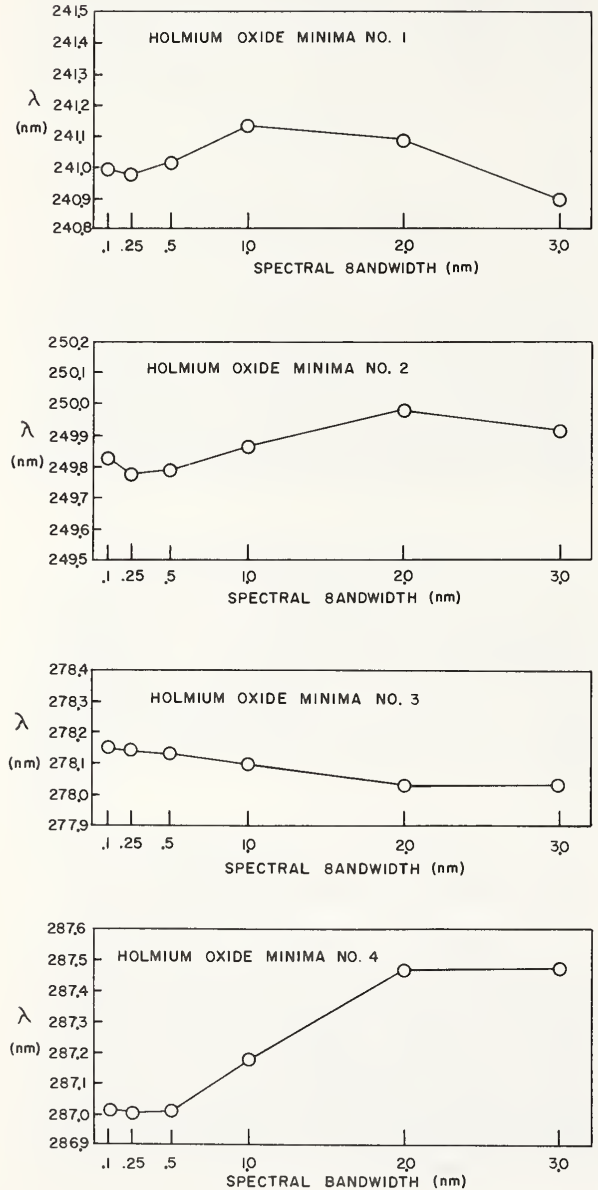
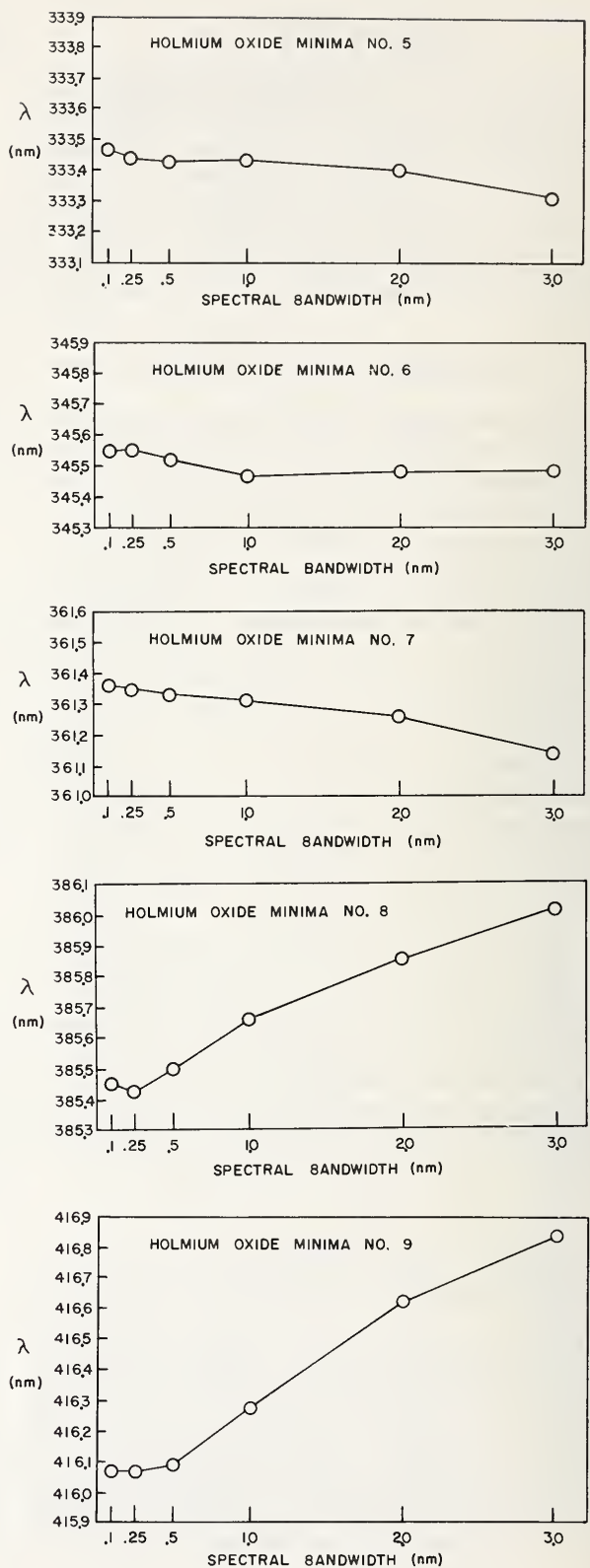

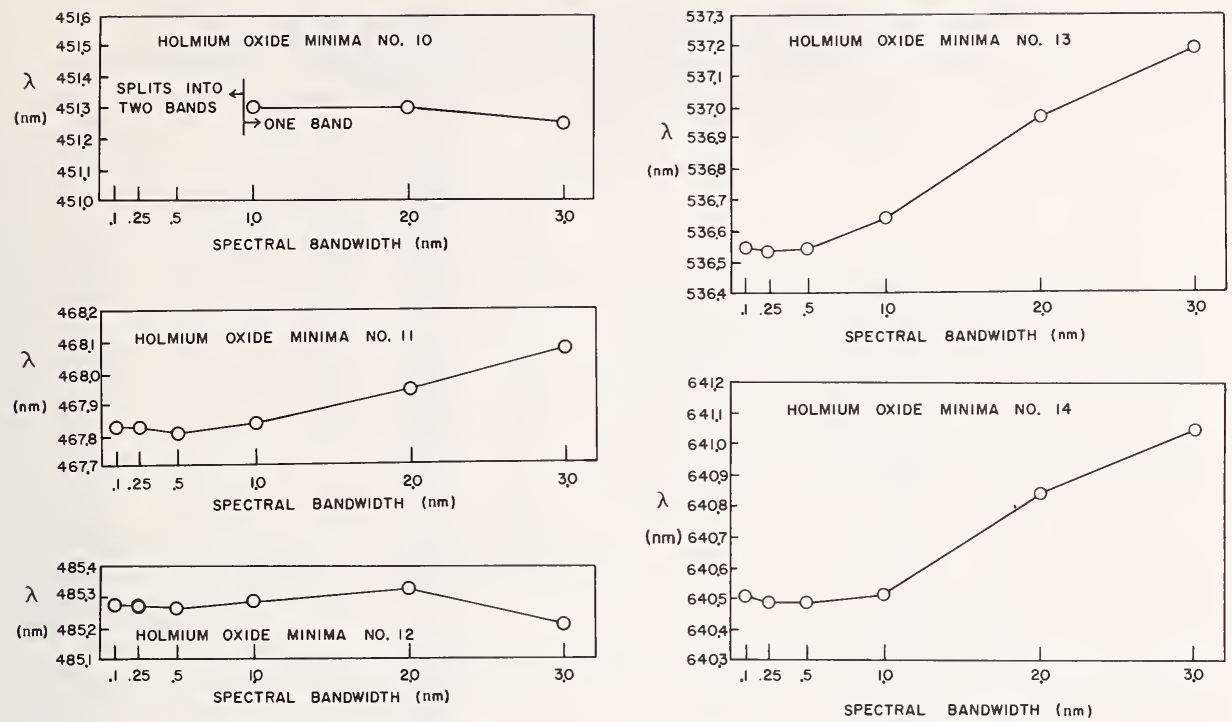

Table 3. Results of holmium oxide solution analysis for transmittance minima 1 through 7 for spectral bandwidths of $0.1,0.25,0.5,1,2$, and $3 \mathrm{~nm} .4 \%$ holmium oxide in a $10 \%$ perchloric acid solution.

\begin{tabular}{|c|c|c|c|c|c|c|c|}
\hline \multirow{2}{*}{$\begin{array}{c}\text { Minimum } \\
\text { No. }\end{array}$} & \multirow{2}{*}{$\begin{array}{l}\text { Temp. } \\
\left({ }^{\circ} \mathrm{C}\right)\end{array}$} & \multicolumn{6}{|c|}{ Spectral Bandwidths } \\
\hline & & $0.1 \mathrm{~nm}$ & $0.25 \mathrm{~nm}$ & $0.5 \mathrm{~nm}$ & $1 \mathrm{~nm}$ & $2 \mathrm{~nm}$ & $3 \mathrm{~nm}$ \\
\hline 1 & 20 & $240.99 \mathrm{~nm}$ & & & $241.13 \mathrm{~nm}$ & & \\
\hline 1 & 25 & 240.99 & $240.97 \mathrm{~nm}$ & $241.01 \mathrm{~nm}$ & 241.13 & $241.08 \mathrm{~nm}$ & $240.90 \mathrm{~nm}$ \\
\hline 1 & 30 & 240.99 & & & 241.15 & & \\
\hline 2 & 20 & 249.79 & & & 249.88 & & \\
\hline 2 & 25 & 249.83 & 249.78 & 249.79 & 249.87 & 249.98 & 249.92 \\
\hline 2 & 30 & 249.79 & & & 249.86 & & \\
\hline 3 & 20 & 278.14 & & & 278.09 & & \\
\hline 3 & 25 & 278.15 & 278.14 & 278.13 & 278.10 & 278.03 & 278.03 \\
\hline 3 & 30 & 278.14 & & & 278.09 & & \\
\hline 4 & 20 & 286.99 & & & 287.17 & & \\
\hline 4 & 25 & 287.01 & 287.00 & 287.01 & 287.18 & 287.47 & 287.47 \\
\hline 4 & 30 & 287.01 & & & 287.18 & & \\
\hline 5 & 20 & 333.48 & & & 333.45 & & \\
\hline 5 & 25 & 333.47 & 333.44 & 333.43 & 333.44 & 333.40 & 333.32 \\
\hline 5 & 30 & 333.48 & & & 333.45 & & \\
\hline 6 & 20 & 345.57 & & & 345.47 & & \\
\hline 6 & 25 & 345.55 & 345.55 & 345.52 & 345.47 & 345.49 & 345.49 \\
\hline 6 & 30 & 345.62 & & & 345.49 & & \\
\hline 7 & 20 & 361.38 & & & 361.33 & & \\
\hline 7 & 25 & 361.36 & 361.35 & 361.33 & 361.31 & 361.16 & 361.04 \\
\hline 7 & 30 & 361.38 & & & 361.31 & & \\
\hline
\end{tabular}

Note: The uncertainty in the wavelengths of minimum transmittance is $\pm 0.1 \mathrm{~nm}$. An extra decimal place is given for rounding purposes. 
Table 4. Results of holmium oxide solution analysis for transmittance minima 8 through 14 for spectral bandwidths of $0.1,0.25,0.5,1,2$, and $3 \mathrm{~nm} .4 \%$ holmium oxide in a $10 \%$ perchloric acid solution.

\begin{tabular}{|c|c|c|c|c|c|c|c|}
\hline \multirow{2}{*}{$\begin{array}{c}\text { Minimum } \\
\text { No. }\end{array}$} & \multirow{2}{*}{$\begin{array}{l}\text { Temp. } \\
\left({ }^{\circ} \mathrm{C}\right)\end{array}$} & \multicolumn{6}{|c|}{ Spectral Bandwidths } \\
\hline & & $0.1 \mathrm{~nm}$ & $0.25 \mathrm{~nm}$ & $0.5 \mathrm{~nm}$ & $1 \mathrm{~nm}$ & $2 \mathrm{~nm}$ & $3 \mathrm{~nm}$ \\
\hline 8 & 20 & $385.45 \mathrm{~nm}$ & & & $385.66 \mathrm{~nm}$ & & \\
\hline 8 & 25 & 385.45 & $385.42 \mathrm{~nm}$ & $385.50 \mathrm{~nm}$ & 385.66 & $385.86 \mathrm{~nm}$ & $386.01 \mathrm{~nm}$ \\
\hline 8 & 30 & 385.44 & & & 385.68 & & \\
\hline 9 & 20 & 416.10 & & & 416.27 & & \\
\hline 9 & 25 & 416.07 & 416.07 & 416.09 & 416.28 & 416.62 & 416.84 \\
\hline 9 & 30 & 416.13 & & & 416.30 & & \\
\hline 10 & 20 & $-\ldots *$ & & & 451.30 & & \\
\hline 10 & 25 & $--^{*}$ & -----* & $--^{*}$ & 451.30 & 451.30 & 451.24 \\
\hline 10 & 30 & ----* & & & 451.34 & & \\
\hline 11 & 20 & 467.83 & & & 467.84 & & \\
\hline 11 & 25 & 467.82 & 467.82 & 467.80 & 467.83 & 467.94 & 468.07 \\
\hline 11 & 30 & 467.84 & & & 467.84 & & \\
\hline 12 & 20 & 485.30 & & & 485.29 & & \\
\hline 12 & 25 & 485.28 & 485.28 & 485.27 & 485.29 & 485.33 & 485.21 \\
\hline 12 & 30 & 485.31 & & & 485.30 & & \\
\hline 13 & 20 & 536.53 & & & 536.65 & & \\
\hline 13 & 25 & 536.54 & 536.53 & 536.54 & 536.64 & 536.97 & 537.19 \\
\hline 13 & 30 & 536.45 & & & 536.63 & & \\
\hline 14 & 20 & 640.48 & & & 640.52 & & \\
\hline 14 & 25 & 640.51 & 640.49 & 640.49 & 640.52 & 640.84 & 641.05 \\
\hline 14 & 30 & 640.52 & & & 640.49 & & \\
\hline
\end{tabular}

* Splits into 2 minima for spectral bandwidths less than $1 \mathrm{~nm}$.

Note: The uncertainty in the wavelengths of minimum transmittance is $\pm 0.1 \mathrm{~nm}$. An extra decimal place is given for rounding purposes.

racy spectrophotometer in some applications. The wavelength scale of the spectrofluorimeter has been carefully calibrated by extensive measurements of emission line sources and is known to have an uncertainty of $\pm 0.1 \mathrm{~nm}$ for spectral bandwidth of $0.1 \mathrm{~nm}$.

This reference instrument was used to confirm the results obtained with the calibrated high-precision commercial spectrophotometer used for the holmium oxide measurements. A comparison was made to confirm the results for three of the transmittance minima at one spectral bandwidth setting. The results of this comparison are shown in table 5. The two instruments provided data for these three transmittance minima that agree to within $0.1 \mathrm{~nm}$. The wavelength scale uncertainty for both instruments is $\pm 0.1 \mathrm{~nm}$.

\subsection{Other Measurements Outside NBS}

A list of the wavelengths of minimum transmittance of the holmium oxide solution reported by other workers is given in table 6. (Ref. 10 offers details of these measurements.)
Table 5. Comparison of values for holmium oxide transmittance minima with values obtained with the NBS Reference Spectrofluorimeter.

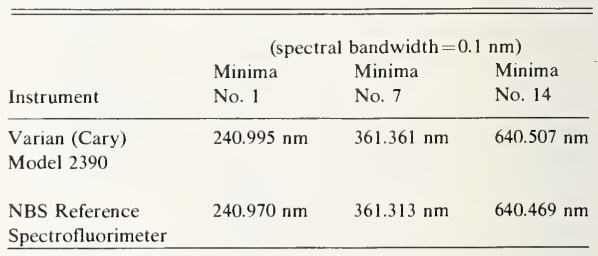

The data shown in table 6 indicate that workers in other laboratories are in generally good agreement with one another and that the NBS data also agree well with these workers' previously published data. These workers also found that the wavelengths of minimum transmittance of holmium oxide in similar solution in perchloric acid are not sensitive to variations in temperature and concentration. They also concluded that the wavelengths of minimum transmittance were least affected by changes in spectral bandwidth for band- 
Table 6. Comparison of values for holmium oxide transmittance minima with values obtained by other workers (see Reference 10).

\begin{tabular}{|c|c|c|c|c|c|c|}
\hline $\begin{array}{l}\text { Min. } \\
\text { No. }\end{array}$ & $\begin{array}{c}\text { NBS } \\
\text { Transmittar } \\
\text { Minima }\end{array}$ & nce & (1) & (2) & (3) & (4) \\
\hline 1 & $240.99 \mathrm{~nm}$ & & $241.15 \mathrm{~nm}$ & $241.0 \mathrm{~nm}$ & $241.1 \mathrm{~nm}$ & $241.1 \mathrm{~nm}$ \\
\hline 2 & 249.83 & * & 249.75 & 250.0 & 249.7 & 249.7 \\
\hline 3 & 278.15 & * & 278.2 & 277.8 & 278.7 & 278.2 \\
\hline 4 & 287.01 & * & 287.15 & 287.5 & 287.1 & 287.2 \\
\hline 5 & 333.47 & * & 333.5 & 333.3 & 333.4 & 333.3 \\
\hline 6 & 345.55 & * & 345.6 & 345.5 & 345.5 & 345.0 \\
\hline 7 & 361.36 & * & 361.5 & 361.0 & 361.5 & 361.2 \\
\hline 8 & 385.45 & * & 385.6 & 385.6 & 385.5 & 385.6 \\
\hline 9 & 416.07 & * & 416.2 & 416.0 & 416.3 & 416.6 \\
\hline 10 & 451.30 & \# & 450.7 & 450.4 & 450.8 & 451.0 \\
\hline 11 & 467.82 & & 467.75 & & & 468.0 \\
\hline 12 & 485.28 & & 485.25 & 485.2 & 485.8 & 485.2 \\
\hline 13 & 536.54 & & 536.3 & & & 536.8 \\
\hline 14 & 640.51 & & 640.5 & & & \\
\hline
\end{tabular}

* Spectral bandwidth $=0.1 \mathrm{~nm}$

\# Spectral bandwidth $=1 \mathrm{~nm}$

widths less than $1 \mathrm{~nm}$, but that large shifts can be encountered at bandwidths in excess of $1 \mathrm{~nm}$.

\section{Conclusions}

The reported wavelengths of minimum transmittance of the holmium oxide solution appearing in tables 3 and 4 are estimated to be uncertain by no more than \pm 0.1 $\mathrm{nm}$ at the $95 \%$ confidence limit. These wavelengths of minimum transmittance were found to be essentially unaffected by changes in temperature at $25^{\circ} \mathrm{C} \pm 5{ }^{\circ} \mathrm{C}$. They were also unaffected by variations in the concentration for solutions containing $2 \%, 4 \%$, and $6 \%$ holmium oxide. The critical parameter affecting the measured values of minimum transmittance was found to be the spectral bandwidth setting of the spectrophotometer. For spectral bandwidths less than $1 \mathrm{~nm}$ the wavelength shift is generally less than $0.2 \mathrm{~nm}$. Users can most effectively determine the wavelength error associated with their instrument by using the NBS data listed in tables 3 and 4 that are representive of the spec tral bandwidth setting ordinarily used with the instru ment. The wavelengths of minimum transmittance of the holmium oxide solution for spectral bandwidths greater than $3 \mathrm{~nm}$ have not been evaluated.

The authors gratefully acknowledge the assistance of Chenq-Tsong Chang, guest worker from Taiwan, for his contribution in measuring the transmittance minima of the holmium oxide solution on the NBS Reference Spectrofluorimeter; Jack J. Hsia, for constructive discussions; Robert W. Burke, for assistance in the preparation of various $\mathrm{Ho}_{2} \mathrm{O}_{3}$ solutions; and the NBS Optical Shop for preparation of the fused silica cuvettes.

\section{References}

[1] The terminology used in this work was defined earlier by K. D. Mielenz in Anal. Chem. 48, 1093 (1976).

[2] Keegan, H. J.; J. C. Schleter and V. R. Weidner, Uitraviolet Wavelength Standard for Spectrophotometry, J. Opt. Soc. Am. 51, 1470 (1961), (abstract).

[3] Venable, W. H., Jr., and K. L. Eckerle, Standard Reference Material: Didymium Glass Filters for Calibrating the Wavelength Scale of Spectrophotometers (SRM 2009, 2010, 2013, 2014).

[4] The holmium oxide was obtained from Research Chemicals, a Division of Nucor Corp., Phoenix, Arizona.

[5] Gschneider, K. A., Jr., and L. E. Yring, Handbook of the Physics and Chemistry of Rare Earths, Vol. 3 North-Holland (1979).

[6] Harrison, G. R., MIT Wavelength Tables, MIT Press, Cambridge, MA (1960).

[7] ASTM Manual on Recommended Practices in Spectrophotometry, Published by American Society for Testing and Materials, 1916 Race St., Philadelphia, PA 19103 (1969).

[8] CRC Handbook of Chemistry and Physics, 63d Edition, CRC Press, Inc., (1982-1983).

[9] Mielenz, K. D., in "Measurement of Photoluminescence" (K. D. Mielenz, Editor), pp 17-19, Academic Press (1982).

[10] Burgess, C., and A. Knowles, Eds. Standards in Absorption Spectrometry, Chapter 7, Wavelength Calibration, Chapman and Hall, London (1981). 
Appendix A-1. Standard Reference Materials for Spectrophotometry Provided by the National Bureau of Standards.

\section{Solid Filters}

\section{0}

Glass Filters for

Spectrophotometry
Solid filters made of Schott NG-4 and NG-5 optically neutral glass. Obtained from the Schott-Jenaer Glaswerk, Mainz, Germany.
Three filters with nominal transmittances of $10,20,30 \%$. Each filter is mounted in a black anodized aluminum holder provided with front and rear shutters. The filters are stored in a cylindrical aluminum container.

\section{1}

Metal-on-Quartz

Filters for

Spectrophotometry
Solid filters made of semitransparent evaporated chromium-on-fused silica (non-fluorescent) plates.
Three filters with nominal transmittances of $10,30,90 \%$. Each filter is made from two fused silica plates assembled by optical contact. The $90 \%$ filter is made by assembling 2 clear plates. The $10 \%$ and $30 \%$ filters are made by assembling a fused silica plate which carries a film of semitransparent chromium to produce the desired transmittance, and a clear plate. Each filter assembly is placed in a metal holder provided with shutters.

Liquids and Cuvettes

\section{$931 \mathrm{~b}$}

Liquid Absorbance

Standards for Ultraviolet and Visible

Spectrophotometry
Liquid filters made from a solution of $\mathrm{Co}$ and $\mathrm{Ni}$ metals dissolved in a mixture of nitric-perchloric acids. The $\mathrm{pH}$ of the solution is about 1 . Prepared in the NBS Center for Analytical Chemistry.
Three solutions and a blank were delivered in sealed ampoules and have nominal absorbances of 0.1 to 0.9 .

\section{5}

Crystalline Potassium

Dichromate for Use as an

Ultraviolet Absorbance Standard
Crystalline potassium dichromate of established purity obtained from the J. T. Baker Chemical Co., Phillipsburg, New Jersey.
The crystalline material of reagent grade purity is offered in glass bottles provided with plastic screw caps. 
The transmittance of each filter is measured with the high-accuracy spectrophotometer at $\lambda 440,465,546.1$, $590,635 \mathrm{~nm}$, using spectral bandpasses of $2.2,2.7,6.5$, $5.4,6.0 \mathrm{~nm}$ respective1y.
This SRM is intended as a reference source for the verification of the transmittance and absorbance scales of conventional spectrophotometers.
The use of this SRM is limited to the visible spectrum and requires narrow spectral bandpasses. For further details, consult the Certificate included in the Appendix; see also NBS Special Publication 260-51.
The transmittance of each filter is measured with the high-accuracy spectrophotometer at $\lambda 250,280,340$, $360,400,465,500,546.1$, $590,635 \mathrm{~nm}$.
This SRM is intended as a reference source for the verification of the transmittance and absorbance scales of conventional spectrophotometers in the ultraviolet and visible spectral region.
SRM 2031 has good optica1 neutrality and can be used to calibrate spectrophotometers with wide spectral bandpasses from about 200 to $800 \mathrm{~nm}$ (with possible extension to $\lambda=3 \mu \mathrm{m}$ ). For further details, consult the Certificate in the Appendix; see, also NBS Special Publication 260-68.
The absorbance of each solution was measured at $\lambda 302$, $395,512,678 \mathrm{~nm}$ using spectral bandpasses of 1.0 $1.7,2.0,6.5 \mathrm{~nm}$ respectively. The certification is made with an uncertainty of about $\pm 1.0 \%$.
This SRM is primarily intended for the verification of the accuracy of transmittance or absorbance scales of spectrophotometers.
Requires the use of SRM 932 and of narrow spectral bandpasses. Provides only one certified value in the ultraviolet. For further details consult the Certificate included in the Appendix.
The apparent specific absorbance is certified for five concentrations at $\lambda 235$, $257,313,345,350 \mathrm{~nm}$ using spectral bandpasses of 1.2 , $0.8,0.8,0.8,0.8 \mathrm{~nm}$ respectively, using SRM 932.
This SRM is intended to be used as a reference standard for the verification of the accuracy and linearity of the absorbance scale of spectrophotometers.
Requires accurate preparation of solutions of potassium dichromate in $0.001 \mathrm{~N}$ perchloric acid. Requires the use of SRM 932 and of narrow spectral bandpasses. Can be used only in the ultraviolet. For further details, consult the Certificate included in the Appendix; see also NBS Special Publication 260-54. 
Appendix A-1. Continued.

\begin{tabular}{lll}
\hline SRM & Material & Composition \\
\hline $\begin{array}{l}\text { Quartz Cuvette for } \\
\text { Spectrophotometry }\end{array}$ & $\begin{array}{l}\text { All-quartz cuvette made of } \\
\text { non-fluorescent fused silica } \\
\text { of optical quality }\end{array}$ & $\begin{array}{l}\text { Each cuvette is made of fused } \\
\text { silica and is provided with a } \\
\text { Teflon stopper. The trans- } \\
\text { parent windows are attached } \\
\text { to the body of the cuvette by } \\
\text { direct fusion. } \\
\text { The cuvettes } \\
\text { are stress-relieved by proper } \\
\text { annealing. The cuvette is } \\
\text { stored in transparent } \\
\text { plastic container. }\end{array}$ \\
\hline
\end{tabular}

Stray Light

2032

Potassium Iodide for Use as a Stray Light Standard
Crystalline potassium iodide of established purity, obtained from the J. T. Baker Chemical Co., Phillipsburg, New Jersey.
The reagent-grade, crystalline $\mathrm{KI}$ is $99.8 \%$ pure as indicated by the manufacturer. Moisture is $0.007 \%$. Homogeneity was determined by absorbance measurements at 265, 267, and $270 \mathrm{~nm}$, and was found adequate.

\section{3}

Potassium Iodide for Use as a Stray Light Standard with Radiation Attenuator
Crystalline potassium iodide of established purity, and two semi-transparent evaporated metal-on-fused silica filters contained in a metal holder provided with shutters. The KI was obtained from the J. T. Baker Chemical Co., Phillipsburg, New Jersey. The filters and the holder were made by the NBS Instrument Shop.
Potassium iodide as for SRM 2032. Two semitransparent evaporated chromium-on-fused silica (non-fluorescent) filters of optical quality.

Wavelength

2009

Didymium Glass Filter for Checking the Wavelength Scale of Spectrophotometers
The didymium glass was prepared by Corning Glass Works, Corning, New York, as Corning 5120 Filter Glass.
Rare earth oxides in a glass matrix. This filter is $1 \mathrm{~cm}$ wide, $3 \mathrm{~cm}$ high, and $3 \mathrm{~mm}$ thick. Each filter is placed in a metal holder which fits into the cuvette holder of the spectrophotometer.

\section{0}

Didymium Glass Filter for

Checking the Wavelength

Scale of Spectrophotometers
Same as SRM 2009.

Rare earth oxides in a glass matrix. This filter is placed $5.1 \mathrm{~cm}$ square and $3 \mathrm{~mm}$ thick. 
The nominal inner pathlength is $i 0 \mathrm{~mm}$ and it is certified at 10 points along the height of the transparent windows with an uncertainty of $+0.0005 \mathrm{~mm}$. The cuvettes are $\overline{1} 2.5 \mathrm{~mm}$ square and $48 \mathrm{~mm}$ high.
To be used when accurate transmittance or absorbance measurements are made on liquid samples. Should be used in conjuntion with SRM's 931, 935, 2032, and 2033.
For further details, consult the Certificate included in the Appendix; see also NBS Special Publication 260-32.
The specific absorbances were measured with the highaccuracy spectrophotometer at $240,245,250,255,265,270$, and $275 \mathrm{~nm}$ at $23.5{ }^{\circ} \mathrm{C}$ using a spectral bandpass of $0.2 \mathrm{~nm}$. The measurements were performed using SRM 932 quartz cuvettes.
SRM 2032 is to be used to assess heterochromatic stray light in the ultraviolet region below $260 \mathrm{~nm}$, in absorption spectrophotometers. It is recommended that SRM 932 be used in the measurements.
SRM 2032 should be stored in the original, low-actinic glass bottle and cardboard container, protected from exposure to light and humidity. The estimated stability is 3 years.
Same as for SRM 2032. The transmittance of the evaporated metal-on-fused silica filters was measured at $255 \mathrm{~nm}$ with the highaccuracy spectrophotometer. The nominal value is $10 \%$ for each filter, and a combined value of $1 \%$.
SRM 2033 is to be used to assess heterochromatic and isochromatic stray light in absorption spectrophotometers.
Same as for SRM 2032. The two semi-transparent evaporated metal-on-fused silica filters in the metal holder should be stored in the plastic container provided with SRM 2033.
The wavelengths of maximum absorption were determined with a high-precision spectrophotometer for bandwidths in the range 1.5 to $10.5 \mathrm{~nm}$ and for 14 to 24 wavelengths in the range 400 to $760 \mathrm{~nm}$. The instrument has a wavelength accuracy of $0.04 \mathrm{~nm}$.
The filters are to be used in calibrating the wavelength scale in the visible spectral region for spectrophotometers having nominal bandwidths in the range 1.5 to $10.5 \mathrm{~nm}$.
SRM 2009 was not measured individually. It is recommended for most applications. For further details, consult NBS Special Publication 260-66. 
Appendix A-1 . Continued.

Didymium Glass Filter for

Didymium Glass Filter for

Checking the Wavelength

Scale of Spectrophotometers

\section{4}

Holmium Oxide for Use as Wavelength Standard for Spect rophotometry
Holmium oxide of established purity dissolved in perchloric acid.
Holmium oxide is offered in solutions in sealed $10 \mathrm{~mm}$ quartz cuvettes.

\section{Fluorescence}

\section{6}

Quinine Sulfate

Dihydrate
The quinine sulfate dihydrate was a special lot of material obtained from J. T. Baker Chemical Co., Phillipsburg, New Jersey.
SRM 936 contains $1.7 \%$ impurities determined by liquid chromatography and believed to be dihydroquinine sulfate dihydrate. The water content is $4.74+0.05 \%$ determined by the Karl Fisher method and $4.57 \pm 0.04 \%$ by weight loss. Theoretical value is $4.60 \%$.

NOTE: For further scientific information concerning the following Standard Reference Materials, write or cal1 at the National Bureau of Standards, Gaithersburg, MD 20899: SRM's 930, 931, 932, 935, 936, 2030, 2031, 2032, and 2033: Dr. R. W. Burke, Inorganic Analytica1 Research Division, Chemistry Building, Room B222. Phone: 301-921-2141. SRM's 2009, 2010, 2013, and 2014: Mr. K. L. Eckerle, SRM 2034: Mr. V. R. Weidner, Radiometric Physics Division, Center for Radiation Research, Metrology Building, Room A321. Phone: 301-921-2791; for scientific information concerning physical parameters involved in spectrophotometry and luminescence measurements: Dr. K. D. Mielenz, Chief, Radiometric Physics Division, Center for Radiation Research, Metrology Building, Room B304. Phone: 301-921-3864.

For information concerning the availability and purchase of the SRM's discussed in this paper contact: Office of Standard Reference Materials, Chemistry Building, Room B311. Phone: 301-921-2045. The NBS Publications discussed in this paper can be purchased from the Superintendent of Documents, U.S. Government Printing Office, Washington, DC 20034. Please write for information concerning availability, delivery, and price. 
Each filter was measured separately; hence the data provide a more accurate representation of the optical properties of the individual filter.
Same as SRM 2009.
SRM 2013 was measured individually and should be used when assurance in the evaluation of an instrument's wavelength scale is highly critical. For further details, consult NBS Special Publication 260-66.
The wavelengths of maximum absorption of holmium oxide solutions in perchloric acid is determined for various spectral bandpasses at the nominal wavelengths $241,250,278,287,333$, $345,361,385,416,451$, $467,485,536,640 \mathrm{~nm}$.
This SRM is to be used as a reference standard for the verification of the accuracy of the wavelength scale of absorption spectrometers, in the ultraviolet and visible spectral regions.
Holmium oxide solutions in perchloric acid were selected as a wavelength standard because the absorption bands are narrower than those of the holmium oxide glass.
The material is certified for the relative molecular emission spectrum $E(\lambda)$, in radiometric units for a solution of $1.28 \times 10^{-6} \mathrm{~mol} / \mathrm{L}$ in 0.105 mol/L perchloric acid, using an excitation wavelength of $347.5 \mathrm{~nm}$. The certified values of the molecular emission spectrum at $5 \mathrm{~nm}$ intervals from 375 to $675 \mathrm{~nm}$ are given. This certification was made with the NBS reference fluorescence spectrometer.
For evaluation of methods and the calibration of fluorescence spectrometers. A solution of $0.1 \mathrm{mg} / \mathrm{mL}$ in $1000 \mathrm{~mL} 0.105 \mathrm{~mol} / \mathrm{L}$ perchloric acid is recommended. It should be stored in the dark in a well-stoppered glass bottle. This solution is stable for three months. SRM 936 is for "in vitro" diagnostic use only.
The material should be kept in its original bottle and stored in the dark at $30{ }^{\circ} \mathrm{C}$ or less. Under these conditions SRM 936 is stable for three years. See NBS Special Publication 260-64. 


\section{Uiertifitate}

\section{Standard Reference Material 930D}

Glass Filters for Spectrophotometry

This Standard Reference Material (SRM) is intended as a reference source for the verification of the transmittance and absorbance scales of spectrophotometers. SRM 930D consists of three individual glass filters in separate metal holders and one empty filter holder. The filter holders are provided with shutters that protect the glass filters when not in use. These shutters must be removed at the time of measurement and be replaced after the measurements have been completed. Each metal holder bears a filter number $(10,20$, or 30$)$ and a set identification number. The upper left corner of each filter has been removed to indicate correct orientation in the metal holder. The certified transmittance values are given below.

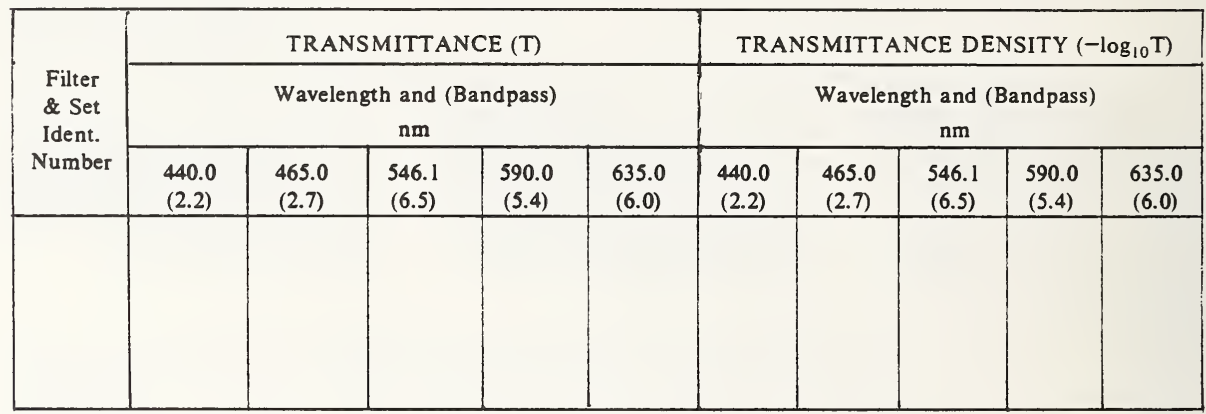

Date of Certification:

The uncertainty of the certified transmittance value is \pm 0.5 percent at the time of certification. This uncertainty includes the effects of the random and systematic errors of the calibration procedure, as well as possible transmittance changes of the filters during the period of calibration.

The transmittance values ( $\mathrm{T}$ ) can be converted to percent transmittance $(\% \mathrm{~T})$ by multiplying by 100 . The transmittance densities are calculated from the measured transmittance (T). These values should be indicated by the absorbance scale of the spectrophotometer if the filters are measured against air. The transmittance values given were measured against air at an ambient temperature of $22.5^{\circ} \mathrm{C}$.

Aging of the glass may cause some filters to change transmittance by about \pm 1 percent over a period of approximately one year from the date of calibration. Improper storage or handling of the filters may also cause changes [5]. It is recommended that the filters in the holders be handled only by the edges with soft plastic (polyethylene) gloves and optical lens tissue. When not in use they should be stored in their holders and in the container provided for this purpose. Extended exposure to laboratory atmosphere and dusty surroundings should be avoided. In cases where verification is desirable, the filters should be returned to the National Bureau of Standards for cleaning and recalibration.

The research, development, and initial production of this SRM were conducted by R. Mavrodineanu and J.R. Baldwin, NBS Inorganic Analytical Research Division.

The transmittance measurements were performed by R. W. Burke, M.V. Smith, and R. Mavrodineanu, NBS Inorganic Analytical Research Division. Technical leadership for the preparation and measurements leading to certification was provided by R.W. Burke.

The overall direction and coordination of the technical measurements leading to certification were performed under the chairmanship of J.R. DeVoe, NBS Inorganic Analytical Research Division.

The technical and support aspects involved in the preparation, certification, and issuance of this Standard Reference Material were coordinated through the Office of Standard Reference Materials by L.J. Powell.

Gaithersburg, MD 20899

Stanley D. Rasberry, Chief

August 15, 1984

Office of Standard Reference Materials

(Revision of Certificate

dated 8-1-77) 
The transmittance measurements were made using the high-accuracy spectrophotometer designed and built at the NBS Center for Analytical Chemistry [1]. This instrument represents the primary transmittance standard; its transmittance accuracy was established using the double-aperture method of linearity testing $[1,3,5,6]$. The estimated standard deviation obtained from a set of 20 measurements of the high-accuracy spectrophotometer used for transmittance measurements on glass filters of the SRM 930 type is $5 \times 10^{-5}$ transmittance units for transmittance between 0.1 and 0.3 . The bounds of the systematic error of the instrument are estimated to be $\pm 10^{-4}$ transmittance units.

The neutral glasses for the filters were provided by Schott of Mainz, Germany, and are designated as "Jena Color and Filter Glass." The glass material was selected for best homogeneity and minimum of inclusions and striae. The glass filters were aged at NBS for about one year prior to certification. They are of the type NG-4 and NG-5, and their nominal transmittances are 10,20 , and 30 percent $[2,5]$. The glasses were selected to provide a means to verify the transmittance scale of conventional spectrophotometers at three levels. The exposed surface of the glass is approximately $29 \times 8 \mathrm{~mm}$, measuring from a point $1.5 \mathrm{~mm}$ above the base of the filter holder (see figure). The empty filterholder is provided to be used in the reference beam of the spectrophotometer so that approximately equivalent conditions of stray radiation are achieved for both beams.

The transmittance of the filters depends upon the intrinsic properties of the material, wavelength, spectral bandpass, geometry of the optical beam, stray light, temperature. and positioning of the filter. A change of ambient temperature of 1 or $2^{\circ} \mathrm{C}$ from $22.5^{\circ} \mathrm{C}$ will not significantly affect the calibration [5]. Changes in the transmittance may be caused by surface conditions, aging of the glass, exposure to a harmful atmosphere, or careless handling as indicated on the face of this certificate $[2,3,4,5]$. The effective spectral bandpass used to determine the certified values was $0.8 \mathrm{~nm}$. The spectral bandpass values indicated in parentheses in this certificate are maximum values that should not be exceeded when accurate measurements are contemplated. The transmittance measurements were made by producing the verticai image of the slit (about $8 \mathrm{~mm}$ by $0.5 \mathrm{~mm}$ ), using a convergent beam geometry with an aperture ratio $\mathrm{f}: 10$, in the middle of the entrance face of the glass filter. The filters were measured in the spectrophotometer in a position perpendicular to the incident light beam as shown in the attached figure. Measurements performed outside these specified conditions will produce transmittance values that might differ from the certified data.

SRM $930 \mathrm{D}$ is stored in a black anodized aluminum container provided with a threaded cap made of the same metal. Each filter is placed in a cylindrical cavity to prevent any contact between the filter face and the walls of the storage container. Contamination of the glass filter surface with particulate matter due to static charge is minimized through the metallic nature of the container. Each filter holder is provided with a flat leaf spring which is inserted into the cylindrical cavity to minimize damage during transportation. These springs can be removed during normal use in the laboratory.

Prior to certification measurements, each filter was examined for surface defects and thoroughly cleaned [5]. Should the surface of the glass filter become contaminated, no attempt should be made to clean it unless the user has the facilities to demonstrate that the cleaning treatment has not altered the glass surface or degraded the accuracy of the certified values. As the Standard Reference Material is a transfer standard, the only means available to verify its integrity is remeasuring its transmittance with a primary standard instrument similar to that used in this certification $[1,4,7]$. In most cases where verification, or recertification, of the transmittance values is desirable, it will be most expeditious to return the filters to the National Bureau of Standards for measurement. Prior to shipment, the NBS Office of Standard Reference Materials should be contacted regarding the conditions and cost of verification and/or recertification.

We wish to acknowledge the cooperation of George N. Bowers, Jr., M. D., of Hartford Hospital, Hartford, Connecticut; Royden N. Rand, Ph.D., of the Eastman Kodak Co. Research Laboratories, Rochester, New York; and Donald S. Young, M.D., and Ph.D., of the Mayo Clinic, Rochester, Minnesota.

SRM 930D

Page 2 


\section{REFERENCES}

1. R. Mavrodineanu, An Accurate Spectrophotometer for Measuring the Transmittance of Solid and Liquid Materials, NBS Journal of Research 76A, No. 5, 405-425 (1972).

2. R. Mavrodineanu, Solid Materials to Check the Photometric Scale of Spectrophotometers, NBS Tech. Note 544, O. Menis and J.I. Shultz, Eds., pp. 6-17, U.S. Government Printing Office, Washington, DC 20402 (Sept. 1970); ibid, NBS Tech. Note 584, pp. $2-21$ (December 1971).

3. K.S. Gibson, Spectrophotometry, NBS Circ. 484 (Sept. 1949).

4. Collected Papers from NBS Conference on Accuracy in Spectrophotometry and Luminescence Measurements, NBS Journal of Research 76A, No. 5, 375-510 (1972).

5. R. Mavrodineanu and J.R. Baldwin, Glass Filters as a Standard Reference Material for SpectrophotometrySelection, Preparation, Certification, Use, SRM 930, NBS Special Publication 260-51, U.S. Government Printing Office, Washington, DC 20402, (1975).

6. K.D. Mielenz and K.L. Eckerle, Spectrophotometer Linearity Testing Using the Double-Aperture Method, Appl. Optics 11, 2294-2303 (1972).

7. R.W. Burke and R. Mavrodineanu, Accuracy in Analytical-Spectrophotometry, NBS Special Publication 260-81, U.S. Government Printing Office, Washington, DC 20402, (1983.)

\section{METAL HOLDER FOR THE COLORED GLASS FILTERS*}

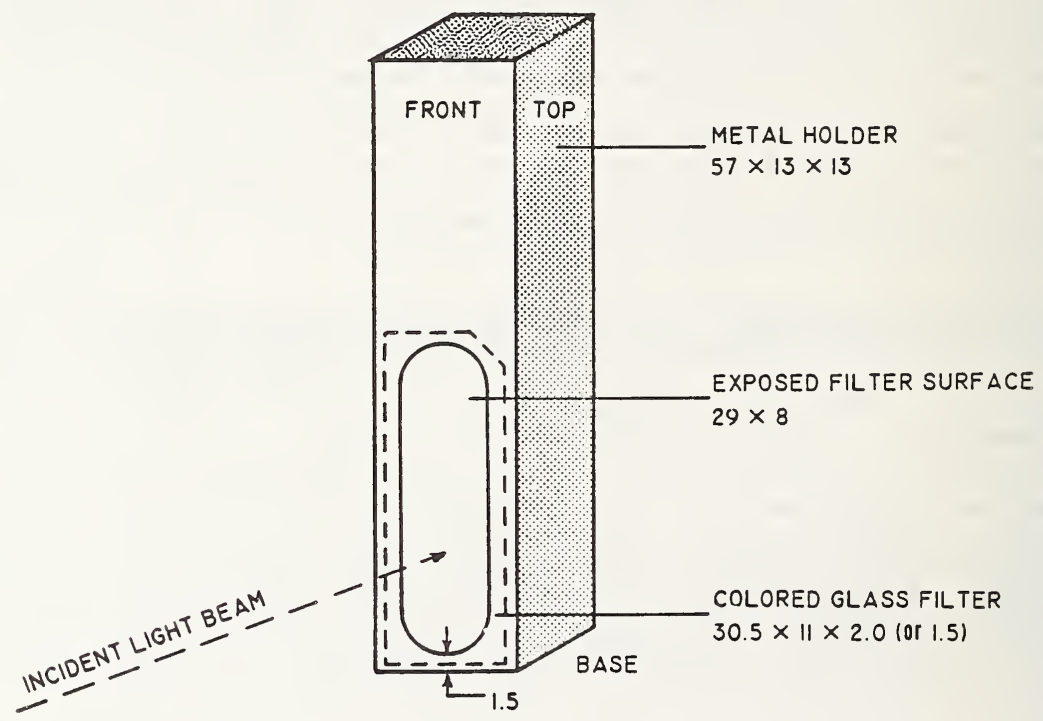

Nominal Dimensions in mm

*Shutters not illustrated. 


\section{Avational 通urreau nf Standards (Tiertificate \\ Standard Reference Material 931C \\ Liquid Absorbance Standards for \\ UItraviolet and Visible Spectrophotometry}

This Standard Reference Material is certified as solutions of known net absorbances at specific spectral wavelengths. It is intended primarily for use in the calibration and checking of accuracy of the photometric scale of narrow bandpass spectrophotometers and for routine critical evaluation of daily working standards used in spectrophotometry. This Standard Reference Material is applicable for calibrating those instruments that provide an effective spectral bandpass of $1.5 \mathrm{~nm}$ or less at $320 \mathrm{~nm}, 2.0 \mathrm{~nm}$ or less at $395 \mathrm{~nm}, 3.3 \mathrm{~nm}$ or less at $512 \mathrm{~nm}$, and $8.5 \mathrm{~nm}$ or less at $678 \mathrm{~nm}$ [1].

\begin{tabular}{|c|c|c|c|c|}
\hline \multirow[b]{2}{*}{ Filter } & \multicolumn{4}{|c|}{$\begin{array}{l}\text { Net Absorbance }{ }^{\mathrm{a}} \\
\text { Wavelength and (Bandpass), nm }\end{array}$} \\
\hline & $302(0.8)$ & $395(0.8)$ & $512(0.8)$ & $678(0.8)$ \\
\hline "I" -"Blank" & $0.305 \pm 0.001$ & $0.309 \pm 0.001$ & $0.307 \pm 0.001$ & $0.116 \pm 0.001$ \\
\hline "II" -"Blank" & $.608 \pm .002$ & $.612 \pm .002$ & $.609 \pm .002$ & $.232 \pm .001$ \\
\hline "III"-"Blank" & $.938 \pm .002$ & $.912 \pm .002$ & $.904 \pm .002$ & $.346 \pm .001$ \\
\hline
\end{tabular}

"Net absorbances ("I" - "Blank", "II" - "Blank", and "III" - "Blank") were determined using I0.00-mm cuvettes (SRM 932) at $25^{\circ} \mathrm{C}$. See Instructions for Use.

The transmittance measurements leading to the certification of this SRM were performed on the high accuracy spectrophotometer located in the NBS Center for Analytical Chemistry. The design and construction of this instrument have been described previously [2]. This instrument is the primary transmittance standard; its accuracy has been verified using the double aperature radiation-addition principle. The bounds of systematic error of this instrument are estimated to be $\pm 10^{-4}$ transmittance units.

These liquid absorbance filters were calibrated at the wavelengths and conditions indicated by measuring the transmittance, T, of the "Blank" and solutions "I", "Il", and "III" against air as a reference. The values of T were used to calculate the corresponding apparent absorbances, $A_{a}$, using the relationship $A_{a}=-\log _{10} T$. The certified net absorbances were obtained by subtracting the apparent absorbances of the "Blank" solution from the apparent absorbances calculated for solutions "I", "II", and "III". The uncertainties of the certified values include all known sources of possible systematic error and the 95 percent confidence level for the mean.

While no long-term stability studies have been made on this lot ( $931 \mathrm{lc}$ ), studies on previous lots (931, $931 \mathrm{la}$, and $931 \mathrm{~b}$ ) over three-year periods showed no degradation of the material when stored in the original sealed ampoules. Therefore, this material is certified only for use within three years following the date of purchase.

The preparation of the filters was performed by E.R. Deardorff, Inorganic Analytical Research Division, and the transmittance measurements were performed by M.V. Smith, Office of Standard Reference Materials. Technical leadership for the preparation and measurements leading to certification was provided by R.W. Burke, Inorganic Analytical Research Division.

The overall direction and coordination of technical measurements leading to certification were performed under the chairmanship of E.L. Garner.

The technical and support aspects involved in the preparation, certification, and issuance of this Standard Reference Material were coordinated through the Office of Standard Reference Materials by R.W. Seward.

Washington, D.C. 20234

George A. Uriano, Chief

February 12, 1982

Office of Standard Reference Materials 
Absorbances at various temperatures $\left(17\right.$ to $\left.35^{\circ} \mathrm{C}\right)$ may be calculated using the equation

$$
A_{1}=A_{25}\left[1+C_{A}(t-25)\right]
$$

where: $\mathrm{A}_{\mathrm{t}}=$ Absorbance at temperature $\mathrm{t}\left({ }^{\circ} \mathrm{C}\right)$

$\mathrm{A}_{25}=$ Absorbance certified at $25.0^{\circ} \mathrm{C}$

$\mathrm{C}_{\mathrm{A}}=$ Fractional change in absorbance per ${ }^{\circ} \mathrm{C}$

The values of $\mathrm{C}_{\mathrm{A}}$, at the four wavelengths, are given below. [NOTE: At wavelength $302 \mathrm{~nm}$, absorbance decreases with increasing temperature; at the other wavelengths, absorbance increases with increasing temperature.]

$\begin{array}{cc}\text { Wavelength, } \mathrm{nm} & \frac{\mathrm{C}_{\mathrm{A}}}{302} \\ 395 & -0.0014 \\ 512 & +0.0014 \\ 678 & +0.0018 \\ & +0.0014\end{array}$

Preparation of Filters

The filters were prepared by dissolving high-purity cobalt and nickel in a mixture of nitric and perchloric acids. The absorbance spectrum of the resulting solution is shown in the following figure. The maxima at 302 and $512 \mathrm{~nm}$ are due to absorbance by $\mathrm{NO}_{3}^{-}$and $\mathrm{Co}\left(\mathrm{H}_{2} \mathrm{O}\right)_{6}{ }_{6}{ }^{+}$respectively. The maximum at $395 \mathrm{~nm}$ and the plateau at $650-700 \mathrm{~nm}$ are due to $\mathrm{Ni}\left(\mathrm{H}_{2} \mathrm{O}\right)_{6} .^{*+}$ The $\mathrm{pH}$ of these solutions is about 1 .

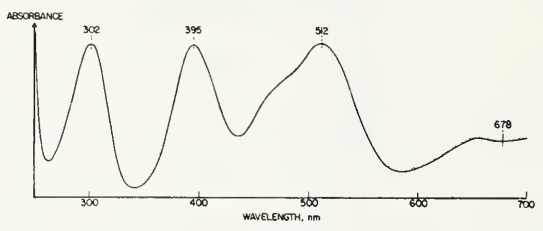

\section{Instructions for Use}

This material is for use as a spectrophotometric absorbance standard.

1. Select two clean $10.00 \mathrm{~mm}$ cuvettes free of scratches. At least one should be fitted with a ground glass or Teflon stopper to minimize evaportation. Reserve it for all sample measurements.

2. Mark each of the cuvettes to assure the same orientation in the spectrophotometer.

3. Place the cuvettes in their respective holders and fill with distilled water. (Borosilicate Pasteur-type pipettes fitted with rubber bulbs are recommended for transferring all solutions to and from the cuvettes. Soft glass pipettes, which are available commercially, contain residual amounts of ultraviolet absorbing material, but may be used after proper cleaning. Several rinses, first with isopropyl alcohol and then with distilled water, are generally adequate.

4. Obtain the optical mismatch of the cuvettes at $302,395,512$, and $678 \mathrm{~nm}$, using the spectral bandpass limitations given on the face of the certificate.

5. Empty the cuvettes by suction without removing them from their holders, refill with distilled water and measure the absorbances again at each of the above wavelengths. 
6. Repeat the emptying and refilling operation until constant absorbance readings are obtained.

7. Using the liquid filters provided, measure, in turn, the absorbance of the "Blank", "I", "II", and "IIl" against distilled water. Shake each ampoule before opening to remix any condensate which may have been collected in the neck. (The ampoules have been prescored directly below the gold band to facilitate opening.)

8. Subtract the appropriate "Blank" reading from the absorbances obtained for "I", "Il", and "III". These net absorbances should agree with the certified values within the uncertainties specified. Consult the manufacturer of the instrument if they do not.

The above instructions are for use with the standard 10-mm rectangular cuvette. For calibration of the several spectrophotometric systems used in various automated instruments, the user is referred to the inst ruction manual for the particular instrument.

The absorbances of these liquid absorbance standards will depend not only on the accuracy of the photometric scale, but also on the wavelength accuracy and the spectral bandpass. A mercury lamp is recommended for checking the wavelength scale. In addition, for those spectrophotometers having a hydrogen $(H)$ or deuterium(D) source, the two emission lines at 486.1 and $656.3 \mathrm{~nm}(\mathrm{H})$ or 486.0 and $656.1 \mathrm{~nm}(\mathrm{D})$ may provide a convenient check at these wavelengths.

To ensure that the measured absorbances are not significantly different from the certified values, the following restrictions are placed on the size of the spect ral bandbass selected: To obtain \pm 0.1 percent of the true value, the effective spectral bandpass should not exceed $1.5,2.0,3.3$, and $8.5 \mathrm{~nm}$ at $302,395,512$, and $678 \mathrm{~nm}$, respectively.

For \pm 0.2 percent, the respective bandpasses should not exceed $2.2,2.9,4.8$, and $12.3 \mathrm{~nm}$. Additional information on the effect of spectral bandpass on the absorbances of these filters is given in the figure below. These curves are not to be used, however, to correct the measured absorbances.

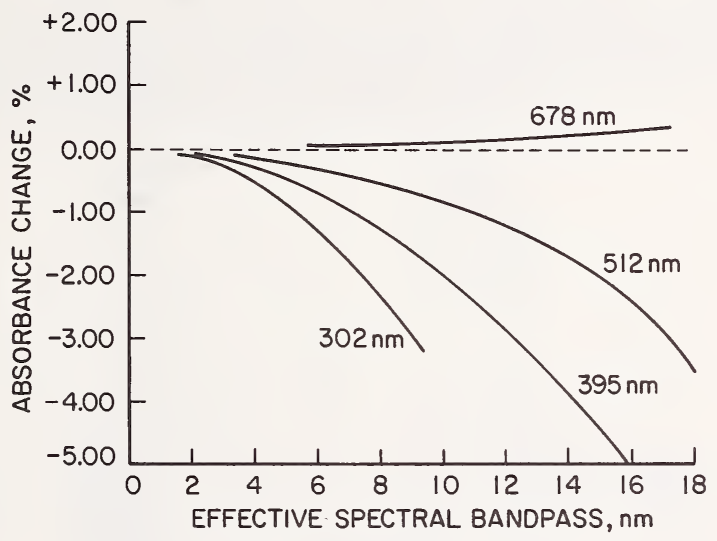

This Standard Reference Material should be kept in the original sealed ampoules. Once opened, the material should be used immediately. No attempt should be made to reseal the ampoule. In addition, it is recommended that this Standard Reference Material not be used after three years from the purchase date.

\section{References}

[1] R. W. Burke, E. R. Deardorff, and O. Menis, J. Research, Nat. Bur. Stand. 76A, 469-482 (1972).

[2] R. Mavrodineanu, J. Research, Nat. Bur. Stand. 76A, 405-425 (1972).

Note: The above papers are also published in NBS Special Publication 378, Accuracy in Spectrophotometry and Luminescence Measurements, R. Mavrodineanu, J. I. Shultz, and O. Menis, Editors, U.S. Government Printing Office, Washington, D.C. 20402, 1973. 


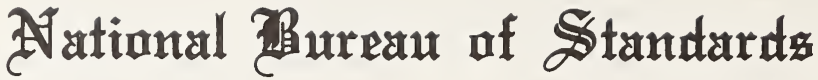 $\mathbb{U}_{\mathfrak{r}}$ rtifirate
}

\section{Standard Reference Material 932}

\section{Quartz Cuvette for Spectrophotometry}

\author{
R. Mavrodineanu and J. W. Lazar
}

This Standard Reference Material consists of a single, accurately calibrated cuvette that is issued for use in the production of accurate spectrophotometric data on liquids. The design and nominal dimensions of the all-quartz cuvette are shown in Figure 1. The pathlength of the cuvette is defined by the distances between the two optically transparent windows measured at several heights within the cuvette. Cuvettes issued as Standard Reference Material 932 have a nominal pathlength of $10 \mathrm{~mm}$. The pathlength and parallelism are certified, at the time of measurements, with an uncertainty of $\pm 0.0005 \mathrm{~mm}$ as determined by measurements (at $20^{\circ} \mathrm{C}$ ) taken at the positions indicated below.

Cuvette number is issued with this certificate. For this cuvette the following measurements were obtained:

Height

$\mathrm{mm}$
Pathlength

$\mathrm{mm}$

Date of Certification:

The overall direction and coordination of the technical measurements leading to certification were performed under the chairmanship of O. Menis and J. A. Simpson.

The technical and support aspects involved in the preparation, certification, and issuance of this Standard Reference Material were coordinated through the Office of Standard Reference Materials by T. W. Mears.

Washington, D.C. 20234

December 2, 1980

(Revision of certificates

dated $11-5-73,6-16-77$, and 8-2-78)
George A. Uriano, Chief Office of Standard Reference Materials 
The original cuvettes were designed and produced at the National Bureau of Standards (NBS) using special techniques and non-fluorescent optical-quality fused quartz as described in NBS SP 260-32[1]. The transparent windows are attached to the body of the cuvette by direct fusion, and the unit was stress-relived by annealing. The radiation pathlength measurements of the cuvette were performed using electronic feeler-gauge type instruments capable of a resolution of 5 parts in $10^{6}$. To preserve the integrity of the certified values, the cuvette must be handled with great care and should be held only by the frosted-quartz side windows. When not in use, it should be stored in the container provided for this purpose. Extended exposure to laboratory atmosphere and dusty surroundings is to be avoided. Improper handling of the cuvette and the use of solutions that can corrode or errode the quartz could degrade the certified pathlength values. In cases where verification of the pathlength is desirable, the cuvette should be returned to NBS for examination and, if needed, recalibration. Prior to shipment the NBS Office of Standard Reference Materials should be contacted regarding the conditions and cost of the verification and/or recertification.

The development and production of SRM 932 is a result of the combined efforts of the Center for Analytical Chemistry. the Center for Mechanical Engineering and Process Technology, and the Instrument Shops Division. The radiation pathlength measurements of all of these cuvettes have been performed, at NBS, by E. G. Erber of the Mechanical Processes Division.

\section{Reference:}

[1] Mavrodineanu, R., and Lazar, J. W., Standard Reference Materials; Standard Quartz Cuvettes for High Accuracy Spectrophotometry, Nat. Bur. Stand. (U.S.), Spec. Publ. 260-32 (December 1973). Superintendent of Documents, U.S. Government Printing Office, Washington, D.C. 20402, 55 cents.

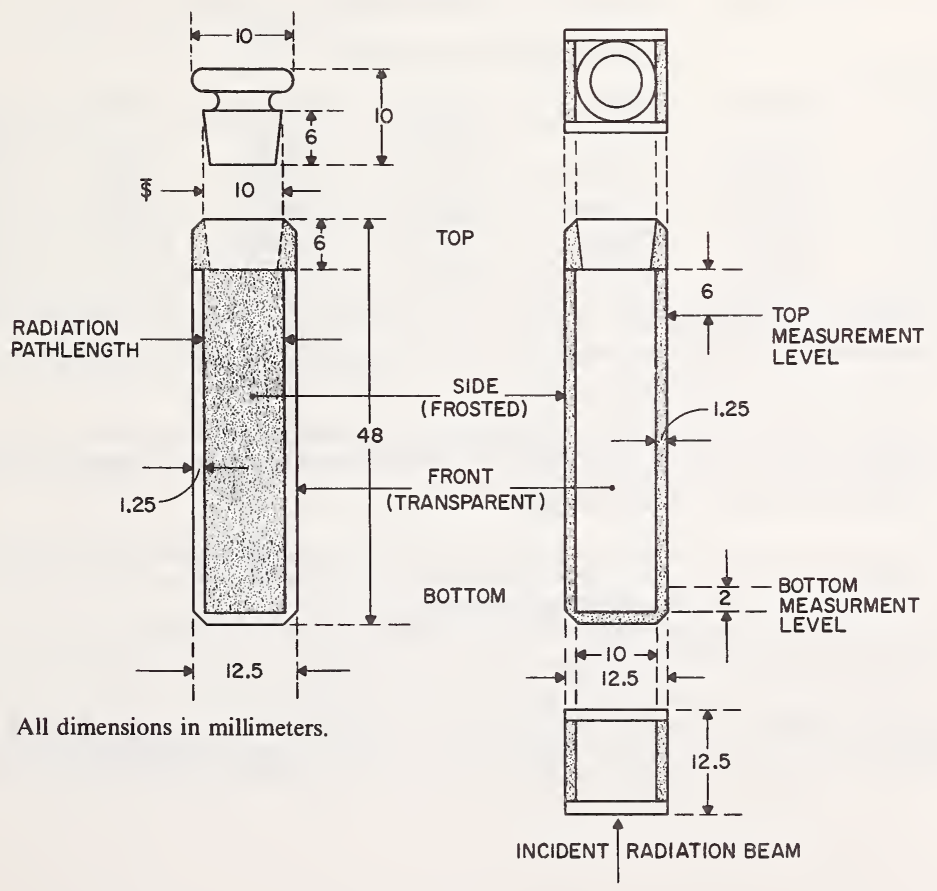




\title{
ANational 设ureau af SStandards Urertificate
}

\section{Standard Reference Material 935 \\ Crystalline Potassium Dichromate \\ for Use as an Ultraviolet Absorbance Standard}

\author{
R. W. Burke and R. Mavrodineanu
}

This Standard Reference Material consists of crystalline potassium dichromate of established purity. Solutions of known concentrations of this SRM in $0.001 \mathrm{~N}$ perchloric acid are certified for their apparent* specific absorbances**, $\epsilon_{\mathrm{a}}$, at $23.5^{\circ} \mathrm{C}$.

This SRM is intended to be used as a reference standard for the verification of the accuracy and linearity of the absorbance scale of absorption spectrometers that can provide an effective spectral bandpass of $1.2 \mathrm{~nm}$ or less at $235 \mathrm{~nm}$, and $0.8 \mathrm{~nm}$ or less at $257,313,345$, and $350 \mathrm{~nm}$. Such verification is accomplished by comparing the measured apparent absorbances, $A_{a}$, to the $A_{a}$ calculated from the certified $\epsilon_{a}$ values as described under "Instructions for Use."

Table 1 gives the certified values of $\epsilon_{\mathrm{a}}$ in $\mathrm{kg} \cdot \mathrm{g}^{-1} \cdot \mathrm{cm}^{-1}$ for five concentrations of the SRM 935 potassium dichromate in $0.001 \mathrm{~N}$ perchloric acid at $23.5^{\circ} \mathrm{C}$ and the indicated wavelengths and spectral bandpasses for a $1-\mathrm{cm}$ internal pathlength.

Table 1. $\epsilon_{\mathrm{a}}$, Apparent Specific Absorbance, ${ }^{\mathrm{a}} \mathrm{kg} \cdot \mathrm{g}^{-1} \cdot \mathrm{cm}^{-1}$

Nominal

Concentration $\mathrm{g} \cdot \mathrm{kg}^{-1}$

0.020

.040

.060

.080

.100
235.0(1.2)

12.260

12.304

12.347

12.390

12.434

Wavelength and (Bandpass) $\mathrm{nm}$

$\begin{array}{ccccc}257.0(0.8) & 313.0(0.8) & 345.0(0.8)^{\mathrm{b}} & 350.0(0.8) & \text { Uncertainty }^{\mathrm{c}} \\ 14.262 & 4.805 & 10.604 & 10.672 & \pm 0.034 \\ 14.318 & 4.811 & 10.603 & 10.682 & \pm .020^{\mathrm{d}} \\ 14.374 & 4.816 & 10.602 & 10.692 & \pm .020^{\mathrm{d}} \\ 14.430 & 4.821 & 10.601 & 10.701 & \pm .020^{\mathrm{d}} \\ 14.486 & 4.827 & 10.600 & 10.711 & \pm .020^{\mathrm{d}}\end{array}$

${ }^{\mathrm{a}} \epsilon_{\mathrm{a}}$ values are given to the third decimal place to preserve the smooth variation of the data with concentration, although the uncertainties are in the second decimal place.

${ }^{b}$ Wavelength $345.0 \mathrm{~nm}$ is near one of the two isosbestic points in $\mathrm{HCrO}_{4}^{-} / \mathrm{Cr}_{2} \mathrm{O} \overline{\overline{7}}$ spectra. Because it is on the slope of the composite spectrum, reproduction of the $\epsilon_{\mathrm{a}}$ values is dependent on wavelength accuracy. Measurements at this wavelength should be made only for verification of the linearity of the absorbance scale.

' $\epsilon_{\mathrm{a}}$ values are not corrected for the effects of internal multiple reflections within the cuvette, nor have the weights been corrected to vacuum. With these two exceptions, the uncertainties given include all known systematic errors and the 95 percent confidence interval of the mean.

${ }^{d}$ At wavelength $313.0 \mathrm{~nm}$, the uncertainty is reduced to \pm 0.010 .

"The term "apparent" is used because no corrections have been applied to the data for the effects of internal multiple reflections within the cuvette or for buoyancy, i.e., the weights used to express concentrations have not been corrected to vacuum. These combined corrections do not exceed 0.2 percent. The specific absorbances are given in reference 1 .

**The nomenclature used in this certificate is that recommended by K. D. Mielenz, Anal. Chem. 48, 1093-1094 (1976), which is reproduced in the Appendix of NBS Special Publication 260-54.

Washington, D.C. 20234

June 1, 1977
J. Paul Cali, Chief

Office of Standard Reference Materials 
The overall direction and coordination of the technical measurements leading to this certificate were performed under the joint chairmanship of I. L. Barnes and J. R. DeVoe.

The technical and support aspects involved in the preparation, certification, and issuance of this Standard Reference Material were coordinated through the Office of Standard Reference Materials by R. W. Seward.

We wish to acknowledge: The contributions of K. D. Mielenz, NBS Analytical Chemistry Division, for his many valuable discussions and suggestions, and $\mathbf{H}$. H. Ku, NBS Applied Mathematics Division, for his statistical treatment of the data; the cooperation and early support of the National Institute of General Medical Sciences in the research leading to this SRM; and the encouragement of George N. Bowers, Jr., M.D., Hartford Hospital, Hartford, Conn., and Royden N. Rand, Ph.D., Eastman Kodak Co., Research Laboratories, Rochester, N.Y.

\section{PREPARATION AND CERTIFICATION}

The details of the preparation and certification of SRM 935 are provided in NBS Special Publication 260-54, Certification and Use of Acidic Potassium Dichromate Solutions as an Ultraviolet Absorbance Standard [2]. This publication should be referred to every time SRM 935 is to be used. Briefly, the transmittances, T, of the solutions prepared from the undried, as received, material were measured with the NBS Institute for Materials Research high-accuracy transmission spectrometer [3].

The $\epsilon_{\mathrm{a}}$ values were calculated for each wavelength using the relation:

$$
\epsilon_{\mathrm{a}}=\frac{D_{\mathrm{s}}-\mathrm{D}_{\mathrm{b}}}{\mathrm{b} \times \mathrm{c}}=\frac{A_{\mathrm{a}}}{\mathrm{b \times c}}
$$

where:

$$
\begin{aligned}
& \epsilon_{\mathrm{a}}=\text { apparent specific absorbance } \\
& \mathrm{A}_{\mathrm{a}}=\text { apparent absorbance } \\
& D_{\mathrm{s}}=\text { transmittance density of the sample solution, }-\log _{10} \mathrm{~T}_{\mathrm{s}} \\
& \mathrm{D}_{\mathrm{b}}=\text { transmittance density of the blank solution, }-\log _{10} \mathrm{~T}_{\mathrm{b}} \\
& \mathrm{b}=\text { internal cuvette pathlength, } \mathrm{cm} \\
& \mathrm{c}=\text { concentration, by weight, of } \mathrm{K}_{2} \mathrm{Cr}_{2} \mathrm{O}_{7} \text { solution, } \mathrm{g} \cdot \mathrm{kg}
\end{aligned}
$$

The crystalline potassium dichromate used for SRM 935 is a special lot of analytical reagent grade material obtained from the J. T. Baker Chemical Co., Phillipsburg, N.J.

Assay: A coulometric assay of the purity of the undried material was performed by G. Marinenko of the NBS Analytical Chemistry Division. The purity of SRM 935, expressed as an oxidant, was found to be $99.972 \pm 0.005$ percent where the uncertainty figure represents the 95 percent confidence interval for the mean based on 11 degrees of freedor.. In addition, the material was examind by optical emission spectrometry for trace elemental impurities by J. A. Norris of the NBS Analytical Chemistry Division. The only significant impurities detected were sodium and rubidium. Their concentrations were estimated to be in the range of 0.02 and 0.03 percent, respectively. Drying at $105^{\circ} \mathrm{C}$ for 12 hours showed that the surface moisture of this material was less than 0.01 percent.

Stability: Solutions prepared from SRM 935 in the concentration range indicated in table 1 and made according to the instructions given in NBS SP 260-54 have been found to be stable within the uncertainties given in table 1 for at least six months when stored at room temperature and protected from evaporation and exposure to light.

\section{INSTRUCTIONS FOR USE}

The use of SRM 935 as an absorbance standard requires the careful preparation of a series of solutions of known concentrations, $c$, of the potassium dichromate in $0.001 \mathrm{~N}$ perchloric acid. These solutions are transferred to a quartz cuvette of known pathlength, $b$, and their apparent absorbances measured at wavelengths $235,257,313$, and $350 \mathrm{~nm}$, using the spectral bandpass requirements given in table 1 . The preparation and measurement of these solutions are described in detail in Section 5 of NBS SP 260-54. 
The accuracy of the absorbance scale of the spectrometer being tested is ascertained by comparing the measured apparent absorbances, $A_{a}$, of a series of $0.001 \mathrm{~N}$ perchloric acid solutions containing 0.020 to 0.100 gram $\mathrm{K}_{2} \mathrm{Cr}_{2} \mathrm{O}_{7} / \mathrm{kg}$ to the $\mathrm{A}_{\mathrm{a}}$ values calculated from the certified $\epsilon_{\mathrm{a}}$ values. Although the $\epsilon_{\mathrm{a}}$ data in table lare given for nominal concentrations of $0.020,0.040,0.060,0.080$, and $0.100 \mathrm{~g} \mathrm{~K}_{2} \mathrm{Cr}_{2} \mathrm{O}_{7} / \mathrm{kg}$, the $\epsilon_{\mathrm{a}}$ values for concentrations between these nominal concentrations can be determined by linear interpolation. Using the appropriate $\epsilon_{\mathrm{a}}$ values, the calculated $\mathrm{A}_{\mathrm{a}}$ values at $23.5^{\circ} \mathrm{C}$ are obtained from the expression:

$$
A_{a}=\epsilon_{a} \times b \times c
$$

\section{Calculations:}

An example of the calculation of $A_{a}$ for one concentration of $\mathrm{K}_{2} \mathrm{Cr}_{2} \mathrm{O}_{7}$ under a specified set of conditions is shown below. Calculations of $A_{a}$ for other concentrations and wavelengths are performed in a similar manner.

Conditions: Wavelength $=350 \mathrm{~nm}$, spectral bandpass $0.8 \mathrm{~nm}$ or less

$$
\begin{aligned}
& \mathrm{b}=0.9982 \mathrm{~cm} \\
& \mathrm{c}=0.04375 \mathrm{~g} \cdot \mathrm{kg}^{-1} \\
& \mathrm{t}=23.5^{\circ} \mathrm{C}
\end{aligned}
$$

From column 6 , table 1 , the $\epsilon_{\mathrm{a}}$ for concentrations of 0.040 and $0.060 \mathrm{~g} \cdot \mathrm{kg}^{-1}$ are 10.682 and 10.692 , respectively. The corresponding $\epsilon_{\mathrm{a}}$ for $\mathrm{c}=0.04375 \mathrm{~g} \cdot \mathrm{kg}^{-1}$ is:

$$
\begin{aligned}
& \epsilon_{\mathrm{a}}=10.682+\frac{0.04375-0.040}{0.060-0.040}(10.692-10.682) \\
& \epsilon_{\mathrm{a}}=10.682+0.0019 \\
& \epsilon_{\mathrm{a}}=10.684
\end{aligned}
$$

The calculated apparent absorbance, $A_{a}$, from equation 2, is:

$$
\begin{aligned}
& A_{a}=10.684 \times 0.9982 \times 0.04375 \\
& A_{a}=0.4666
\end{aligned}
$$

The uncertainty, $\Delta \mathrm{A}_{\mathrm{a}}$, in the calculated $\mathrm{A}_{\mathrm{a}}$ is determined from the combined uncertainties in $\epsilon_{\mathrm{a}}, \mathrm{b}$, and $\mathrm{c}$ in equation 2, provided no other systematic errors are present. Thus:

$$
\Delta \mathrm{A}_{\mathrm{a}}=\mathrm{bc}\left|\Delta \epsilon_{\mathrm{a}}\right|+\epsilon_{\mathrm{a}} \mathrm{c}|\Delta \mathrm{b}|+\epsilon_{\mathrm{a}} \mathrm{b}|\Delta \mathrm{c}|
$$

To evaluate $\Delta \mathrm{A}_{\mathrm{a}}, \Delta \boldsymbol{\epsilon}_{\mathrm{a}}$ is taken from column 7 of table $\mathrm{l}$ and the $\Delta \mathrm{b}$ and $\Delta \mathrm{c}$ values must be determined experimentally.

In the experiments performed to obtain the $\epsilon_{\mathrm{a}}$ values in table 1 , the uncertainties for $\mathrm{b}$ and $\mathrm{c}$ did not exceed 1 part in $10^{4}$ and 2 parts in $10^{4}$, respectively.

The solution of equation 3 gives:

$$
\begin{aligned}
\Delta \mathrm{A}_{\mathrm{a}} & =\mathrm{l}(0.044)(0.020)+10.7(0.044)(0.0001)+10.7(1)(0.0000088) \\
& =0.0010
\end{aligned}
$$

Thus, the uncertainty of $A_{a}$, for the above set of conditions, is \pm 0.0010 .

The correction of the absorbance scale of the absorption spectrometer under test is determined by plotting the differences between $A_{a}$ measured and $A_{a}$ calculated as a function of absorbance. A typical plot of such a graph is shown in figure 1. The apparent absorbances measured on this instrument at $350 \mathrm{~nm}$ are accurate when the indicated correction is subtracted from the corresponding absorbance scale reading, provided that the conditions of wavelength accuracy, spectral bandpass, and absence of stray light are fulfilled as specified in NBS SP 260-54. Correction curves for wavelengths 235, 257, and $313 \mathrm{~nm}$ are obtained in a similar manner. 


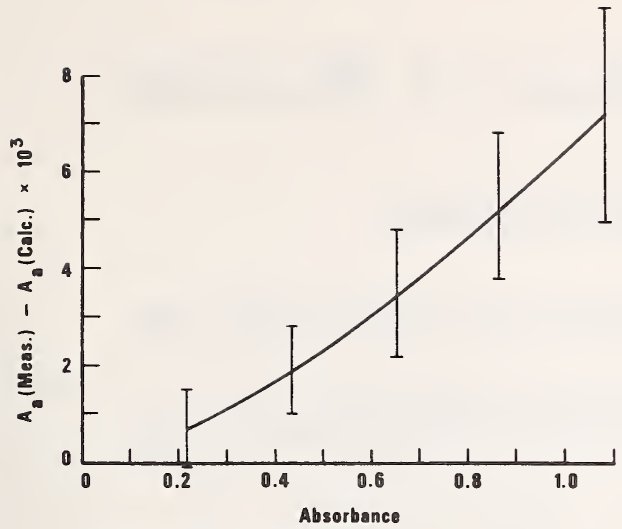

Figure 1. Correction curve for the absorbance scale of a precision spectrometer. The error bars are the sum of the errors arising from the uncertainties in the certified apparent specific absorbances, $\epsilon_{\mathrm{a}}$, cuvette pathlength, $\mathrm{b}$, and concentration, $\mathrm{c}$.

Temperature Correction:

Although $\epsilon_{\mathrm{a}}$ values in table 1 are certified at $23.5^{\circ} \mathrm{C}, \mathrm{SRM} 935$ can be used as an absorbance standard at other temperatures in the range 20 to $30^{\circ} \mathrm{C}$ provided corrections are made to the $\epsilon_{\mathrm{a}}$ values. Over this range the apparent specific absorbances decrease linearly with increasing temperature for all the wavelengths given in table 1 . The corresponding temperature coefficients, $\mathrm{k}$, for these wavelengths are given in table 2 .

Table 2. Variation of $\epsilon_{\mathrm{a}}$ with Temperature Over the Range 20 to $30^{\circ} \mathrm{C}$.

$\begin{array}{lr}\lambda, \mathrm{nm} & \begin{array}{c}\text { Temperature Coe } \\ \text { Percent per degr }\end{array} \\ 235 & -0.05 \\ 257 & -0.05 \\ 313 & -0.02 \\ 345 & -0.08 \\ 350 & -0.05\end{array}$

The value of $\epsilon_{\mathrm{a}}$ at any temperature in the range 20 to $30^{\circ} \mathrm{C}$ can be calculated from the certified value and the appropriate temperature coefficient using the relation:

$\epsilon_{\mathrm{a}}^{\mathrm{t}}=\epsilon_{\mathrm{a}}^{23.5}\left[1+\frac{\mathrm{k}}{100}(\mathrm{t}-23.5)\right]$

where: $\epsilon_{\mathrm{a}}^{\mathrm{t}}=$ apparent specific absorbance at temperature $\mathrm{t}\left({ }^{\circ} \mathrm{C}\right)$

$\epsilon_{\mathrm{a}}^{23.5}=$ apparent specific absorbance certified at $23.5^{\circ} \mathrm{C}$.

$\mathrm{k}=$ temperature coefficient, percent per ${ }^{\circ} \mathrm{C}$.

\section{REFERENCES}

1. Burke, R. W., and Mavrodineanu, R., Acidic Potassium Dichromate Solutions as Ultraviolet Absorbance Standards, J. Res. Nat. Bur. Stand. (U.S.), 80A (Phys. and Chem.), No. 4, $631-636$ (July-Aug. 1976).

2. Burke, R. W., and Mavrodineanu, R., Certification and Use of Acidic Potassium Dichromate Solutions as an Ultraviolet Absorbance Standard, NBS Spec. Publ. 260-54 (1977). Copies may be obtained from the Office of Standard Reference Materials, National Bureau of Standards, Washington, D.C. 20234.

3. Mavrodineanu, R., An Accurate Spectrophotometer for Measuring the Transmittance of Solid and Liquid Materials, J. Res. Nat. Bur. Stand. (U.S.), 76A (Phys. and Chem.), No. 5, 405-425 (1972). 


\title{
A vational 通ureau of Standardz
}

\section{(Uiertificate}

\section{Standard Reference Material 936}

\section{Quinine Sulfate Dihydrate}

\author{
R. A. Velapoldi and K. D. Mielenz
}

This Standard Reference Material is intended for use in the evaluation of methods and the calibration of fluorescence spectrometers. It is certified for the relative molecular emission spectrum, $E(\lambda)$, in radiometric units for a solution of $1.28 \times 10^{-6} \mathrm{~mol} / \mathrm{L}$ quinine sulfate dihydrate in $0.105 \mathrm{~mol} / \mathrm{L}$ perchloric acid using an excitation wavelength of $347.5 \mathrm{~nm}$. The certified values of the molecular emission spectrum at $5 \mathrm{~nm}$ wavelength intervals from 375 to $675 \mathrm{~nm}$ are given in table 1 . These values have been corrected for instrument and sample parameters, including the spectral responsivity of the detection system, monochromator bandwidth, photomultiplier tube nonlinearity, monochromator wavelength error, solvent refractive index, and cell window transmittance. The relative standard error in $E(\lambda), \operatorname{RSE}[E(\lambda)]$, is given in table 1. The estimate of the relative systematic error limits in the molecular emission spectrum, $\operatorname{RSEL}[\operatorname{E}(\lambda)]$, is also given in table 1 and was determined by the addition of the absolute values of the estimated systematic errors. These relative error limits include uncertainties in the calibration values for the spectral responsivity, the wavelength position of the emission peak maximum, and in the corrections applied for instrument and sample parameters.

From the certified values of $\mathrm{E}(\lambda)$, values may be calculated for the molecular emission spectrum in the various photon, radiometric, wavelength, and wavenumber units using the following equation: $[1,2]$

$$
E(\lambda)=\frac{E_{p}(\lambda)}{\lambda}=\frac{E(\widetilde{v})}{\lambda^{2}}=\frac{E_{p}(\widetilde{v})}{\lambda^{3}}
$$

These values have been calculated and are given in NBS Special Publication 260-64.

The technical emission spectrum, $E^{T}(\lambda)$, i.e., the emission spectrum corrected for inst rument parameters only, is also given in SP 260-64. The quinine sulfate dihydrate used for SRM 936 was a special lot of material obtained from the J. T. Baker Chemical Co., Phillipsburg, N.J.

The technical and support aspects concerning the preparation, certification, and issuance of this Standard Reference Material were coordinated through the Office of Standard Reference Materials by T. W. Mears and R. W. Seward.

Washington, D.C. 20234

April 1, 1979

George A. Uriano, Chief Office of Standard Reference Materials 
Table 1. The Molecular Emission Spectrum, $\mathrm{E}(\lambda)$, of Quinine Sulfate Dihydrate in $0.105 \mathrm{~mol} / \mathrm{L} \mathrm{HC1O}_{4}$, the Relative Standard Error, RSE, and the Estimated Relative Systematic Error Limits, RSEL, in the $E(\lambda)$ Values.

$\begin{array}{lccccccc}\lambda, \mathrm{nm} & \mathrm{E}(\lambda) & \mathrm{RSE}[\mathrm{E}(\lambda)] & \mathrm{RSEL}[\mathrm{E}(\lambda)] & \lambda, \mathrm{nm} & \mathrm{E}(\lambda) & \mathrm{RSE}[\mathrm{E}(\lambda)] & \mathrm{RSEL}[\mathrm{E}(\lambda)] \\ 375.0 & 0.005 & 0.019 & 0.087 & 525.0 & 0.302 & 0.001 & 0.029 \\ 380.0 & .012 & .006 & .078 & 530.0 & .264 & .003 & .029 \\ 385.0 & .028 & .003 & .071 & 535.0 & .231 & .003 & .029 \\ 390.0 & .057 & .003 & .064 & 540.0 & .201 & .002 & .029 \\ 395.0 & .103 & .002 & .059 & 545.0 & .175 & .002 & .029 \\ 400.0 & .170 & .002 & .054 & 550.0 & .153 & .001 & .029 \\ 405.0 & .257 & .003 & .049 & 555.0 & .132 & .001 & .029 \\ 410.0 & .359 & .003 & .045 & 560.0 & .116 & .001 & .029 \\ 415.0 & .471 & .003 & .041 & 565.0 & .101 & .002 & .029 \\ 420.0 & .586 & .003 & .037 & 570.0 & .088 & .002 & .029 \\ 425.0 & .694 & .003 & .034 & 575.0 & .076 & .003 & .029 \\ 430.0 & .792 & .002 & .031 & 580.0 & .065 & .003 & .029 \\ 435.0 & .874 & .002 & .028 & 585.0 & .057 & .001 & .029 \\ 440.0 & .940 & .001 & .026 & 590.0 & .050 & .003 & .030 \\ 445.0 & .984 & .001 & .024 & 595.0 & .043 & .004 & .030 \\ 450.0 & .999 & .001 & .023 & 600.0 & .037 & .006 & .030 \\ 455.0 & .997 & .001 & .023 & 605.0 & .032 & .002 & .030 \\ 460.0 & .982 & .001 & .024 & 610.0 & .028 & .006 & .030 \\ 465.0 & .947 & .001 & .024 & 615.0 & .024 & .003 & .030 \\ 470.0 & .897 & .001 & .025 & 620.0 & .021 & .011 & .030 \\ 475.0 & .838 & .002 & .026 & 625.0 & .018 & .003 & .030 \\ 480.0 & .782 & .002 & .027 & 630.0 & .016 & .015 & .030 \\ 485.0 & .719 & .002 & .027 & 635.0 & .014 & .014 & .030 \\ 490.0 & .657 & .002 & .027 & 640.0 & .011 & .037 & .030 \\ 495.0 & .595 & .003 & .027 & 645.0 & .010 & .015 & .030 \\ 500.0 & .541 & .002 & .027 & 650.0 & .009 & .027 & .030 \\ 505.0 & .486 & .001 & .028 & 655.0 & .008 & .035 & .031 \\ 510.0 & .434 & .003 & .028 & 660.0 & .007 & .073 & .031 \\ 515.0 & .386 & .003 & .028 & 665.0 & .006 & .046 & .032 \\ 520.0 & .342 & .002 & .028 & 670.0 & .005 & .053 & .032 \\ & & & & 675.0 & .004 & .065 & .033\end{array}$

SRM 936

Page 2 


\section{SUPPLEMENTARY DATA}

The following data for the specific molar absorbances, water content, photon yields, and fluorescence lifetimes are considered to be supplementary and are not to be considered certified values.

The quinine sulfate dihydrate (QSD) used for SRM 936 was found to be homogeneous to better than $0.5 \%$ by thin-layer chromatography with development by two solvent systems and the determination of specific molar absorbances, $\epsilon$, at three different wavelengths. The SRM contains approximately $1.7 \%$ of an impurity as determined by high performance liquid chromatography using absorbance and fluorescence detection. This impurity is believed to be dihydroquinine sulfate dihydrate, which has optical characteristics that are similar to those of the quinine sulfate dihydrate. The ultraviolet absorption spectrum of SRM 936 in $0.105 \mathrm{~mol} / \mathrm{L} \mathrm{HClO}_{4}$ exhibits the following absorption maxima:

$$
\begin{aligned}
& 250.0 \mathrm{~nm}, \epsilon_{\max }=56,990 \pm 90 \mathrm{~L} \cdot \mathrm{mol}^{-1} \cdot \mathrm{cm}^{-1} \\
& 347.5 \mathrm{~nm}, \epsilon_{\max }=10,810 \pm 20 \mathrm{~L} \cdot \mathrm{mol}^{-1} \cdot \mathrm{cm}^{-1}
\end{aligned}
$$

and, on the side of a peak:

$$
365.0 \mathrm{~nm}, \epsilon_{\mathrm{obs}}=6,920 \pm 10 \mathrm{~L} \cdot \mathrm{mol}^{-1} \cdot \mathrm{cm}^{-1}
$$

The water content of this material was measured by two methods. The average of six determinations by the Karl-Fischer method gave a value of $(4.74 \pm 0.05 \%)$, while the average of four determinations by a weight loss procedure gave a value of $(4.57 \pm 0.04 \%)$. The theoretical value for water in quinine sulfate dihydrate is $4.60 \%$.

The photon yield, $\mathrm{Q}$, and the fluorescence lifetime, $\tau$, of SRM 936 were compared to values obtained for a sample of purified quinine sulfate dihydrate and are summarized below:

\footnotetext{
Q

$$
\begin{aligned}
& 0.544 \pm 0.03 \\
& 0.546^{\mathrm{a}}
\end{aligned}
$$$$
0.5 \mathrm{~mol} / \mathrm{L} \mathrm{H}_{2} \mathrm{SO}_{4} \quad 0.5 \mathrm{~mol} / \mathrm{L} \mathrm{H}_{2} \mathrm{SO}_{4}
$$$$
r, \mathrm{~ns}
$$$$
\text { SRM 936, QSD }
$$$$
19.1 \pm 0.1
$$$$
\text { Purified QSD }
$$$$
19.2 \pm 0.1
$$

${ }^{a}$ Melhuish, W. H., J. Phys. Chem. 65, 229 (1961); ibid, New Zealand J. Sci. Tech. 37, 142 (1955).
}

SRM 936

Page 3 


\section{PREPARATION AND USE OF SRM 936}

This Standard Reference Material is for "in vitro" diagnostic use as a clinical laboratory standard. A "stock" standard solution containing $0.1 \mathrm{mg} / \mathrm{mL}$ of quinine sulfate may be prepared as follows: Weigh $0.100 \mathrm{~g}$ of SRM 936 to the nearest one-tenth milligram and quantitatively transfer it to a $1000-\mathrm{mL}$ volumetric flask. Dilute to the calibrated volume with $0.105 \mathrm{~mol} / \mathrm{L} \mathrm{HClO}_{4}$, to give a solution that is $1.28 \times 10^{-4} \mathrm{~mol} / \mathrm{L}(0.1 \mathrm{mg} / \mathrm{mL})$ in quinine sulfate. Store this solution in the dark in a well-stoppered, glass bottle. A "working" standard solution containing $1 \mu \mathrm{g} / \mathrm{mL}$ may be prepared by transferring $10 \mathrm{~mL}$ of the above "stock" standard solution to a $1000-\mathrm{mL}$ volumetric flask and diluting to the calibrated volume with $0.105 \mathrm{~mol} / \mathrm{L} \mathrm{HClO}_{4}$ to give a solution that is $1.28 \times 10^{-6} \mathrm{~mol} / \mathrm{L}(1 \mu \mathrm{g} / \mathrm{mL})$ in quinine sulfate. Store this solution in the same manner as the above "stock" standard solution.

Several opinions regarding the stability of quinine sulfate solutions have appeared in the literature [3]. NBS considers the $0.1 \mathrm{mg} / \mathrm{mL}$ "stock" standard solution prepared from SRM 936 to be stable for 3 months when stored as specified; and the $1 \mu \mathrm{g} / \mathrm{mL}$ "working" standard solution to be stable for 1 month when so stored.

SRM 936 should be kept in its original bottle and stored in the dark at room temperature $\left(30^{\circ} \mathrm{C}\right.$ or less). It should not be subjected to heat or direct sunlight during storage. Experience at NBS indicates that under proper storage this material is stable for at least 3 years. If this material degrades beyond the limits certified, purchasers will be notified by NBS. It is recommended that the material not be used after 3 years from the date of purchase.

\section{References:}

[1] Ejder, E. J., J. Opt. Soc. Amer. 59, 223 (1969).

[2] Melhuish, W. H., J. Res. Nat. Bur. Stand. (U.S.) 76A, No. 6, 547 (1972).

[3] Melhuish, W. H., J. Phys. Chem. 65, 229 (1961); Gill, J. E., Photochem. and Photobiol. 9, 313 (1969); Birks, J. B., J. Res. Nat. Bur. Stand. (U.S.) 80A, 389 (1976); Heller, C. A., Henry, R. A., McLaughlin, B. A., and Bless, D. E., J. Chem. Eng. Data 19, 214 (1974); West, M. A., and Kemp, D. R., Int'l. Lab., p. 27 (May/June 1976); and White, J. U., Pittsburgh Conf. Abstracts, Paper 488 (1977).

This Standard Reference Material has been measured and certified at the laboratories of the National Bureau of Standards, Gaithersburg, Maryland. All inquiries should be addressed to:

Office of Standard Reference Materials

Room B311, Chemistry Building

National Bureau of Standards

Washington, D.C. 20234

The date of issuance and certification of SRM 936 was April 1, 1979

SRM 936

Page 4 


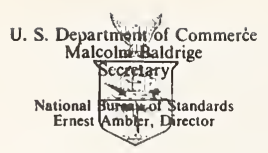

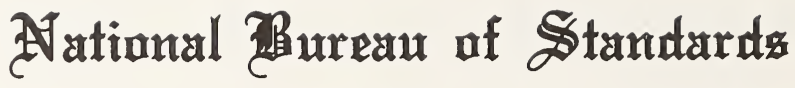

\section{Uertifieate}

\section{Standard Reference Material 2010a}

\author{
Didymium Glass Filter for Checking the \\ Wavelength Scale of Spectrophotometers
}

\author{
SERIAL NO. \\ Kenneth L. Eckerle
}

This Standard Reference Material (SRM) is a $51 \times 51 \times 3 \mathrm{~mm}$ didymium glass filter. SRM 2010a is intended for use in calibrating the wavelength scale in the visible wavelength region of scanning spectrophotometers having nominal bandwidths in the range 1.5 to $10.5 \mathrm{~nm}$. Depending upon the band width of the spectrophotometer, 12 to 22 wavelength corrections can be determined from 389 to $760 \mathrm{~nm}$. Detailed instructions on the use of this SRM and examples of its use are given in the accompanying NBS Special Publication 260-66. Each didymium glass filter is identified by serial number.

All measurements on these filters were made at $25{ }^{\circ} \mathrm{C}$ with a high-accuracy reference spectrophotometer that has a wavelength accuracy of $0.04 \mathrm{~nm}$.

Table 1 gives the wavelengths of the transmittance minima as obtained from measurements on two filters representative of this melt of didymium glass. These values are given for seven equally spaced values of the half-height width of triangular passbands. The minima numbers are shown on Figure 1, which illustrates the spectral transmittance as a function of wavelength.

Table 2 gives the wavelength values of nine points of inflection on the spectral transmittance curve as obtained on two filters. These inflection points are representative of this glass melt and are also shown on Figure 1. These inflection points should only be used with the transmittance minima as described in Sections 2.2 and 2.3 in SP 260-66. Table 2 also indicates the range of the measured wavelengths of the inflection points.

Table 3 gives the estimated random and systematic errors of the transmittance minima given in Table 1 (as obtained from 4 sets of measurements on a single filter).

Table 4 gives the spectral transmittance as a function of wavelength for a filter representative of this melt. These values are not certified but are provided for use as specified in SP 260-66. They should not be used to check the photometric scale of a spectrophotometer.

Trial calibrations made on several instruments, using both minima and inflection points, indicate that wavelength corrections made with these SRM's can be accurate to $0.2 \mathrm{~nm}$. The uncertainty of a calibration, however, will depend upon the stability and other characteristics of a particular instrument.

This filter should be handled only by its edges; when not in use it should be stored in the box provided. If cleaning is necessary, wet the filter with water and rub gently with optical lens tissue soaked with a mild soap solution, rinse with distilled water, rinse with isopropyl alcohol, and rinse again with distilled water. Dry after each rinsing by wiping lightly with optical lens tissue. 
Figure 1. Spectral transmittance as a function of wavelength. The numbers indentify minima, and the letters identify selected inflection points.

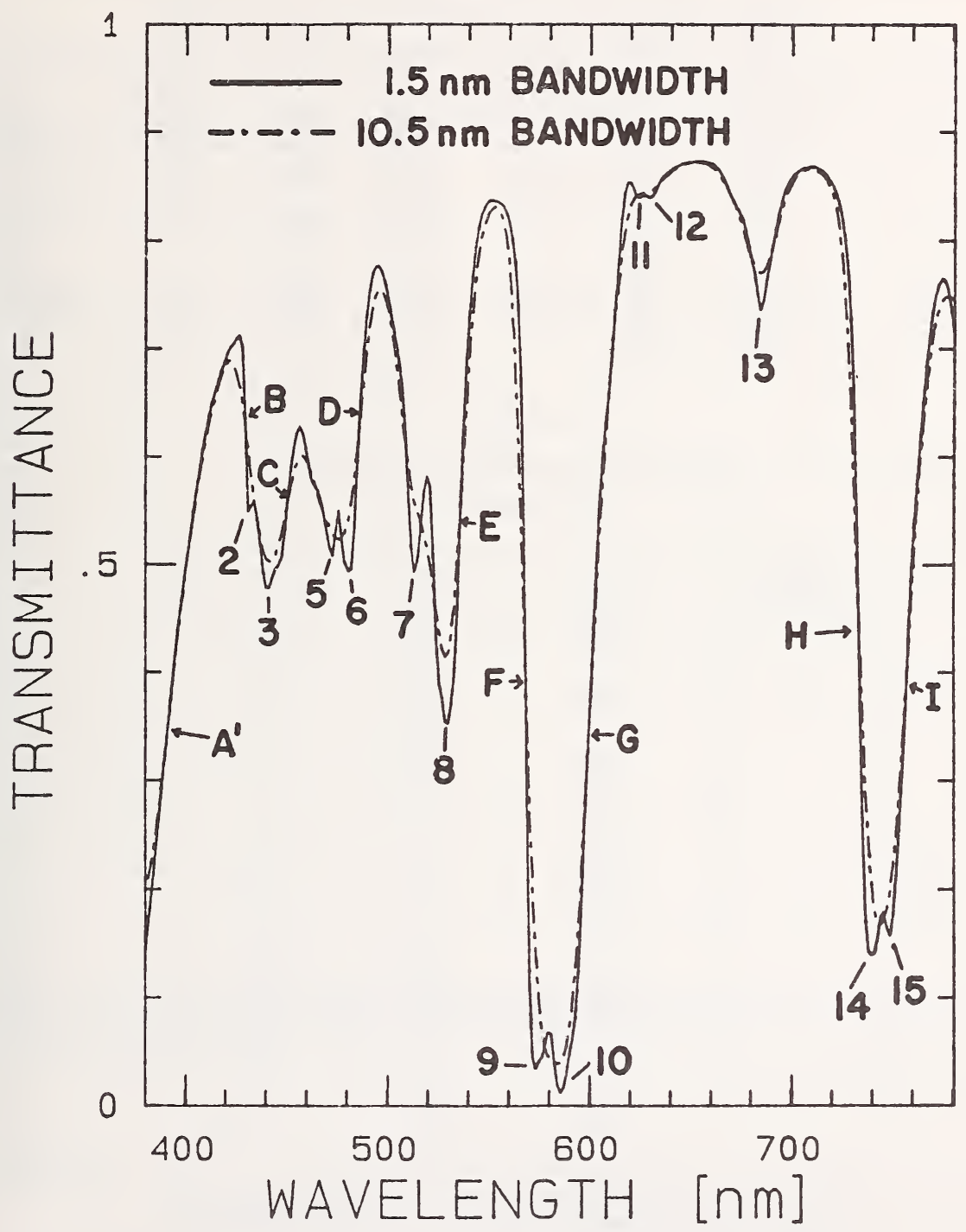

Page 2

SRM 2010a 
TABLE 1

Certified Wavelengths ( $\mathrm{nm}$ ) of the Transmittance

Minima for the Indicated Bandwidths

\begin{tabular}{|cccccccc|}
\hline $\begin{array}{c}\text { Bandwidth } \\
\text { Minimum No. }\end{array}$ & $1.5 \mathrm{~nm}$ & $3.0 \mathrm{~nm}$ & $4.5 \mathrm{~nm}$ & $6.0 \mathrm{~nm}$ & $7.5 \mathrm{~nm}$ & $9.0 \mathrm{~nm}$ & $10.5 \mathrm{~nm}$ \\
\hline 1 & -- & -- & -- & -- & -- & -- & -- \\
2 & 431.58 & -- & -- & -- & - & - & -- \\
3 & 440.78 & 440.98 & 441.41 & 441.94 & 442.19 & 442.17 & 441.87 \\
4 & -- & -- & -- & -- & -- & -- & -- \\
5 & 472.67 & 472.43 & 472.31 & -- & -- & -- & -- \\
6 & 481.20 & 480.68 & 480.37 & 479.67 & 478.36 & 477.26 & 476.18 \\
7 & 513.66 & 513.76 & 513.94 & 514.25 & 514.87 & - & -- \\
8 & 529.37 & 529.47 & 529.26 & 529.11 & 529.08 & 528.98 & 528.74 \\
9 & 573.12 & 573.88 & 574.75 & 575.72 & -- & -- & -- \\
10 & 585.50 & 585.68 & 585.86 & 586.03 & 585.91 & 585.29 & 584.39 \\
11 & 623.85 & 624.42 & -- & -- & -- & - & -- \\
12 & 629.51 & 629.26 & 628.17 & 627.17 & 627.17 & - & - \\
13 & 684.71 & 684.74 & 684.78 & 684.80 & 684.77 & 684.73 & 684.65 \\
14 & 739.61 & 740.20 & 740.58 & 741.33 & 742.55 & 743.50 & 744.16 \\
15 & 748.64 & 748.48 & -- & -- & -- & -- & -- \\
\hline
\end{tabular}

TABLE 2

Wavelengths and Transmittances at Nine Selected

Points of Inflection

\begin{tabular}{|c|c|c|c|}
\hline $\begin{array}{c}\text { Point } \\
\text { Identification }\end{array}$ & $\begin{array}{l}\text { Wavelength } \\
\text { (nm) }\end{array}$ & $\begin{array}{l}\text { Range* } \\
(\mathrm{nm})\end{array}$ & Transmittance $e^{+}$ \\
\hline A & 388.68 & $\begin{array}{l}+.02 \\
-.02\end{array}$ & 0.3027 \\
\hline B & 429.67 & $\begin{array}{l}+.06 \\
-.10\end{array}$ & .6268 \\
\hline $\mathrm{C}$ & 450.21 & $\begin{array}{l}+.03 \\
-.03\end{array}$ & .5569 \\
\hline D & 485.75 & $\begin{array}{l}+.08 \\
-.12\end{array}$ & .6210 \\
\hline E & 536.39 & $\begin{array}{l}+.04 \\
-.06\end{array}$ & .5597 \\
\hline F & 568.40 & $\begin{array}{l}+.06 \\
-.03\end{array}$ & .3969 \\
\hline G & 599.57 & $\begin{array}{l}+.02 \\
-.02\end{array}$ & .3375 \\
\hline $\mathrm{H}$ & 733.55 & $\begin{array}{l}+.05 \\
-.03\end{array}$ & .4493 \\
\hline I & 757.22 & $\begin{array}{l}+.01 \\
-.02\end{array}$ & .3959 \\
\hline
\end{tabular}

*The range of wavelengths within which the wavelength for the given transmittance will fall for symmetric triangular passbands with half-height bandwidths from 1.5 to $10.5 \mathrm{~nm}$.

+ These values of transmittance are not certified. 
TABLE 3

Estimated Random and Systematic Errors of the Transmittance Minima

\begin{tabular}{|c|c|c|c|c|c|c|c|c|}
\hline \multirow[b]{2}{*}{$\begin{array}{c}\text { Band } \\
\text { Number }\end{array}$} & \multirow{2}{*}{$\begin{array}{c}\text { Nominal } \\
\text { Wavelength } \\
\text { of Minimum } \\
\text { Transmittance } \\
\end{array}$} & \multicolumn{7}{|c|}{ Standard Deviation for Indicated Bandwidth } \\
\hline & & $1.5 \mathrm{~nm}$ & $3.0 \mathrm{~nm}$ & $4.5 \mathrm{~nm}$ & $6.0 \mathrm{~nm}$ & $7.5 \mathrm{~nm}$ & $9.0 \mathrm{~nm}$ & $10.5 \mathrm{~nm}$ \\
\hline 1 & $402 \mathrm{~nm}$ & $\cdots$ & - & - & - &.- & $\cdots$ & $\cdots$ \\
\hline 2 & 431 & $\begin{array}{l}0.013 \mathrm{~nm} \\
(0.06)^{*}\end{array}$ & $0.010 \mathrm{~nm}$ & - & - & - & - & - \\
\hline 3 & 440 & $\begin{array}{r}0.021 \\
(0.05)\end{array}$ & 0.013 & $0.050 \mathrm{~nm}$ & $0.028 \mathrm{~nm}$ & $0.009 \mathrm{~nm}$ & $0.005 \mathrm{~nm}$ & $\begin{array}{l}0.007 \mathrm{~nm} \\
(0.25)\end{array}$ \\
\hline 4 & 446 & -- & - & - & - & - & - - & -. \\
\hline 5 & 473 & $\begin{array}{c}0.011 \\
(0.08)\end{array}$ & 0.012 & 0.032 & - & $\cdots$ & - & $\cdots$ \\
\hline 6 & 481 & $\begin{array}{l}0.015 \\
(0.15)\end{array}$ & 0.013 & 0.009 & 0.009 & 0.009 & 0.014 & $\begin{array}{r}0.017 \\
(0.25)\end{array}$ \\
\hline 7 & 513 & $\begin{array}{c}0.022 \\
(0.08)\end{array}$ & 0.016 & 0.014 & 0.013 & 0.010 & $\cdots$ & $\cdots$ \\
\hline 8 & 530 & $\begin{array}{c}0.012 \\
(0.21)\end{array}$ & 0.010 & 0.010 & 0.011 & 0.010 & 0.011 & $\begin{array}{l}0.010 \\
(0.25)\end{array}$ \\
\hline 9 & 573 & $\begin{array}{c}0.004 \\
(0.05)\end{array}$ & 0.010 & 0.010 & 0.012 & 0.014 & - & - \\
\hline 10 & 585 & $\begin{array}{c}0.007 \\
(0.06)\end{array}$ & 0.004 & 0.007 & 0.008 & 0.008 & 0.007 & $\begin{array}{r}0.007 \\
(0.25)\end{array}$ \\
\hline II & 624 & $\begin{array}{c}0.058 \\
(0.06)\end{array}$ & 0.061 & $-\cdot$ & $\cdots$ & -- & - & $\cdots$ \\
\hline 12 & 630 & $\begin{array}{l}0.210 \\
(0.02)\end{array}$ & 0.120 & 0.171 & 0.133 & 0.091 & - & - \\
\hline 13 & 685 & $\begin{array}{r}0.019 \\
(0.05)\end{array}$ & 0.029 & 0.024 & 0.017 & 0.014 & 0.014 & $\begin{array}{c}0.012 \\
(0.25)\end{array}$ \\
\hline 14 & 740 & $\begin{array}{r}0.009 \\
(0.25)\end{array}$ & 0.013 & 0.011 & 0.010 & 0.009 & 0.009 & $\begin{array}{l}0.010 \\
(0.25)\end{array}$ \\
\hline 15 & 748 & $\begin{array}{c}0.020 \\
(0.04)\end{array}$ & 0.016 & - & $\cdots$ & $\cdots$ & $\cdots$ & - \\
\hline
\end{tabular}

* Values in parentheses a re estimates of the systematic error. The estimates for the $1.5 \mathrm{~nm}$ bandwidth were obtained from the data taken at $1.5 \mathrm{~nm}$ intervals as compared to data taken at $0.15 \mathrm{~nm}$ intervals. The method of estimating the systematic errors for the $10.5 \mathrm{~nm}$ band width is described in Section 3.4 in SP 260-66.

Page 4

SRM 2010a 
TABLE 4

Transmittance $(T)$ as a function of wavelength from 380 to $780.5 \mathrm{~nm}$ for a band width of $1.5 \mathrm{~nm}$. The estimates of random and systematic errors are also provided. These data are not certified.

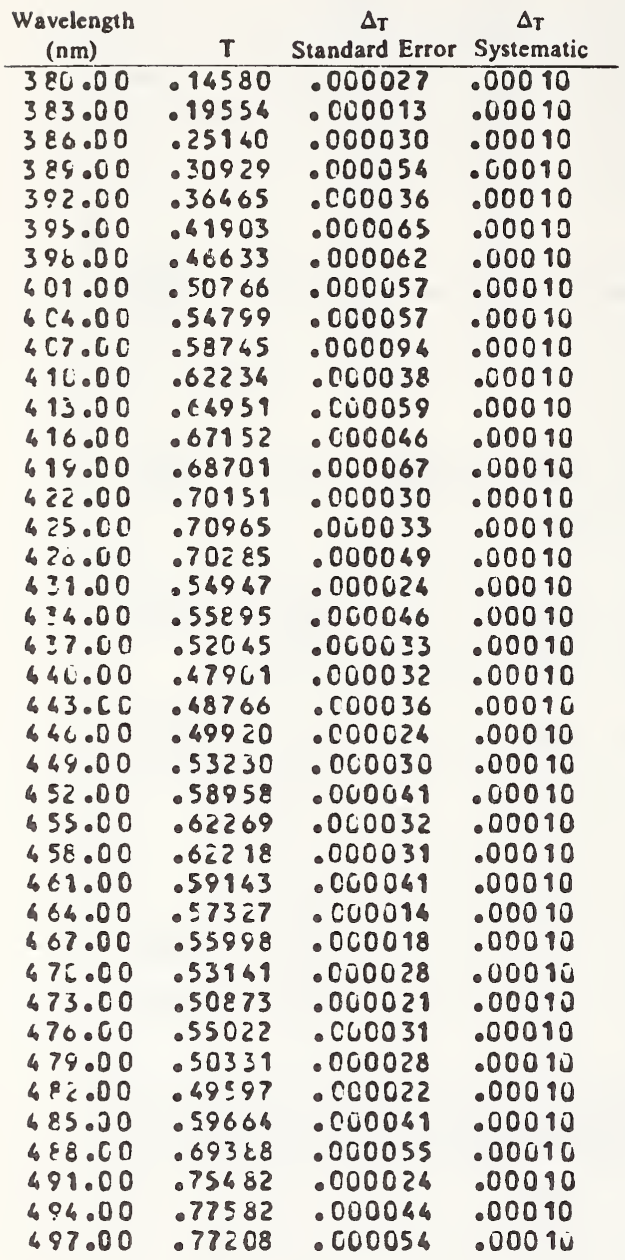

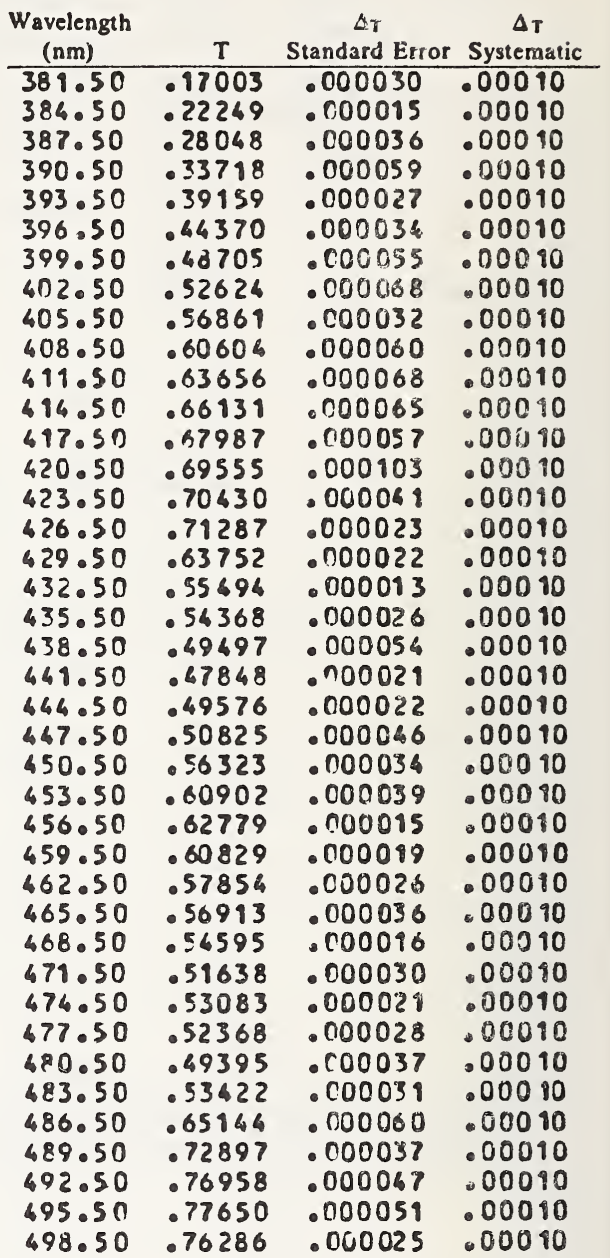


TABLE 4 (Continued)

Transmittance (T) as a function of wavelength from 380 to $780.5 \mathrm{~nm}$ for a band width of $1.5 \mathrm{~nm}$. The estimates of random and systematic errors are also provided. These data are not certified.

Wavelength

$(\mathrm{nm})$

500.00

503.00

560.00

508.00

512.00

515.00

518.00

521.00

524.00

527.00

530.00

533.00

536.00

539.00

542.00

545.00

548.00

551.00

554.00

$5 \$ 7.00$

$5<0.00$

563.00

566.00

569.00

572.00

575.00

578.00

581.00

584.00

587.00

590.00

583.00

596.00

599.00

$6 \mathrm{C2} .00$

$6 \mathrm{CS} .00$

600.00

611.00

614.00

697.00
$\Delta T$

$\Delta T$ Standard Error Systematic

$.75007 .000038 \quad .00010$

.71949 .000049

$.68654 \quad .000029$

.62231 .000040

.51720 .000029

.50708 .000031

.56851

.57281

.43289

.37679

.35279

.39916

.56124

.68105

.76653

.81171

.83233

.83719

.83571

.83133

.81679

.78036

.67208

.31171

.04666

.04138

.05465

.00696

.01915

.01731

.04805

.08229

.18778

.31676

.43508

.55363

.03107

. 68896

.78043

.84619
. 000063

. 000036

.000017

. 000020

.000016

- 000017

.000035

.000048

. 000033

- 000029

. 000043

.000045

.000028

.000029

. 000044

.000034

.000029

.000019

.000020

.000008

.000093

.000085

- 0,00006

.000007

.000019

.000008

.000025

.000016

.000046

- $C 00037$

- 000066

.000030

.000024

.000022
.00010

.00010

.00010

.00010

.00010

.00010

.00010

.00010

.00010

.00010

.00010

.00010

.00010

.00010

.00010

.00010

.00010

.00010

.00010

.00010

.00010

.00010

.00010

.00010

.00010

.00010

.00010

.00010

.00010

.00010

.00010

.00010

.00010

.00010

.00010

.00010

.00010

.00010

.00010

Wavelength $\Delta r \quad \Delta r$ (am) T Standard Error Systematic

501.50

504.50

507.50

510.50

513.50

516.50

519.50

522.50

525.50

528.50

531.50

534.50

537.50

540.50

543.50

546.50

549.50

552.50

555.50

558.50

561.50

564.50

567.50

570.50

573.50

576.50

579.50

582.50

585.50

588.50

591.50

594.50

597.50

600.50

603.50

606.50

609.50

612.50

615.50

618.50

\section{$-7$}

.70383

.66262

.56707

. 49346

- $\$ 3946$

- 58209

.51543

.39072

.35483

- 37015

.45853

.68975

.72896

.79325

.82444

.83615

.83660

.83426

.82586

.80277

.74242

.53386

.11909

.03514

.04491

.06821

.04148

.01262

.03031

.06187

.12409

.25829

. 37306

.49640

.59925

.65692

.73245

.82033

.85409 .000045

.000045

$.0000 ? 4$

.000031

.000056

- 000027

.000030

.000052

.000015

.000018

- 800025

.000042

.000031

.000044

. 000059

.000060

.000081

. 000048

.000029

.000025

.000038

.000038

.000026

.000013

.000016

.000012

.000009

.000013

.000006

.000092

.000007

.000025

.000021

.000031

- 000049

.000042

.000042

- 100043

.000027

.000056 
TABLE 4 (Continued)

Transmittance ( $T$ ) as a function of wavelength from 380 to $780.5 \mathrm{~nm}$ for a band width of $1.5 \mathrm{~nm}$. The estimates of random and systematic errors are also provided. These data are not certified.

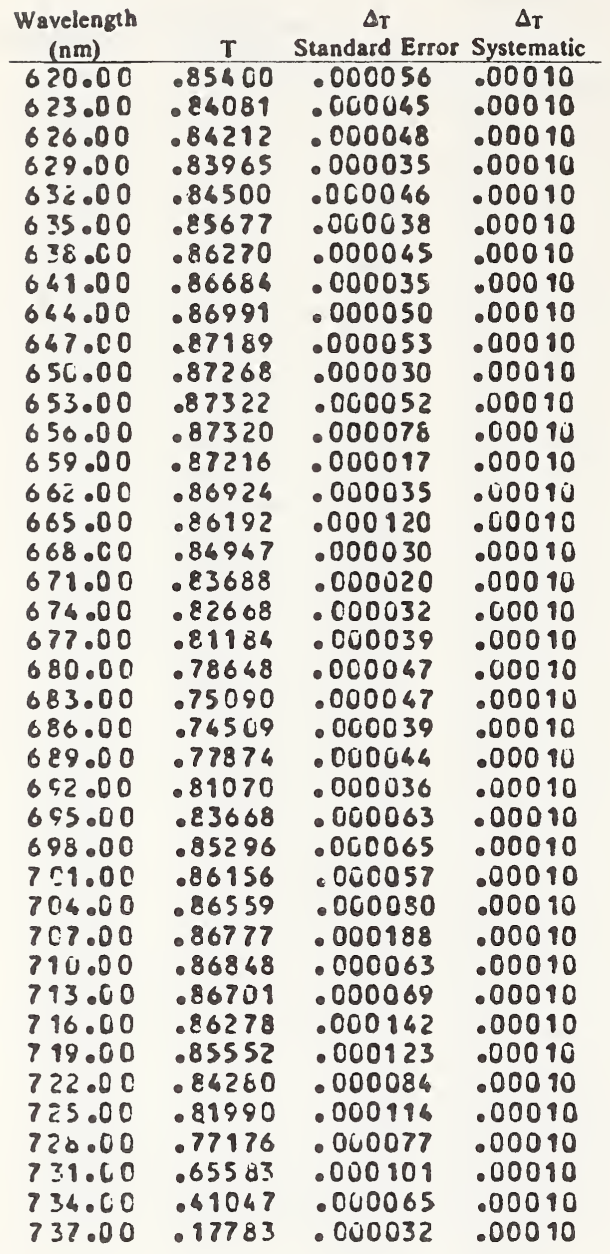

\begin{tabular}{|c|c|c|c|}
\hline Wavelength & & $\Delta_{T}$ & $\Delta r$ \\
\hline$(\mathrm{nm})$ & $T$ & Standard Error & Systematic \\
\hline 628.50 & .84757 & .000045 & .00010 \\
\hline 626.50 & .84027 & .000028 & .00010 \\
\hline $627 \cdot 50$ & .84985 & .000048 & .00010 \\
\hline 630.50 & .84039 & .000047 & .00010 \\
\hline 633.50 & .85109 & .000062 & .00010 \\
\hline 636.50 & .86029 & .000032 & .00010 \\
\hline 639.50 & .86501 & .000022 & .00010 \\
\hline 642.50 & .86847 & .000026 & .00010 \\
\hline 665.50 & .87114 & .000068 & .00010 \\
\hline 648.50 & .87232 & .000098 & .00010 \\
\hline 651.50 & .87294 & .000108 & .00010 \\
\hline 654.50 & .87322 & .000064 & .00080 \\
\hline 657.50 & .87276 & - $\mathrm{COOOO59}$ & .00010 \\
\hline 660.50 & .87106 & .000029 & .00010 \\
\hline 663.50 & .86636 & .000018 & .00010 \\
\hline 666.50 & .85616 & .000054 & $.000: 0$ \\
\hline $669^{\circ}$ & .84273 & .000043 & .00010 \\
\hline 672.50 & .83157 & .000038 & .00010 \\
\hline 675.50 & .82088 & .000031 & .00010 \\
\hline 678.50 & .79967 & .000058 & .00010 \\
\hline 681.50 & .77033 & .000078 & .00010 \\
\hline 686.50 & .73735 & .000031 & .00080 \\
\hline 687.50 & .76335 & .000040 & .00010 \\
\hline 690.50 & .79470 & - 100040 & .00010 \\
\hline 693. & .82509 & .000080 & .00010 \\
\hline 696. & .86584 & .000038 & .00010 \\
\hline 699. & .85807 & .000074 & .00010 \\
\hline 702.50 & .86388 & .000070 & .00010 \\
\hline $7 C 5.50$ & .86695 & .000087 & .00010 \\
\hline 70.8 .50 & .86848 & .000069 & .00010 \\
\hline 718.50 & .86809 & .000113 & .00010 \\
\hline 794.50 & 6522 & .000073 & .00010 \\
\hline 717.50 & .85960 & .000047 & .00010 \\
\hline 820.50 & 002 & .000116 & .00010 \\
\hline 723.50 & 306 & .000031 & .00010 \\
\hline 726.50 & & .000070 & .00010 \\
\hline & & .000057 & .00010 \\
\hline 732.50 & 906 & .000059 & .00010 \\
\hline 73 & 146 & .000070 & .00010 \\
\hline & .14350 & .000025 & .00010 \\
\hline
\end{tabular}

Page 7

SRM 2010a 
TABLE 4 (Continued)

Transmittance ( $T$ ) as a function of wavelength from $380 t 0780.5 \mathrm{~nm}$ for a bandwidth of $1.5 \mathrm{~nm}$. The estimates of random and systematic errors are also provided. These data are not certified.

\begin{tabular}{cccc}
$\begin{array}{c}\text { Wavelength } \\
\text { (nm) }\end{array}$ & $T$ & \multicolumn{2}{c}{$\Delta$ Standard Error Systematic } \\
\hline 740.00 & .14029 & .000039 & .00010 \\
743.00 & .15422 & .000013 & .00010 \\
740.00 & .17950 & .000046 & .00010 \\
749.00 & .15817 & .000026 & .00010 \\
752.00 & .21278 & .000036 & .00010 \\
755.00 & .00634 & .060047 & .00010 \\
758.00 & .42896 & .000027 & .00010 \\
761.00 & .53598 & .000089 & .00010 \\
764.00 & .01508 & .000065 & .00010 \\
767.00 & .08350 & .000108 & .00010 \\
774.00 & .73432 & .000079 & .00010 \\
773.00 & .76019 & .000081 & .00010 \\
776.00 & .76438 & .000145 & .00010 \\
779.00 & .74102 & .000081 & .00010
\end{tabular}

\begin{tabular}{cccc}
$\begin{array}{c}\text { Wavelength } \\
(\mathrm{nm})\end{array}$ & $\mathrm{T}$ & $\begin{array}{c}\Delta \mathrm{T} \\
\text { Standard Error Systematic }\end{array}$ \\
\hline 741.50 & .14205 & .000027 & .00010 \\
764.50 & .17506 & .000027 & .00010 \\
747.50 & .16393 & .000038 & .00010 \\
750.50 & .17794 & .000030 & .00010 \\
753.50 & .25589 & .000065 & .00010 \\
756.50 & .36590 & .000050 & .00010 \\
759.50 & .48660 & .000056 & .00010 \\
762.50 & .57747 & .000099 & .00010 \\
765.50 & .65041 & .000071 & .00010 \\
768.50 & .71193 & .000061 & .00010 \\
771.50 & .75005 & .000086 & .00010 \\
774.50 & .76505 & .000161 & .00010 \\
777.50 & .75658 & .000066 & .00010 \\
780.50 & .71767 & .000142 & .00010
\end{tabular}

Page 8

SRM 2010a 


\section{(Tiertifitate of}

\section{Standard Reference Material 2031}

\section{Metal-on-Quartz Filters for Spectrophotometry}

This Standard Reference Material (SRM) is intended for use in the verification of the transmittance and absorbance scales of conventional spectrophotometers in the ultraviolet and visible regions of the electromagnetic spectrum. SR M 2031 consists of three individual filters in their metal holders and one empty filter holder. Two filters, having nominal transmittances of 10 and 30 percent, were produced by evaporating different thicknesses of chromium metal on 1.5 -rnm thick fused silica plates that had been precision ground and polished. These metal films are protected by $1.5-\mathrm{mm}$ clear fused silica cover plates optically contacted to the base plates. The third filter is a single fused silica plate 3-mm thick, having a nominal transmittance of 90 percent. The metal holders for these filters are provided with shutters to protect the filters when not in use. The shutters must be removed at the time of measurement and be replaced after the measurements have been completed. Each filter holder bears a filter number $(10,30$, or 90$)$ and a set identification number.

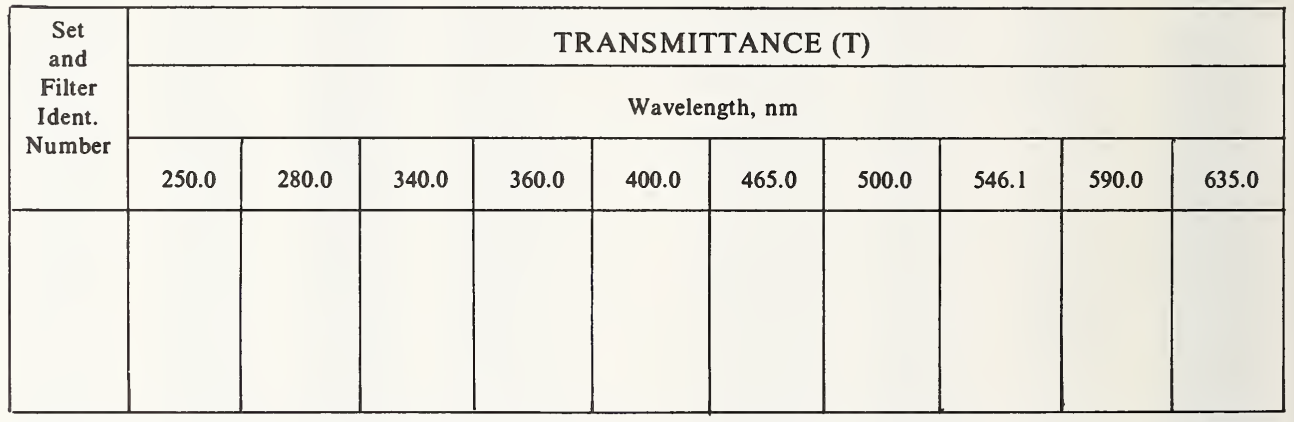

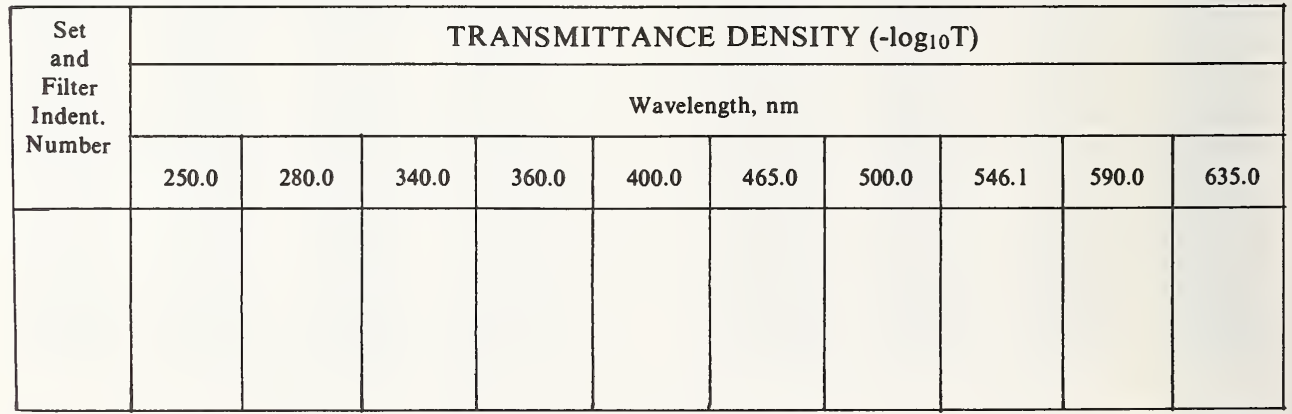

Date of Certification:

Gaithersburg, MD 20899

Stanley D. Rasberry, Chief

October 22, 1984

Office of Standard Reference Materials

(Revision of Certificates

dated 6-1-79 and 9-20-82) 
The transmittance values $(\mathrm{T})$ can be converted to percent transmittance $(\% \mathrm{~T})$ by multiplying by 100 . The transmittance densities were calculated from the measured transmittance $(T)$. These transmittance densities should be indicated by the absorbance scale of the spectrophotometer when the filters are measured against air. All of the certified transmittance values were obtained by measuring against air at an ambient temperature of $23.5^{\circ} \mathrm{C}$.

The uncertainty of the certified transmittance values of the two metal film filters is \pm 1.0 percent. This uncertainty includes 0.5 percent for random and systematic errors of the calibration procedure, as well as 0.5 percent for possible changes in the transmittance with time. The total uncertainty of the certified transmittance values for the clear quartz plate is 0.5 percent (see note below). The long-term stability of the filters with the chromium film has not been rigorously established. Measurements to date, however, suggest that the transmittance of the chromium-coated filters could change by as much as 0.5 percent in the first year after calibration. Therefore, this SRM should be returned to the National Bureau of Standards for free verification of the transmittance values on the first anniversary of the certification date. Information regarding subsequent verifications or recalibrations, including costs for such service, will be included with this first verification report. Before returning this SRM to NBS, information regarding such shipment should be obtained from the Service Analysis Coordinator, Center for Analytical Chemistry, Room B222, Chemistry Building, National Bureau of Standards, Gaithersburg, MD 20899. Telephone: (301) 921-2141.

When not in use, the filters should be stored in their holders with the shutters in place and in the metal container provided for this purpose. Exterded exposure to laboratory atmosphere and dirty surroundings should be avoided.

The transmittance measurements were made using the high-accuracy spectrophotometer designed and built in the NBS Center for Analytical Chemistry [1]. This instrument is a primary transmittance standard; its transmittance accuracy was established using the double-aperture method of linearity testing $[1,3,5,6]$.

Transmittance measurements for SRM 2031 were made by producing the vertical image of the slit (about $8 \mathrm{~mm}$ by $1.5 \mathrm{~mm}$ ), using a convergent beam geometry with an aperture ratio $\mathrm{f}: 10$, in the middle of the entrance face of the filter. The filters were measured in the spectrophotometer in a position perpendicular to the incident light beam. A spectral bandpass of $1.6 \mathrm{~nm}$ was used for measurements at all wavelengths. Because the transmittances of these filters exhibit an appreciable optical neutrality, the dependence of transmittance on bandpass is not critical and wider bandpasses may be used in routine measurements. For a quantitative discussion of this subject, the user should consult reference 5, pp. 32 and 33.

The transmittance, $\mathrm{T}$, was measured against air in the reference bea $\mathrm{m}$; hence it includes the reflection losses that occur at the air-filter interface. Under these circumstances the measured transmittance, $T$, has a corresponding transmittance density, defined as $-\log _{10} T$. The internal transmittance, $T_{i}$, of a material is defined as the transmittance of the material corrected for reflection losses. This is obtained experimentally when the measurements are made against a blank sample in the reference beam. The absorbance, $A$, of a material is related to this internal transmittance, $T_{i}$, by the expression, $A=-\log _{10} T_{i}$.

The exposed surface of each filter is approximately $29 \times 8 \mathrm{~mm}$, measuring from a point $1.5 \mathrm{~mm}$ above the base of the filter holder (see figure). The empty filter holder provided is to be used in the reference beam of the spectrophotometer so that approximately equivalent conditions of stray radiation are achieved for both bea ms. The transmittance of the filters depends upon the intrinsic properties of the material, wavelength, spectral bandpass, geometry of the optical beam, temperature, and positioning of the filter. While changes in ambient temperature of 1 or $2^{\circ} \mathrm{C}$ from $23.5^{\circ} \mathrm{C}$ have not significantly affected the calibration, the effect of temperature variations exceeding $2^{\circ} \mathrm{C}$ have not been investigated. Changes in the transmittance may be caused by surface conditions, aging of the material, exposure to a harmful atmosphere, or careless handling $[2,3,4,5,7]$.

SRM 2031 is stored in a black-anodized aluminum container provided with a threaded cap made of the same metal. Each filter is placed in a cylindrical cavity to prevent any contact between the filter face and the walls of the storage container. Contamination of the filter surface with particulate matter due to static charges is minimized through the metallic nature of the container. A fiat iaf spring is inserted into the cylindrical cavity with each filter holder to minimize damage during transportation. These springs can be removed during normal use in the laboratory.

NOTE: In some commercial instruments, the metal-on-quartz filters can generate reflection effects in the sample compartment that can degrade the accuracy of the measured transmittances. During the development of SR M 2031, the presence and magnitude of reflection effects were studied and were found negligible, within the uncertainty specified, in all spectrophotometers tested (see Ref. 5 page 4, pp. 16-30 for additional details of this study). However for certain instruments, these effects could become significant. If such effects are detected or suspected, the user should contact R.W. Burke, NBS Inorganic Analytical Research Division, for assistance and instructions.

Page 2

SRM 2031 
The filter is shown in the assembled unit with its front surface facing up. The filter, in its filter holder, should be placed in the cuvette compartment of the spectrophotometer with its front surface facing the incident light beam and the rear surface facing the photodetector.

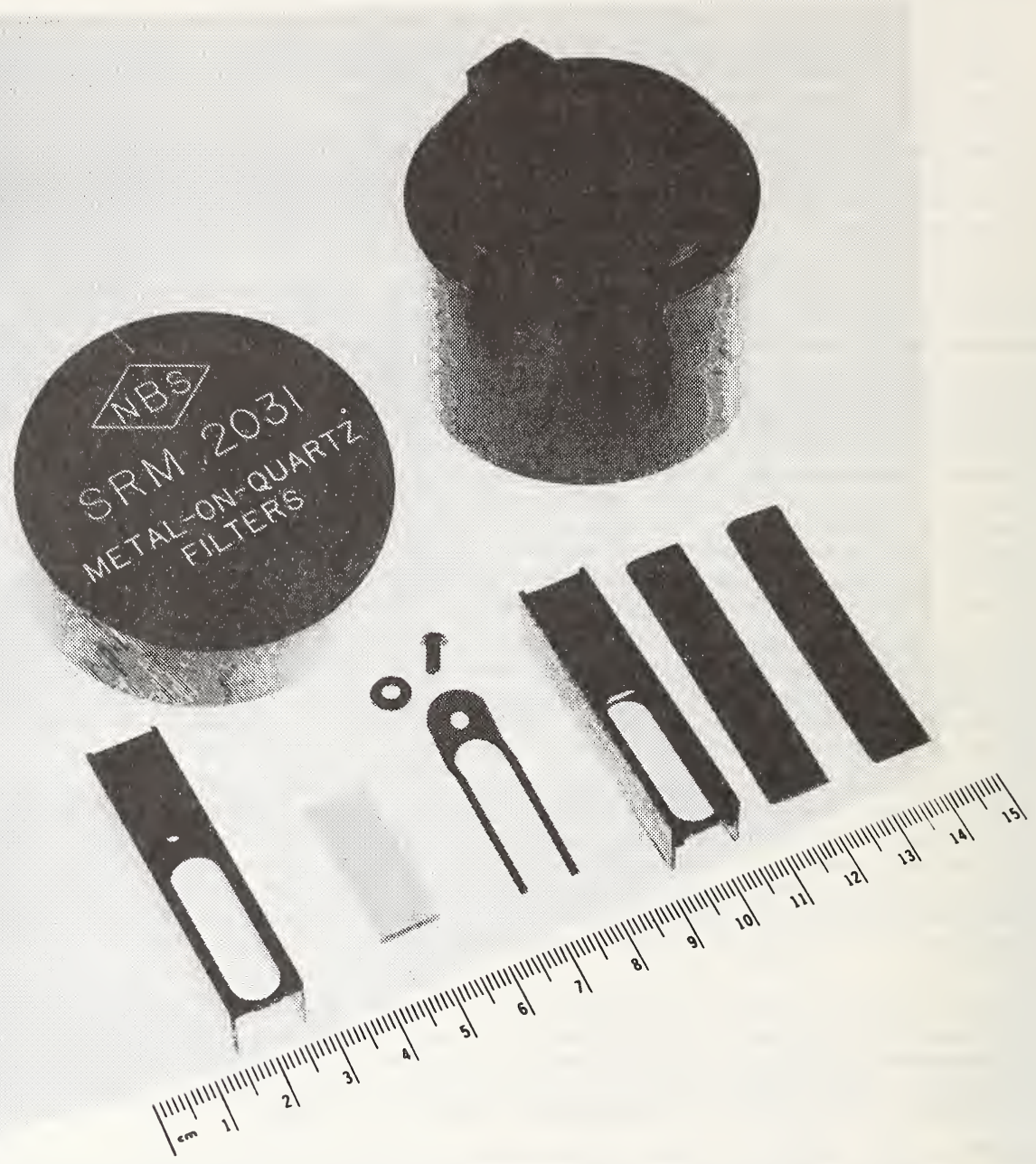

Top: Cylindrical container with its screw cap, both made of black-anodized aluminum alloy. Four filter holders can be stored in the cylindrical container. Bottom (from left to right): Aluminum alloy filter holder, $12.5 \mathrm{~mm}$ square and $58 \mathrm{~mm}$ high; Metal-on-quartz filter; Retaining spring of beryllium-copper with nylon screw and washer; Assembled unit; and two Delrin shutters. All metal and plastic parts are flat black. 
Prior to certification measurements, each filter was examined for surface defects and the condition of the optical contact [5]. Should the surface of the filter become contaminated, no attempt should be made to clean it unless the user has the facilities to demonstrate that the cleaning treatment will not alter the surface or degrade the accuracy of the certified values. As SRM 2031 is a transfer standard, the only means available to verify its integrity is to remeasure its transmittance with a primary standard instrument similar to that used in this certification $[1,5]$. In most cases, where verification or recertification of the transmittance values is desirable, it will be most expeditious to return the filters to the National Bureau of Standards for measurement.

Further information concerning the selection, preparation, and properties of SRM 2031 will be found in reference 5.

The research, development, and initial production of this SRM were conducted by R. Mavrodineanu and J.R. Baldwin, NBS Inorganic Analytical Research Division.

The transmittance measurements were performed by R.W. Burke and M.V. Smith, NBS Inorganic Analytical Research Division. Technical leadership for the preparation and measurements leading to certification was provided by R.W. Burke.

The overall direction and coordination of technical measurements leading to certification were performed under the chairmanship of J.R. DeVoe, NBS Inorganic Analytical Research Division.

The technical and support aspects involved in the preparation, certification, and issuance of this Standard Reference Material were coordinated through the Office of Standard Reference Materials by L.J. Powell.

We wish to acknowledge the cooperation of George N. Bowers, Jr., M.D., of Hartford Hospital, Hartford, Connecticut; Royden N. Rand, Ph.D., of the Eastman Kodak Co. Research Laboratories, Rochester, New York; and Donald S. Young, M.D., Ph.D., of the Mayo Clinic, Rochester, Minnesota.

The contributions of H.E. Bennett and J.M. Bennett of the Michelson Laboratory, Physical Optics Branch, Naval Weapons Center, China Lake, California, who helped in the initial production of SRM 2031 are also gratefully acknowledged.

\section{References}

1. R. Mavrodineanu, An Accurate Spectrophotometer for Measuring the Transmittance of Solid and Liquid Materials, NBS Journal of Research 76a, No. 5, 405-425 (1972).

2. R. Mavrodineanu, Solid Materials to Check the Photometric Scale of Spectrophotometers, NBS Tech. Note 544, O. Menis, and J.I. Shultz, Eds., pp. 6-17, U.S. Government Printing Office, Washington, D.C. 20402 (Sept. 1970); ibid, NBS Tech. Note 584, pp. 2-21 (December 1971).

3. K.S. Gibson, Spectrophotometry, NBS Circ. 484 (Sept. 1949).

4. R. Mavrodineanu, Considerations for the Use of Semi-Transparent Metallic Thin Films as Potential Transmittance Standards in Spectrophotometry. NBS Journal of Research 80A, No. 4, 637-641 (1976).

5. R. Mavrodineanu and J.R. Baldwin, Metal-on-Quartz Filters as a Standard Reference Material for Spectrophotometry, SRM 2031. NBS Special Publication 260-68, U.S. Government Printing Office, Washington, D.C. 20402 (1979).

6. K.D. Mielenz and K.L. Eckerle, Spectrophotometer Linearity Testing Using the Double-Aperture Method, Appl. Optics $11,2294-2303$ (1972).

7. R.W. Burke and R. Mavrodineanu, Accuracy in Analytical Spectrophotometry NBS Special Publication 260-81, U.S. Government Printing Office, Washington, DC 20402 (1983).

Page 4

SRM 2031 


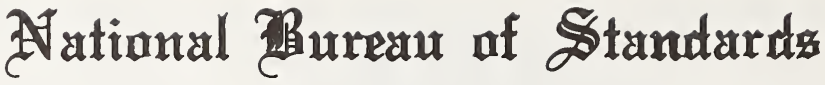

Uertificate

\section{Standard Reference Material 2032}

\section{Crystalline Potassium Iodide \\ Heterochromatic Stray Radiant Energy Standard for Ultraviolet Absorption Spectrophotometry}

\author{
K. D. Mielenz and R. Mavrodineanu
}

This Standard Reference Material consists of reagent-grade, crystalline potassium iodide (KI) to be used to assess heterochromatic stray radiant energy (stray light) in ultraviolet absorption spectrophotometers in the spectral region below $260 \mathrm{~nm}$. Stray light is assessed by measuring the spectral absorbance of aqueous solutions of SRM 2032 of known pathlengths and concentrations, and comparing the result with the certified values of the specific absorbance, $\epsilon$.

\begin{tabular}{ccccccccc}
\multicolumn{10}{c}{ Specific Absorbance } \\
\multicolumn{10}{c}{$\epsilon\left(\mathrm{L} \mathrm{g}^{-1} \mathrm{~cm}^{-1}\right)$, vs } & Wavelength, $\lambda(\mathrm{nm})$, at $23.5^{\circ} \mathrm{C}$ \\
$\lambda$ & 240 & 245 & 250 & 255 & 260 & 265 & 270 & 275 \\
\hline$\epsilon$ & 25.6 & 10.67 & 3.66 & 1.05 & 0.260 & 0.0560 & 0.0121 & 0.0031
\end{tabular}

\footnotetext{
${ }^{a_{a}}$ "Specific absorbance" is defined here as absorbance per unit pathlength and unit concentration. The term "absorptivity" has been avoided
} since it is ambiguously defined. See K. D. Mielenz, Anal. Chem. 48, 1093-1094 (1976).

The estimated uncertainty of these values is $\pm 5 \%$, which includes the random and systematic errors of the calibration procedure, as well as variations due to possible instability of the KI. (See, Certification Procedure.)

The material used to produce SRM 2032 was obtained from the J. T. Baker Chemical Co., Phillipsburg, N.J., in two bottles, as reagent-grade $(99.8 \%$ purity) potassium iodide.

SRM 2032 was issued with the technical assistance of J. R. Baldwin, R. W. Burke, A. L. Cummings, B. I. Diamondstone, and G. A. Sleater, and under the overall direction of I. L. Barnes.

The technical and support aspects concerning preparation, certification, and issuance of this SRM were coordinated through the Office of Standard Reference Materials by R. W'. Seward.

Washington, D.C. 20234

October 31, 1979
George A. Uriano, Chief Office of Standard Reference Materials 


\section{Supplementary Information}

Material Testing:

Material homogeneity was tested by measuring the absorbance of $1 \%$ aqueous solutions of the KI sampled from the top, middle, and bottom of each bottle. These measurements, at 265,267 , and $270 \mathrm{~nm}$, showed no evidence of inhomogeneity. Tests for moisture content (Karl Fischer method) gave an average of $0.007 \%$. This value was sufficiently small that all certified data are based on weighed samples of the undried, as received, material.

Stability of the material to UV and visible light was tested by exposing the KI salt in a low-actinic glass bottle to radiation from a $3 \mathrm{~kW}$ xenon-arc lamp at a distance of $25 \mathrm{~cm}$ for four days at room temperature. The average absorbances at five wavelengths between 240 and $270 \mathrm{~nm}$ of aqueous solutions of the exposed material were $1.1 \%$ lower than those of solutions of the unexposed material. In view of the severity of this test, this change was considered minor. Nonetheless, the $1.1 \%$ was included in the overall uncertainty of the certified values.

\section{Certification Procedure:}

The certified specific absorbances were measured in the NBS Center for Analytical Chemistry high-accuracy spectrophotometer [1, 2], equipped with a deuterium lamp and UV averaging sphere [3, 4]. Thirteen aqueous solutions of $\mathrm{KI}$ with concentrations ranging from 0.03 to $30 \mathrm{~g} \mathrm{~L}^{-1}$ were prepared and measured against distilled water, using standard fused-silica cuvettes with pathlengths between 10.001 and $10.009 \mathrm{~mm}^{\mathrm{b}}$. The absorbance measurements were performed at the temperature, $t=23.5 \pm 0.5^{\circ} \mathrm{C}$. A $0.2 \mathrm{~nm}$ bandpass was used, and wavelength settings were made with an accuracy of $0.05 \mathrm{~nm}$. The measurements were made on at least three concentrations at each wavelength. These concentrations were chosen so that most absorbance readings fell between 0.1 and 1.0 to minimize stray light and bandwidth errors. The data were found to obey Beer's law.

Thus, the equation,

$$
\epsilon=A / c \ell
$$

was used to calculate the specific absorbances, $\epsilon$, from the measured absorbances, $A$, and the known values of concentration, $c$, and pathlength, $\ell$.

Limits to random error (two standard deviations) of these measurements (including the photometric imprecision of the spectrophotometer, errors in the repositioning of cuvettes, concentration errors, pathlength uncertainties, temperature errors, Beer's law uncertainties, and bandwidth errors) were determined to be \pm $2.4 \%$. The error due to the $0.05 \mathrm{~nm}$ uncertainty of the wavelength calibration of the spectrophotometer is $\pm 1.1 \%$.

The uncertainty of $5 \%$ stated on the face of this certificate represents the sum of these errors and the above mentioned $1.1 \%$ uncertainty due to instability of the KI. No corrections were applied for the effects of internal reflections inside the sample and reference cuvettes, nor were the weights corrected to vacuum. These and all other sources of error were considered negligible.

The temperature coefficient at $260 \mathrm{~nm}$ was determined to be

$$
\frac{1}{\epsilon} \frac{\mathrm{d} \epsilon}{\mathrm{dt}}=0.031^{\circ} \mathrm{C}^{-1} \text {. }
$$

For precision measurements, it is recommended that SRM 2032 be used in thermostated cuvettes at $23.5^{\circ} \mathrm{C}$, or that a temperature correction according to Eq. (2) be applied.

bIssued by NBS as SRM 932, Quartz Cuvettes for Spectrophotometry. 


\section{Instructions for Use}

Storage and Preparation:

SRM 2032 should be stored in the original, low-actinic glass bottle and the cardboard container in which it was issued to protect it from unnecessary exposure to light and humidity. When so stored, the expected stability of this material is at least three years. Thus, until additional stability data are obtained, this material should be used within three years of the date of purchase.

All solutions prepared from SRM 2032 should be made in borosilicate glass containers using distilled water and transfer pipettes (Pasteur type) of the same glass and fitted with rubber bulbs ${ }^{c}$. Use clean spectrophotometer cuvettes, free of scratches, made of non-fluorescent fused silica, and fitted with ground-glass or Teflon stoppers to minimize evaporation; or preferably use NBS SRM 932. Mark all cuvettes to assure the same orientation in the spectrophotometer, and place them into their respective holders. Using transfer pipettes of the type mentioned, rinse each cuvette several times with distilled water. Prepare a solution of KI in distilled water (e.g., $1 \%$ ), fill the sample cuvette with the KI solution and the reference cuvette with distilled water. Measure the absorbance, leaving the cuvettes in their holders, empty them (using the pipettes), and repeat the rinsing and filling operations until constant absorbance readings are obtained. Fresh solutions should be made before every test.

\section{Measurements:}

A $1 \% \mathrm{KI}$ solution $\left(\mathrm{c}=10 \mathrm{~g} \mathrm{~L}^{-1}\right)$ with a $1 \mathrm{~cm}$ pathlength exhibits a sharp cutoff in transmittance near $260 \mathrm{~nm}$; i.e., it transmits more than $90 \%$ above $273 \mathrm{~nm}$, but less than $0.01 \%$ below $258 \mathrm{~nm}$. Therefore, with the monochromator set for a wavelength below $260 \mathrm{~nm}$, any appreciable amount of light detected is heterochromatic stray light, which consists of wavelengths above the cutoff. The amount of stray light in the spectrophotometer at wavelength $\lambda$ may be determined from the equations:

$$
\begin{aligned}
T^{\prime}(\lambda) & =\frac{T(\lambda)+x(\lambda)}{1+x(\lambda)} \\
x(\lambda) & =\frac{T^{\prime}(\lambda)-T(\lambda)}{1-T^{\prime}(\lambda)}
\end{aligned}
$$

where:

$$
\begin{aligned}
& x(\lambda) \text { is the stray light ratio, } \\
& T^{\prime}(\lambda) \text { is the apparent transmittance, } \\
& T(\lambda) \text { is the true transmittance. }
\end{aligned}
$$

The stray light ratio, $x(\lambda)$, is the proportion of heterochromatic stray radiant energy in the spectrophotometer for the wavelength setting $\lambda$. Equation (4) forms the theoretical basis for the determination of the stray light ratio by comparing apparent transmittance to true transmittance. For SRM 2032, the true transmittance, T( $\lambda$ ), of KI solutions may be calculated as:

$$
T(\lambda)=10^{-\epsilon(\lambda) \cdot c \ell}
$$

where $\epsilon(\lambda)$ is the certified specific absorbance given on the face of this certificate.

\footnotetext{
'Soft glass containers and pipettes contain residual amounts of UV absorbing material, but can be used after proper cleaning. Several rinses, first with isopropyl alcohol and then with distilled water, are generally adequate.
} 
The apparent transmittances of KI solutions depend not only on the stray light ratio of the spectrophotometer, but also on the wavelength accuracy and the spectral bandwidth, which can significantly affect the results obtained because of the steep slope of the absorbance cutoff of KI. A low-pressure mercury discharge lamp is suggested for verifying the wavelength scale, and a bandwidth as narrow as compatible with adequate signal-tonoise ratios should be used.

Many instruments do not permit the direct measurement of transmittances below certain limits, e.g., $1 \%$ or $0.1 \%$. For such instruments, the use of SRM 2032 will only measure stray light ratios above these limits. To measure stray light ratios below these limits, the reference beam of the spectrophotometer must be attenuated to extend the transmittance scale into the low-transmittance region.

References

1. R. Mavrodineanu, J. Res. NBS 76A, 405-425 (1972).

2. J.F. Barkley, F. C. Ruegg, and R. Mavrodineanu, 29th Pittsburgh Conf., Abstract 452, Cleveland, Ohio, (1978).

3. K. D. Mielenz, R. Mavrodineanu, and E. D. Cehelnik, J. Res. NBS 78A, 631-635 (1974).

4. K. D. Mielenz, R. Mavrodineanu, and E. D. Cehelnik, Appl. Optics 14, 1940-1947 (1975). 


\section{Ayational 通urean of Standardm}

\section{(Uírtifitate}

\section{Standard Reference Material 2033}

\section{Crystalline Potassium Iodide with Attenuator \\ Heterochromatic and Isochromatic Stray Radiant Energy \\ Standard for Ultraviolet Absorption Spectrophotometry}

\section{K. D. Mielenz and R. Mavrodineanu}

This Standard Reference Material consists of reagent-grade crystalline potassium iodide (KI) and a radiation attenuator to be used to assess the heterochromatic stray radiant energy (stray light) in ultraviolet absorption spectrophotometers in the spectral region below $260 \mathrm{~nm}$.. The radiation attenuator consists of two semitransparent evaporated metal-on-fused silica (non-fluorescent) filters, each having a nominal transmittance of $10 \%$. One filter is mounted in a cuvette-style holder that can be inserted into the sample compartment of the spectrophotometer. The other is mounted in one of the two shutters of the holder. The use of this attenuator permits the expansion of the transmittance scale into the lowtransmittance region by providing a two-step attenuation of the reference beam of the spectrophotometer to about $1 \%$. The attenuator can also be used to assess isochromatic stray light by following the instructions given in this certificate.

The heterochromatic stray light is assessed by measuring the spectral absorbance of aqueous solutions of SRM 2033 of known pathlengths and concentrations, and comparing the results with the certified values of the specific absorbance, $\epsilon$.

Specific Absorbance ${ }^{a}$

\begin{tabular}{|l|cccccccc|}
\hline \multirow{3}{*}{$\lambda$} & \multicolumn{7}{|c|}{$\epsilon\left(\mathrm{L} \mathrm{g}^{-1} \mathrm{~cm}^{-1}\right)$, vs Wavelength, $\lambda(\mathrm{nm})$, at } & $23.5^{\circ} \mathrm{C}$ \\
\cline { 2 - 9 } & 240 & 245 & 250 & 255 & 260 & 265 & 270 & 275 \\
\hline$\epsilon$ & 25.6 & 10.67 & 3.66 & 1.05 & 0.260 & 0.0560 & 0.0121 & 0.0031 \\
\hline
\end{tabular}

" "Specific Absorbance" is defined here as absorbance per unit pathlength and unit concentration. The term "absorptivity" has been avoided since it is ambiguously defined. See K. D. Mielenz, Anal. Chem. 48, 1093-1094 (1976).

The estimated uncertainty of these values is $\pm 5 \%$, which includes the random and systematic errors of the calibration procedure, as well as variations due to possible instability of the KI. (See Certification Procedure.)

The material used to produce SRM 2033 was obtained from the J.T. Baker Chemical Co., Phillipsburg, N.J., in two bottles, as reagent-grade $(99.8 \%$ purity) potassium iodide.

The transmittance of the filter mounted in the holder at $\lambda 255 \mathrm{~nm}$ is the transmittance of both filters at $\lambda 255$ is

SRM 2033 was issued with the technical assistance of J. R. Baldwin, R. W. Burke, A. L. Cummings, B. I. Diamondstone, and G. A. Sleater, and under the overall direction of E. L. Garner, NBS Inorganic Analytical Research Division.

The technical and support aspects concerning preparation, certification, and issuance of this SRM were coordinated through the Office of Standard Reference Materials by R. W. Seward. 
Potassium Iodide Material Testing:

Material homogeneity was tested by measuring the absorbance of $1 \%$ aqueous solutions of the KI sampled from the top, middle, and bottom of each bottle. These measurements, at 265, 267, and $270 \mathrm{~nm}$, showed no evidence of inhomogeneity. Tests for moisture content (Karl Fischer method) gave an average of $0.007 \%$. This value was sufficiently small that all certified data are based on weighed samples of the undried, as received, material.

Stability of the material to UV and visible light was tested by exposing the KI salt in a low-actinic glass bottle to radiation from a $3 \mathrm{~kW}$ xenon-arc lamp at a distance of $25 \mathrm{~cm}$ for four days at room temperature. The average absorbances at five wavelengths between 240 and $270 \mathrm{~nm}$ of aqueous solutions of the exposed material were $1.1 \%$ lower than those of solutions of the unexposed material. In view of the severity of this test, this change was considered minor. Nonetheless, the $1.1 \%$ was included in the overall uncertainty of the certified values.

\section{Potassium Iodide Certification Procedure:}

The certified specific absorbances were measured in the NBS Center for Analytical Chemistry high-accuracy spectrophotometer [1,2], equipped with a deuterium lamp and UV averaging sphere [3,4]. Thirteen aqueous solutions of KI with concentrations ranging from 0.03 to $30 \mathrm{~g} \mathrm{~L}^{-1}$ were prepared and measured against distilled water, using standard fused-silica cuvettes with pathlengths between 10.001 and $10.009 \mathrm{~mm}^{\mathrm{b}}$. The absorbance measurements were performed at the temperature, $\mathrm{t}=23.5 \pm 0.5^{\circ} \mathrm{C}$. A $0.2 \mathrm{~nm}$ bandpass was used, and wavelength settings were made with an accuracy of $0.05 \mathrm{~nm}$. The measurements were made on at least three concentrations at each wavelength. These concentrations were chosen so that most absorbance readings fell between 0.1 and 1.0 to minimize stray light and bandwidth errors. The data were found to obey Beer's law.

Thus, the equation,

$$
\epsilon=\mathrm{A} / \mathrm{cl}
$$

was used to calculate the specific absorbances, $\epsilon$, from the measured absorbances, A, and the known values of concentration, $\mathrm{c}$, and pathlength, $\ell$.

Limits to random error (two standard deviations) of these measurements (including the photometric imprecision of the spectrophotometer, errors in the repositioning of cuvettes, concentration errors, pathlength uncertainties, temperature errors, Beer's law uncertainties, and bandwidth errors) were determined to be $\pm 2.4 \%$. The error due to the $0.05 \mathrm{~nm}$ uncertainty of the wavelength calibration of the spectrophotometer is $\pm 1.1 \%$.

The uncertainty of $5 \%$ stated on the face of this certificate represents the sum of these errors and the above mentioned $1.1 \%$ uncertainty due to instability of the KI. No corrections were applied for the effects of internal reflections inside the sample and reference cuvettes, nor were the weights corrected to vacuum. These and all other sources of error were considered negligible.

The temperature coefficient at $260 \mathrm{~nm}$ was determined to be

$$
\frac{1}{\epsilon} \cdot \frac{\mathrm{d} \epsilon}{\mathrm{dt}}=0.031^{\circ} \mathrm{C}^{-1} \text {. }
$$

For precision measurements, it is recommended that SRM 2033 be used in thermostated cuvettes at $23.5^{\circ} \mathrm{C}$, or that a temperature correction according to Eq. (2) be applied.

${ }^{b}$ Issued by NBS as SRM 932, Quartz Cuvette for Spectrophotometry.

SRM 2033

Page 2 
Storage and Preparation:

SRM 2033 should be stored in the original, low-actinic glass bottle and the cardboard container in which it was issued to protect it from unnecessary exposure to light and humidity. When so stored, the expected stability of this material is at least three years. Thus, until additional stability data are obtained, this material should be used within three years of the date of purchase.

All solutions prepared from SRM 2033 should be made in borosilicate glass containers using distilled water and transfer pipettes (Pasteur type) of the same glass and fitted with rubber bulbs ${ }^{c}$. Use clean spectrophotometer cuvettes, free of scratches, made of non-fluorescent fused silica, and fitted with ground-glass or Teflon stoppers to minimize evaporation; or preferably use NBS SRM 932. Mark all cuvettes to assure the same orientation in the spectrophotometer, and place them into their respective holders. Using transfer pipettes of the type mentiond, rinse each cuvette several times with distilled water. Prepare a solution of KI in distilled water (e.g., 1\%), fill the sample cuvette with the KI solution and the reference cuvette with distilled water. Measure the absorbance, leaving the cuvettes in their holders, empty them (using the pipettes), and repeat the rinsing and filling operations until constant absorbance readings are obtained. Fresh solutions should be made before every test.

\section{Measurements:}

A $1 \% \mathrm{KI}$ solution $\left(\mathrm{c}=10 \mathrm{~g} \mathrm{~L}^{-1}\right)$ with a $1 \mathrm{~cm}$ pathlength exhibits a sharp cutoff in transmittance near $260 \mathrm{~nm}$; i.e., it transmits more than $90 \%$ above $273 \mathrm{~nm}$, but less than $0.01 \%$ below $258 \mathrm{~nm}$. Therefore, with the monochromator set for a wavelength below $260 \mathrm{~nm}$, any appreciable amount of light detected is heterochromatic stray light, which consists of wavelengths above the cutoff. The amount of stray light in the spectrophotometer at wavelength $\lambda$ may be determined from the equations:

$$
\begin{aligned}
& T^{\prime}(\lambda)=\frac{T(\lambda)+x(\lambda)}{1+x(\lambda)} \\
& x(\lambda)=\frac{T^{\prime}(\lambda)-T(\lambda)}{1-T^{\prime}(\lambda)}
\end{aligned}
$$

where:

$$
\begin{aligned}
& x(\lambda) \text { is the stray light ratio, } \\
& T^{\prime}(\lambda) \text { is the apparent transmittance, } \\
& T(\lambda) \text { is the true transmittance. }
\end{aligned}
$$

The stray light ratio, $x(\lambda)$, is the proportion of heterochromatic stray radiant energy in the spectrophotometer for the wavelength setting $\lambda$. Equation (4) forms the theoretical basis for the determination of the stray light ratio by comparing apparent transmittance to true transmittance. For SRM 2033, the true transmittance, T( $\lambda)$, of KI solutions may be calculated as:

$$
T(\lambda)=10^{-\epsilon(\lambda) c \ell}
$$

where $\epsilon(\lambda)$ is the certified specific absorbance given on the face of this certificate.

'Soft glass containers and pipettes contain residual amounts of UV absorbing material, but can be used after proper cleaning. Several rinses, first with isopropyl alcohol and then with distilled water, are generally adequate. 
The apparent transmittances of KI solutions depend not only on the stray light ratio of the spectrophotometer, but also on the wavelength accuracy and the spectral bandwidth, which can significantly affect the results obtained because of the steep slope of the absorbance cutoff of KI. A low-pressure mercury discharge lamp is suggested for verifying the wavelength scale, and a bandwidth as narrow as compatible with adequate signal-to-noise ratios should be used.

\section{Optical Attenuator:}

Many instruments do not permit the direct measurement of transmittances below certain limits, e.g., $1 \%$ or $0.1 \%$. To measure stray light ratios below these limits, the reference beam of the spectrophotometer must be attenuated to extend the transmittance scale into the low-transmittance region.

As mentioned on the face of this Certificate, the optical attenuator consists of two filters, each of which has a nominal transmittance of 10 percent. One filter is mounted in a metal holder that can be inserted in the sample compartment of the spectrophotometer (5). This holder is provided with a front and rear shutter, one of which has a window in which the second filter is mounted. The holder and shutters are flat black. This unit was produced in the NBS Instrument Shops.

\section{Instructions for Use of the Attenuator}

This unit can be used to attenuate the incident radiation in the reference beam of the spectrophotometer in two steps by a total factor of about 100 , corresponding to about 1 percent transmittance (6). To attenuate by a factor of 10 , the attenuator is inserted in the sample compartment of the spectrophotometer facing the incident beam, with both shutters removed. A further attenuation by a factor of about 10 is obtained when the shutter carrying the second filter is inserted in the holder, in front of the first filter. Under these conditions, and with an instrument that cannot measure transmittances lower than 1 percent, the use of the attenuator will permit heterochromatic stray light to be measured down to about 0.01 percent. This attenuation procedure can be used with spectrophotometers capable of scale expansion.

Isochromatic Stray Light:

The radiation attenuator can be used to assess the isochromatic stray light that results from reflection of the incident radiation at the surface of the sample and various optical components, and reaches the photodetector without passing through the sample. It is implicitly assumed that the sample compartment of the spectrophotometer is light-tight.

The measurement is performed by placing the attenuator in the sample beam of the spectrophotometer, with the opaque shutter placed at the rear of the filter holder. Under these conditions, if a signal is detected, it is caused by reflection at the surface of the filter exposed to the incident radiation. This radiation is scattered from the walls and other components of the sample compartment and reaches the photodetector without passing through the sample (5). This signal is the isochromatic stray light.

Isochromatic stray light, which passes through the sample, is generally caused by interreflections between lenses and/or other sample compartment elements. Tests for this stray light component, which is not detected by the methods described above, are discussed in references 7 and 8 .

References:

1. R. Mavrodineanu, J. Res. NBS 76A, 405-425 (1972).

2. J. F. Barkley, F. C. Ruegg, and R. Mavrodineanu, 29th Pittsburgh Conf., Abstract 452, Cleveland, Ohio, (1978).

3. K. D. Mielenz, R. Mavrodineanu, and E. D. Cehelnik, J. Res. NBS 78A, 631-635 (1974).

4. K. D. Mielenz, R. Mavrodineanu, and E. D. Cehelnik, Appl. Optics 14, 1940-1947 (1975).

5. R. Mavrodineanu, J. Res. NBS 80A, 637-641 (1976).

6. Estimating Stray Radiant Energy, ASTM Manual on Recommended Practices in Spectrophotometry, pp. 94-105, 3rd. Edition, 1969, 1916 Race St., Philadelphia, Pa. 19103.

7. K. D. Mielenz, J. Res. NBS 76A, 455-467 (1972).

8. K. D. Mielenz and R. Mavrodineanu, J. Res. NBS 77A, 699-703 (1973).

SRM 2033

Page 4 


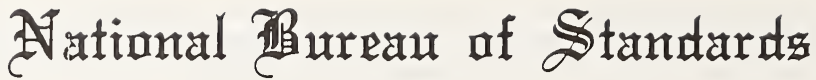

\section{$\mathbb{U}_{\mathfrak{e r}}$ tifirate}

\section{Standard Reference Material 2034}

\author{
Holmium Oxide Solution Wavelength Standard
}

From 240 to $650 \mathrm{~nm}$

This Standard Reference Material (SRM) is intended as a reference material for establishing the accuracy of the wavelength scale of conventional spectrophotometers in the spectral range 240 to $650 \mathrm{~nm}$. It consists of a solution of 4 percent holmium oxide in 10 percent perchloric acid in water, sealed in a nonfluorescent fused silica cuvette of nominal $10 \mathrm{~mm}$ light path. (The cuvette fits most conventional spectrophotometers; see note 1.) The cuvette should be handled only by the tubular end, and, while not in use it should be stored in the container provided. The certified wavelengths of minimum transmittance, expressed in nanometers, are given in Table 1 for six spectral bandwidths from 0.1 to $3.0 \mathrm{~nm}$ for 14 bands. They are illustrated in Figure 1 . The estimated uncertainty of the measured minimum transmittance wavelengths is believed to be no greater than $\pm 0.1 \mathrm{~nm}$ at the measurement temperature of $25^{\circ} \mathrm{C} \pm 5^{\circ} \mathrm{C}$, and includes the random and systematic errors of the measuring procedure. For details concerning the materials, instrumentation, and method used in the certification of SRM 2034 the user is referred to NBS Special Publication 260-102. This Special Publication also describes the influence of purity and concentration of the holmium oxide solution and temperature. and describes the procedure used for assessment of the wavelengths of minimum transmittance and the establishment of the accuracy of the wavelength scale of the spectrometer used.

The initial research at NBS concerning the potential use of the $\mathrm{Ho}_{2} \mathrm{O}_{3}-\mathrm{HClO}_{4}$ solution as a wavelength standard was performed by K.D. Mielenz and R.A. Velapoldi.

The transmittance measurements given in this certificate and investigations on the various chemical and physical parameters that might influence the results were performed by V.R. Weidner and R. Mavrodineanu.

The overall direction and coordination of the technical measurements leading to certification were performed under the chairmanship of K.D. Mielenz, NBS Radiometric Physics Division, Center for Radiation Research.

The technical and support aspects involved in the issuance of this Standard Reference Material were coordinated through the Office of Standard Reference Materials by R.L. McKenzie and L.J. Powell.

Gaithersburg, MD 20899

June 20, 1985
Stanley D. Rasberry, Chief Office of Standard Reference Materials 


\section{CAUTION:}

If the cuvette of SRM 2034, which contains holmium oxide as well as perchloric acid, is accidentially broken, the following action should be taken:

"Perchloric acid spills should be diluted immediately with water, taken up with swabs (preferably wool) and then washed with generous amounts of water. The swabs should also be washed with water before discarding. Swabs of cotton or other cellulose material contaminated with perchloric acid should be regarded as fire or explosion hazards if not washed thoroughly with large amounts of water" $(1,2)$.

\section{References:}

(1) Schilt, Alfred A., Perchloric Acid and Perchlorates, the G. Frederick Smith Chemical Co., Publisher, 867 McKinley Ave., Columbus, Ohio 43223, pg. 157 (1979).

(2) Schumacher, Joseph C., Perchlorates, Their Properties, Manufacture and Use, Reinhold Publishing Corp., NY; Chapman \& Hall, LTD, London, pg. 187 (1960).

\section{NOTES:}

(1) If the cuvette is too tall for the sample compartment of the spectrophotometer, a piece of black opaque cloth can be used to provide a temporary lightproof enclosure.

(2) The cuvettes have been individually tested for leaks. Should a leak subsequently develop, follow the procedure recommended above (under "CAUTION").

\section{Table 1}

Wavelengths of Minimum Transmittance at Six Spectral Bandwidths for a 4 Percent Holmium Oxide Solution in 10 Percent Perchloric Acid in Water.

Minimum

Transmittance

Band No.

\section{1}

2

3

4

5

6

7

8

9

10

11

12

13

14

\begin{tabular}{|c|c|}
\hline 0.1 & 0.25 \\
\hline 240.99 & 240.97 \\
\hline 249.83 & 249.78 \\
\hline 278.15 & 278.14 \\
\hline 287.01 & 287.00 \\
\hline 333.47 & 333.44 \\
\hline 345.55 & 345.55 \\
\hline 361.36 & 361.35 \\
\hline 385.45 & 385.42 \\
\hline 416.07 & 416.07 \\
\hline$\ldots$ & $\ldots$ \\
\hline 467.82 & 467.82 \\
\hline 485.28 & 485.28 \\
\hline 536.54 & 536.53 \\
\hline 640.51 & 640.49 \\
\hline
\end{tabular}

Spectral Bandwidths ( $\mathrm{nm}$ )

$\begin{array}{cccc}0.5 & \frac{1}{2} & & 3 \\ 241.01 & 241.13 & 241.08 & 240.90 \\ 249.79 & 249.87 & 249.98 & 249.92 \\ 278.13 & 278.10 & 278.03 & 278.03 \\ 287.01 & 287.18 & 287.47 & 287.47 \\ 333.43 & 333.44 & 333.40 & 333.32 \\ 345.52 & 345.47 & 345.49 & 345.49 \\ 361.33 & 361.31 & 361.16 & 361.04 \\ 385.50 & 385.66 & 385.86 & 386.01 \\ 416.09 & 416.28 & 416.62 & 416.84 \\ -\cdots & 451.30 & 451.30 & 451.24 \\ 467.80 & 467.83 & 467.94 & 468.07 \\ 485.27 & 485.29 & 485.33 & 485.21 \\ 536.54 & 536.64 & 536.97 & 537.19 \\ 640.49 & 640.52 & 640.84 & 641.05\end{array}$



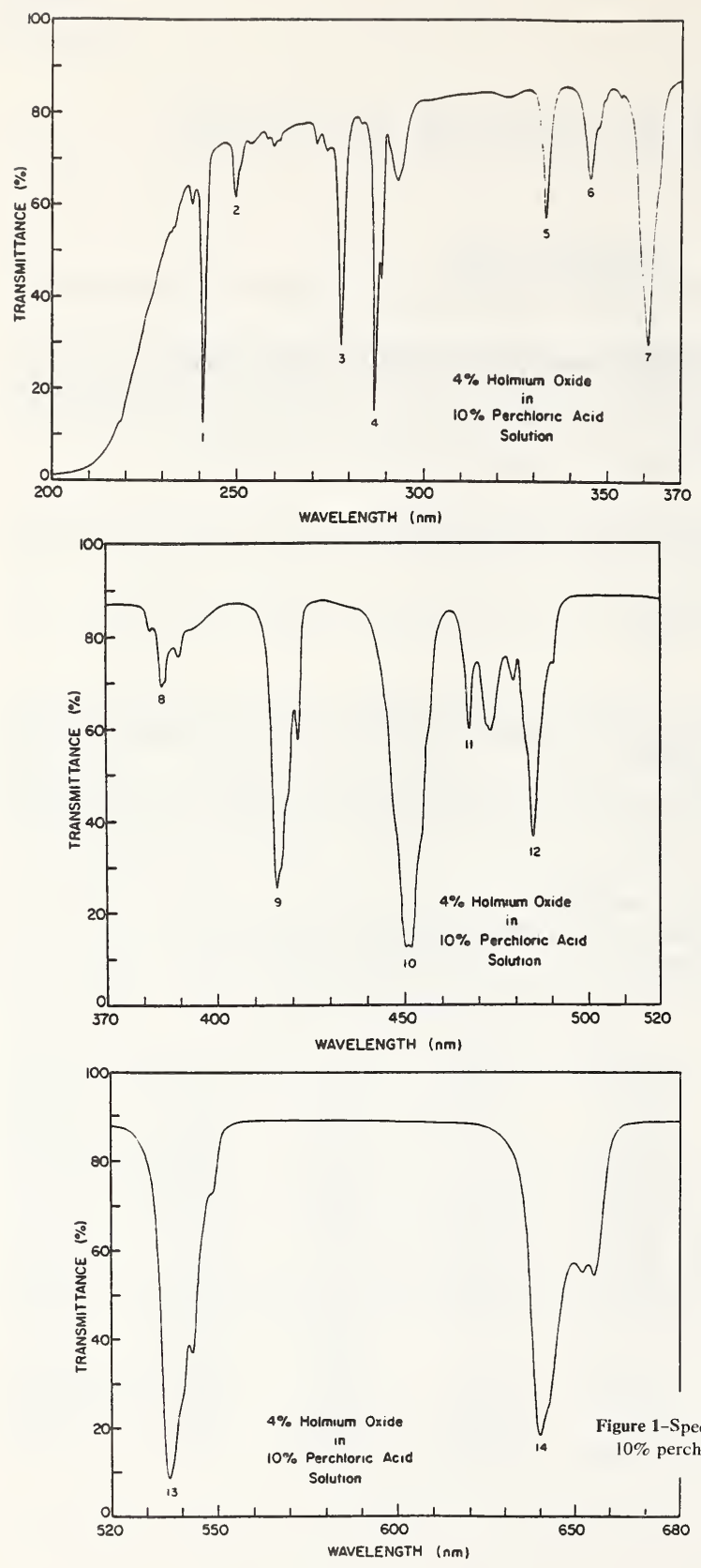
NBS-114A (REV. 2-8C)

U.S. DEPT. OF COMM.

BIBLIOGRAPHIC DATA

SHEET (See in structions)

1. PUBLICATION OR
REPORT NO.
NBS/SP-260/102

2. Performing Organ. Report No. 3. Publication Date

NBS/SP-260/102

July 1986

4. TITLE AND SUBTITLE

Holmium Oxide Solution Wavelength Standard From 240 to 640 nm - SRM 2034

Victor R. Weidner, Radu Mavrodineanu, Klaus D. Mielenz, Rance A. Velapoldi, Kenneth L. Eckerle, Bradley Adams

\begin{tabular}{l|l|l}
\hline 6. PERFORMING ORGANIZATION (If joint or other than NBS, see instructions) & 7. Contract/Grant No.
\end{tabular}

NATIONAL BUREAU OF STANDARDS

DEPARTPIENT OF COMMERCE

GAITHERSBURG, MD 20899

8. Type of Report \& Period Covered

9. SPONSORING ORGANIZATION NAME AND COMPLETE ADDRESS (Street. City, State, ZIP)

Final

Same as item \#6.

10. SUPPLEMENTARY NOTES

Likrary of Congress Catalog Card Number: 86-600560

Document describes a computer program; SF-185, FIPS Software Summary, is attached.

11. ABSTRACT (A 200-word or less factual summary of most significant information. If document includes a significant bibliography or literature survey, mention it here)

The work describes the methods and procedures used to determine the wavelengths of minimum transmittance of holmium oxide in perchloric acid solution. Measurements of spectral transmittance of the solutions were made by means of a high precision spectrophotometer over the wavelength range $200 \mathrm{~nm}$ to $680 \mathrm{~nm}$. The wavelength scale accuracy of this instrument was verified by extensive measurements of mercury and deuterium emission lines. The measurements of spectral transmittance of the holmium oxide solutions were made as a function of temperature, purity, concentration, and spectral bandwidth. Analysis of the uncertainties associated with these parameters and the uncertainties associated with the calibration of the instrument wavelength scale and the data analysis have resulted in an estimated uncertainty of $\pm 0.1 \mathrm{~nm}$ for the determination of the wavelengths of minimum transmittance of the holmium oxide sulution.

12. KEY WORDS (Six to twelve entries; alphabetical order: capitalize only proper names; and separate key words by semicolons) holmium oxide; spectral bandwidth; spectrophotometer calibration; spectral transmittance; wavelength calibration; wavelength standard

13. AVAILABILITY

[X] Unlimited

$\square$ For Official Distribution. Do Not Release to NTIS

$\mathrm{X}$ Order From Superintendent of Documents, U.S. Government Printing Office, Washington, D.C. 20402.

[ Order From National Technical Information Service (NTIS), Springfield, VA. 22I6I
14. NO. OF PRINTED PAGES

67

15. Price 





\section{Periodical}

Journal of Research-The Journal of Research of the National Bureau of Standards reports NBS research and development in those disciplines of the physical and engineering sciences in which the Bureau is active. These include physics, chemistry, engineering, mathematics, and computer sciences. Papers cover a broad range of subjects, with major emphasis on measurement methodology and the basic technology underlying standardization. Also included from time to time are survey articles on topics closely related to the Bureau's technical and scientific programs. Issued six times a year.

\section{Nonperiodicals}

Monographs-Major contributions to the technical literature on various subjects related to the Bureau's scientific and technical activities.

Handbooks-Recommended codes of engineering and industrial practice (including safety codes) developed in cooperation with interested industries, professional organizations, and regulatory bodies.

Special Publications-Include proceedings of conferences sponsored by NBS, NBS annual reports, and other special publications appropriate to this grouping such as wall charts, pocket cards, and bibliographies.

Applied Mathematics Series-Mathematical tables, manuals, and studies of special interest to physicists, engineers, chemists, biologists, mathematicians, computer programmers, and others engaged in scientific and technical work.

National Standard Reference Data Series-Provides quantitative data on the physical and chemical properties of materials, compiled from the world's literature and critically evaluated. Developed under a worldwide program coordinated by NBS under the authority of the National Standard Data Act (Public Law 90-396).

NOTE: The Journal of Physical and Chemical Reference Data (JPCRD) is published quarterly for NBS by the American Chemical Society (ACS) and the American Institute of Physics (AIP). Subscriptions, reprints, and supplements are available from ACS, 1155 Sixteenth St., NW, Washington, DC 20056.

Building Science Series-Disseminates technical information developed at the Bureau on building materials, components, systems, and whole structures. The series presents research results, test methods, and performance criteria related to the structural and environmental functions and the durability and safety characteristics of building elements and systems.

Technical Notes-Studies or reports which are complete in themselves but restrictive in their treatment of a subject. Analogous to monographs but not so comprehensive in scope or definitive in treatment of the subject area. Often serve as a vehicle for final reports of work performed at NBS under the sponsorship of other government agencies.

Voluntary Product Standards-Developed under procedures published by the Department of Commerce in Part 10, Title 15, of the Code of Federal Regulations. The standards establish nationally recognized requirements for products, and provide all concerned interests with a basis for common understanding of the characteristics of the products. NBS administers this program as a supplement to the activities of the private sector standardizing organizations.

Consumer Information Series-Practical information, based on NBS research and experience, covering areas of interest to the consumer. Easily understandable language and illustrations provide useful background knowledge for shopping in today's technological marketplace.

Order the above NBS publications from: Superintendent of Documents, Government Printing Office, Washington, DC 20402.

Order the following NBS publications-FIPS and NBSIR's-from the National Technical Information Service, Springfield, VA 22161.

Federal Information Processing Standards Publications (FIPS PUB)-Publications in this series collectively constitute the Federal Information Processing Standards Register. The Register serves as the of ficial source of information in the Federal Government regarding standards issued by NBS pursuant to the Federal Property and Administrative Services Act of 1949 as amended, Public Law 89-306 (79 Stat. 1127), and as implemented by Executive Order 11717 (38 FR 12315, dated May 11, 1973) and Part 6 of Title 15 CFR (Code of Federal Regulations).

NBS Interagency Reports (NBSIR)-A special series of interim or final reports on work performed by NBS for outside sponsors (both government and non-government). In general, initial distribution is handled by the sponsor; public distribution is by the National Technical Information Service, Springfield, VA 22161, in paper copy or microfiche form. 
U.S. Department of Commerce National Bureau of Standards

Gaithersburg, MD 20899

Official Business

Penalty for Private Use $\$ 300$ 